\title{
9th International Symposium on Mechanisms of Vasodilatation and Endothelium-Derived Hyperpolarizing Factors (EDHF)
}

(www.karger.com/jvr_42_S1_05)

Antwerp, Belgium

May 31-June 4, 2005

Guest Editors

Arnold G. Herman, Antwerp, Belgium

Paul M. Vanhoutte, Hong Kong, China 
S. Karger

Medical and Scientific Publishers Basel $\bullet$ Freiburg $\bullet$ Paris $\bullet$ London New York $\bullet$ Bangalore $\cdot$ Bangkok Singapore $\bullet$ Tokyo $\bullet$ Sydney
Drug Dosage

The authors and the publisher have exerted every effort to ensure that drug selection and dosage set forth in this text are in accord with current recommendations and practice at the time of publication. However, in view of ongoing research, changes in government regulations, and the constant flow of information relating to drug therapy and drug reactions, the reader is urged to check the package insert for each drug for any change in indications and dosage and for added warnings and precautions. This is particularly important when the recommended agent is a new and/or infrequently employed drug.
All rights reserved.

No part of this publication may be translated into other languages, reproduced or utilized in any form or by any means, electronic or mechanical, including photocopying, recording, microcopying, or by any information storage and retrieval system, without permission in writing from the publisher or, in the case of photocopying, direct payment of a specified fee to the Copyright Clearance Center (see 'General Information').

(C) Copyright 2005 by S. Karger AG,

P.O. Box, CH-4009 Basel (Switzerland)

Printed in Switzerland on acid-free paper by

free electronic supplement:

www.karger.com/jvr_42_S1_05

\section{KARGER}

Fax +41613061234

E-Mail karger@karger.ch

www.karger.com 
Vol. 42, Supplement 1, 2005

Journal of Vaseular
Research

\section{Committee}

Organising Committee:

Herman Arnold G. (Antwerp, Belgium)

Vanhoutte Paul M. (Hong Kong, China)

Balligand Jean-Luc (Brussels)

Berkenboom Guy (Brussels)

Bult Hidde (Antwerp)

Holvoet Paul (Leuven)

Van de Voorde Johan (Ghent)

Van den Eynde Liliane (Antwerp)

Van Hove Cor (Antwerp)

\section{Scientific Committee:}

Chairpersons
Herman Arnold G. (Antwerp, Belgium)
Vanhoutte Paul M. (Hong Kong, China)
Members
Balligand Jean-Luc (Belgium)
Berkenboom Guy (Belgium)
Boulanger Chantal (France)
Bult Hidde (Belgium)
Busse Rudi (Germany)
Campbell Bill (USA)
Cohen Richard (USA)
De Mey Jo (The Netherlands)
Duckles Sue (USA)
Félétou Michel (France)
Fleming Ingrid (Germany)
Gao Yuansheng (China)
Griffith Tudor (Great Britain)
Holvoet Paul (Belgium)
Huang Yu (China)

Ku David (Great Britain)

Levy Bernard (France)

Lüscher Thomas (Switzerland)

Man Ricky (China)

Moncada Salvador (Great Britain)

Mulvany Michael (Denmark)

Pohl Ulrich (Germany)

Schini-Kerth Valerie (France)

Shimokawa Hiroaki (Japan)

Skott Ole (Denmark)

Soares De Mourato Roberto (Brasil)

Stoclet Jean-Claude (France)

Su Ding-Feng (China)

Toda Noboru (Japan)

Van Breemen Cornelis (Canada)

Van de Voorde Johan (Belgium)

Vanoverschelde J.-L. (Belgium)

Verbeuren Toon (France)

Vilaine Jean-Paul (France)

Weston Arthur (Great Britain) 


\section{New wine in old skins: the unexpected side of eNOS}

by

Professor Ingrid Fleming,

Vascular Signalling Group

Institut für Kardiovaskuläre Physiologie

Johann Wolfgang Goethe-Universität,

Frankfurt am Main

Germany

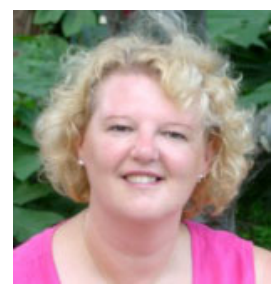

"In science, I like the challenge and combining classical vascular pharmacology with more modern approaches. High points have been being able to alter ideas/concepts that have become fixed in people's minds. Examples are showing that the activation of eNOS is not a completely Ca2+-dependent process, that NO in platelets regulates granule secretion and that CYP enzymes can generate superoxide anions."

\begin{tabular}{|c|c|c|c|}
\hline $09.00-09.45$ & $\begin{array}{l}\text { 5th Robert F. Furchgott Lecture } \\
\text { New wine in old skins: the unexpected side of eNOS }\end{array}$ & Ingrid Fleming & $\begin{array}{l}\text { Invited } \\
\text { Lecture }\end{array}$ \\
\hline $09.45-10.00$ & $\begin{array}{l}\text { Targeted and sustained effect of NO by s-nitrosation of } \\
\text { cysteine residues in arteries exhibiting endothelial } \\
\text { dysfunction }\end{array}$ & Stoclet, Jean-Claude & $\mathrm{S} 1 \mathrm{O} 1$ \\
\hline $10.00-10.15$ & $\begin{array}{l}\text { Endothelium-dependent NO-mediated relaxations to Concord } \\
\text { grape juice is mediated through the redox-sensitive PI3- } \\
\text { kinase/Akt-dependent phosphorylation of endothelial NO } \\
\text { synthase in the porcine coronary artery and rat aorta }\end{array}$ & Schini-Kerth, Valérie & $\mathrm{S} 1 \mathrm{O} 2$ \\
\hline $10.15-10.30$ & Adrenoceptors on endothelium revisited & McGrath, John & $\mathrm{S} 1 \mathrm{O} 3$ \\
\hline $10.30-11.00$ & $\begin{array}{c}\text { POSTER SESSION } 1 \\
\text { coffee break } \\
\end{array}$ & & \\
\hline $11.00-11.15$ & $\begin{array}{l}\text { Mechanisms involved in the relaxation of rat basilar artery } \\
\text { induced by the soluble guanylyl cyclase stimulator BAY 41- } \\
2272\end{array}$ & Teixeira, Cleber & $\mathrm{S} 1 \mathrm{O} 4$ \\
\hline $11.15-11.30$ & $\begin{array}{l}\text { Dynamic association of soluble guanylyl cyclase and protein } \\
\text { kinase A with caveolin-1 in rat aortic endothelium mediating } \\
\text { vasodilation }\end{array}$ & Linder, Elizabeth & S1 05 \\
\hline $11.30-11.45$ & $\begin{array}{l}\text { A model for hyperacute hypotension and shock: nitric oxide } \\
\text { or no nitric oxide? }\end{array}$ & Cauwels, Anje & S1 06 \\
\hline $11.45-12.00$ & $\begin{array}{l}\text { Renovascular hypertension and acute pressure elevation } \\
\text { selectively impairs NO-mediated vasodilation in rat small } \\
\text { arteries }\end{array}$ & Simonsen, Ulf & S1 O7 \\
\hline $12.00-12.15$ & $\begin{array}{l}\text { Flow augments the contractions to phenylephrine in the } \\
\text { rabbit carotid artery by reducing the release of endothelium- } \\
\text { derived NO }\end{array}$ & Rasmussen, Lasse $\mathrm{E}$. & $\mathrm{S} 108$ \\
\hline $12.15-12.30$ & $\begin{array}{l}\text { Blood pressure in mice with a targeted deletion of the } \\
\text { soluble guanylate cyclase alpha1 subunit }\end{array}$ & Brouckaert, Peter & S1 09 \\
\hline
\end{tabular}


$\mathrm{S} 1 \mathrm{O} 1$

TARGETED AND SUSTAINED EFFECT OF NO BY S-NITROSATION OF CYSTEINE RESIDUES IN ARTERIES EXHIBITING ENDOTHELIAL DYSFUNCTION

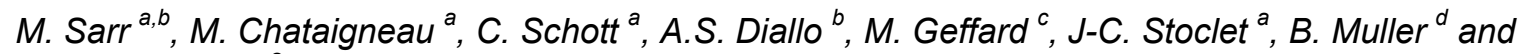
V.B. Schini-Kert ${ }^{a}$

${ }^{a}$ UMR CNRS 7034, F-67401 Illkirch

${ }^{\mathrm{b}}$ Pharmacologie et Physiologie, Faculté de Médecine et de Pharmacie de Dakar

${ }^{c}$ Physique des Interactions Ondes-Matières, F-33600 Pessac

d INSERM E356, Université Victor Segalen, F-33076 Bordeaux.

Objective: S-nitrosating nitric oxide (NO) donors like S-nitrosoglutathione (GSNO) induce a persistent inhibition of tone in endothelium-denuded arteries, through the formation of releasable NO stores on tissue thiols. The aim of the present study was to investigate whether such effects of GSNO could be obtained in arteries exhibiting endothelial dysfunction.

Methods: Rats were sham-operated or implanted with a minipump delivering Angiotensin II (Ang II, 0.4 $\mathrm{mg} / \mathrm{kg} /$ day for 14 days). Aortic rings from these rats were suspended in organ chambers for isometric tension recordings or processed for detection of reactive oxygen species (with dihydroethidine as fluorescent probe) and cysteine-NO residues (with anti-cysteine-NO antiserum).

Results: Ang II-induced hypertension was associated with increased levels of superoxide anion and with reduced relaxation to acetylcholine in the aorta. In aortic rings with endothelium from sham-operated controls, pre-exposure to GSNO neither induced persistent inhibition of the contractile effect of phenylephrine, nor a relaxant effect upon addition of N-acetylcysteine (NAC), a low molecular weight thiol which can displace NO from NO stores. In contrast, in rings with endothelium obtained from Ang II-infused rats, GSNO induced persistent hyporeactivity to phenylephrine, and a relaxant effect of both NAC and mercuric chloride (which cleaves cysteine-NO bonds). In these rings, GSNO induced a persistent increase in cysteine-NO residues, which was blunted both by NAC and mercuric chloride.

Conclusions: Unlike control ones, arteries presenting endothelial dysfunction and increased superoxide levels exhibit a long lasting inhibition of tone after exposure to GSNO which was mediated by persistent S-nitrosation of tissue thiols. Thus, S-nitrosating NO donating agents offer the possibility of targeted protective effects at sites of endothelial dysfunction, through the formation of releasable NO stores. 
S1O2

ENDOTHELIUM-DEPENDENT NO-MEDIATED RELAXATIONS TO CONCORD GRAPE JUICE IS MEDIATED THROUGH THE REDOX-SENSITIVE PI3-KINASE/AKT-DEPENDENT PHOSPHORYLATION OF ENDOTHELIAL NO SYNTHASE IN THE PORCINE CORONARY ARTERY AND RAT AORTA

\section{E. Anselm, M. Chataigneau, M. Ndiaye, T. Chataigneau, V.B. Schini-Kerth \\ UMR CNRS 7034, Faculté de Pharmacie, Université Louis Pasteur, Illkirch, France}

Objective: Several epidemiological studies have indicated that regular intake of vegetables, fruits, and beverages rich in polyphenols is associated with a decreased global mortality due to a reduced number of cancer and coronary diseases. The vascular protective effect has been attributed at least in part to the direct action of polyphenols on blood vessels. Polyphenols present in red wine cause endothelium-dependent relaxations of isolated coronary arteries by stimulating the endothelial formation of nitric oxide (NO) and endothelium-derived hyperpolarizing factor (EDHF). The present study examined whether a purple grape juice, a non-alcohol containing rich source of polyphenols, is able to induce endothelium-dependent relaxations of coronary arteries, and if so to examine the underlying mechanism.

Methods: Rings of either rat aorta or porcine coronary arteries were suspended in organ chambers for the measurement of changes in isometric tension. Experiments were performed in the presence of indomethacin to prevent the formation of vasoactive prostanoids. Some experiments were also performed in the presence of charybdotoxin plus apamin to prevent the effect of EDHF, and/or $\mathrm{N}^{\omega}$-nitro-L-arginine (L-NA) to prevent the formation of endothelial NO. Porcine coronary artery and human umbilical vein endothelial cells were obtained by collagenase digestion and used at confluence at first passage. The cellular content of cyclic GMP, a biochemical index of NO formation, was determined in the presence of isobutyl-methyl xanthine (100 $\mu \mathrm{M})$ by an ELISA including an acetylation step. The formation of $\mathrm{NO}$ was assessed by electron spin resonance spectroscopy, and the phosphorylation of Akt at Ser 473 and endothelial NO synthase (eNOS) at Ser1177 by Western blot analysis in cultured endothelial cells. Concord grape juice (CGJ containing $2.2 \mathrm{~g} / \mathrm{l}$ polyphenols) was provided by Welch Food Inc. (USA).

Results: CGJ caused pronounced concentration-dependent relaxations in coronary artery and aortic rings with endothelium but only minor ones in those without endothelium. In aortic rings, CGJ-induced relaxations were abolished by L-NA. In coronary artery rings, relaxations to CGJ were slightly but significantly reduced by L-NA without affecting the maximal relaxation, not affected by charybdotoxin plus apamin whereas the combination of L-NA, charybdotoxin plus apamin reduced maximal relaxation to about $50 \%$. In the presence of charybdotoxin plus apamin, relaxations to CGJ were markedly reduced by the membrane permeant mimetic of superoxide dismutase (SOD), MnTMPyP, and the membrane permeant analogue of catalase polyethyleneglycol-catalase (PEG-catalase) but not by native SOD and native catalase. They were also reduced by wortmannin, an inhibitor of the PI3kinase/Akt pathway. In contrast, sodium nitroprusside-induced relaxations were not affected by wortmannin. CGJ stimulated the L-NA-sensitive formation of NO and caused within one minute the formation of cyclic GMP, which reached a plateau after 3 minutes and persisted for at least 10 minutes in endothelial cells. These effects were associated with a time-dependent phosphorylation of Akt and eNOS; both responses were prevented by MnTMPyP, PEG-SOD, PEG-catalase, and by wortmannin.

Conclusions: CGJ induces endothelium-dependent relaxations of coronary arteries, which include a NOmediated component, a EDHF-mediated component and also a non-NO non-EDHF-mediated component. In addition, CGJ-induced NO formation is due to the redox-sensitive activation of the PI3-kinase/Akt pathway and subsequent phosphorylation of eNOS. 
$\mathrm{S} 1 \mathrm{O} 3$

ADRENOCEPTORS ON ENDOTHELIUM REVISITED

J.C. McGrath, M. McBride, M.M. Shafaroudi, N. Brahmadevara, J.M. Gonzalez, A.M. Briones, E. Vila, A. MacDonald and C.J. Daly

Autonomic Physiology Unit, University of Glasgow, Glasgow, UK.

Objective: To visualise adrenoceptors on endothelial cells of large and small arteries using fluorescent antagonist ligands and, if possible, to relate this to functional responses.

Methods: Freshly dissected or fixed arteries from rat and mouse were incubated in the fluorescent alphaadrenoceptor ligand quinazilyl piperadyl BODIPY (QAPB) and/or the fluorescent beta-adrenoceptor ligand BODIPY TMR-CGP 12177. Binding was visualised with confocal microscopy, using optical dissection, from different directions, to optimise visualisation of the endothelium. Selective competitor antagonists were used to confirm receptor subtypes. Comparison was made with binding on smooth muscle and adventitial cells. Functional responses were separately analysed using wire myography, agonist/antagonist pharmacology and adrenoceptor KO mouse strains.

Results: Alpha-adrenoceptors: mouse arterial endothelium showed good binding of QAPB. Competitor antagonists showed, unexpectedly, that binding was to both alpha-1 and alpha-2-adrenoceptors. Functional experiments could show endothelial alpha-2-mediated relaxant responses as the most sensitive part of the concentration-response curve for UK14304. We could not produce evidence for alpha-1 because of the dominance of the smooth muscle contractile response via these receptors. D79N mutants and KOs of alpha-2Aadrenoceptors showed that the alpha-2-adrenoceptor was responsible for relaxation in aorta and carotid but not mesenteric (main or first branch) arteries. KOs of alpha-1-adrenoceptor subtypes suggested that the alpha-1adrenoceptor binding involved more than one subtype.

Beta-adrenoceptors: Endothelium on large and small arteries binds BODIPY TMR-CGP 12177 suggesting a population of beta-adrenoceptors. We could find no evidence for the function of these receptors in terms of contraction/relaxation, except that in carotid arteries contraction to noradrenaline was enhanced by propranolol suggesting that beta-adrenoceptors inhibit the release of nitric oxide.

Conclusions: Endothelium contains binding sites with the properties of alpha-2-adrenoceptors. Relaxation via these receptors can be obtained. In large conducting arteries this involves alpha-2A-adrenoceptors but in mesenteric arteries, representing resistance vessels, another alpha-2-adrenoceptor subtype is indicated. Binding indicates a population of endothelial alpha-1-adrenoceptors that may involve all three subtypes but we have no evidence for their function. Binding also indicates a population of endothelial beta-adrenoceptors that we speculate could be inhibitory to EDRF function. Overall we find evidence for several adrenoceptor subtypes on endothelium. They seem well placed for circulating rather than nerve-released catecholamines. While the density of these receptors is adequate for detection by microscopy, the relatively small volume of endothelial cells means that they represent a very small fraction of the total receptor population in relation to smooth muscle and adventitia, so would be unlikely to be detectable by biochemical means. 
$\mathrm{S} 1 \mathrm{O} 4$

MECHANISMS INVOLVED IN THE RELAXATION OF RAT BASILAR ARTERY INDUCED BY THE SOLUBLE GUANYLYL CYCLASE STIMULATOR BAY 41-2272.

\author{
C. E. Teixeira, J. Todd Jr. and R. C. Webb
}

Department of Physiology, Medical College of Georgia, Augusta, GA, 30912-3000, U.S.A.

Objective: Cyclic GMP (cGMP) mediates smooth muscle relaxation in the central nervous system and decreases in intrinsic nitric oxide (NO) cause cerebral vasospasms due to the disregulation of cGMP formation by NO-mediated pathways. Since BAY 41-2272 was recently identified as a potent soluble guanylyl cyclase (sGC) stimulator in a NO-independent manner, this study aimed to investigate the mechanisms underlying the relaxant effects of BAY 41-2272 in the rat basilar artery.

Methods: Rings of basilar artery were mounted in myographs and data were recorded in a PowerLab system.

Results: In endothelium-intact $(\mathrm{E}+)$ rings, BAY 41-2272 $(100 \mathrm{pM}-1 \mu \mathrm{M})$ relaxed the preparations in a concentration-dependent manner, with a $\mathrm{pEC}_{50}$ value of $8.13 \pm 0.03$. In endothelium-denuded (E-) rings, the curve for BAY 41-2272 was shifted to the right (3.2-fold) in comparison to endothelium-intact preparations $\left(\mathrm{pEC}_{50}=7.63 \pm 0.05\right)$. The $\mathrm{sGC}$ inhibitor ODQ $(10 \mu \mathrm{M})$ markedly displaced the curve for BAY 41-2272 to the right in both E+ and E- rings (9.3- and 8.9-fold, respectively). The NO synthesis inhibitor L-NAME $(100 \mu \mathrm{M})$ caused a rightward shift in the curve for BAY 41-2272 (4.0-fold). BAY 41-2272-induced relaxations were significantly enhanced by the phosphodiesterase type 5 inhibitor sildenafil $(0.1 \mu \mathrm{M})$ in both $\mathrm{E}+\left(\mathrm{pEC}_{50}=7.96 \pm\right.$ 0.06 in absence and $8.39 \pm 0.04$ in presence of sildenafil) and $\mathrm{E}-\left(\mathrm{pEC}_{50}=7.59 \pm 0.07\right.$ in absence and $8.16 \pm 0.06$ in presence of sildenafil) rings. Treatment of the preparations with the $\mathrm{K}^{+}$channel blockers charybdotoxin $(0.1$ $\mu \mathrm{M}$, to block $\mathrm{Ca}^{2+}$-activated $\mathrm{K}^{+}$channels) or glybenclamide (10 $\mu \mathrm{M}$, to block ATP-dependent $\mathrm{K}^{+}$channels) had no effect on the relaxant responses to BAY 41-2272. Incubation of E- rings with increasing concentrations of BAY 41-2272 (0.001-1 $\mu \mathrm{M})$ caused significant rightward shifts in the contractile responses to serotonin (5-HT, $0.001-10 \mu \mathrm{M}$ ), whereas the NO donor glyceryl trinitrate (GTN, 0.001-1 $\mu \mathrm{M}$ ) only shifted the curves to 5-HT at the highest concentration. BAY 41-2272 and GTN had no significant effect on the contractions elicited by 5-HT when added separately at $0.01 \mu \mathrm{M}$. However, co-incubation of these compounds caused a marked rightward shift in the curves to 5 -HT (5.6-fold; $\mathrm{P}<0.01)$.

Conclusions: These findings indicate that BAY 41-2272 potently relaxes the rat isolated basilar artery in a synergistic fashion with NO. Targeting the sGC present in cerebral arteries with selective activators such as BAY 41-2272 may be a possible new way of treating cerebrovascular disease. 
S105

DYNAMIC ASSOCIATION OF SOLUBLE GUANYLYL CYCLASE AND PROTEIN KINASE A WITH CAVEOLIN-1 IN RAT AORTIC ENDOTHELIUM MEDIATING VASODILATION

\section{A.E. Linder, L.P. McCluskey and R.C. Webb}

Department of Physiology, Medical College of Georgia, Augusta, GA, USA, 30912

Objective: Classically, nitric oxide (NO) produced in endothelial cells by NO synthase (eNOS) diffuses to smooth muscle (SM) cells to activate soluble guanylyl cyclase (sGC) leading to cyclic GMP (cGMP) production. eNOS is associated with caveolin-1 (cav-1), the major coat protein of caveolae, membrane invaginations rich in cholesterol. Co-localization of components in a signal transduction cascade appears to be a critical determinant of signalling efficiency by eNOS activation. The relaxation induced by YC-1, a sGC activator, and by $8-\mathrm{Br}-$ cGMP is impaired in rat aortic rings subjected to endothelium denudation or to treatment with methyl-bcyclodextrin (CD), a drug that depletes membrane cholesterol and disassembles caveolae. We have also observed that the relaxation induced by 8 -Br-cGMP in endothelium intact rat aortic rings is mediated by the cyclic AMP-dependent protein kinase (PKA) but not by cGMP-dependent protein kinase (PKG), indicating cross-talk between these cyclic nucleotides. Aim: Our hypothesis is that SGC and PKA are in close association with endothelial caveolae to be sensitized by $\mathrm{NO}$ contributing to vasodilation.

Methods: Aortic segments were isolated, cleaned and freezed for immunohistochemistry and electron microscopy. Primary antibodies against cav-1, sGC or PKA and fluorescent secondary antibodies were used.

Results: Co-localization of cav-1 with sGC or PKA in the endothelium was confirmed by immunohistochemistry. We also observed that CD prevents co-localization of cav-1 with sGC and PKG in the endothelium. CD disassembles caveolar structures in the endothelium, as observed by electron microscopy

Conclusions: In summary, we propose that sGC and PKA are compartmentalized in endothelial caveolae as a necessary spatial organization to facilitate $\mathrm{NO}$ vasodilatory effects. 
S106

\section{A MODEL FOR HYPERACUTE HYPOTENSION AND SHOCK : NITRIC OXIDE OR NO NITRIC OXIDE ?}

\section{A. Cauwels ${ }^{a}$, B. Janssen ${ }^{b}$ and P. Brouckaert ${ }^{a}$}

a Department for Molecular Biomedical Research, Ghent University and VIB, Belgium

${ }^{\mathrm{b}}$ Department of Pharmacology, Cardiovascular Research Institute Maastricht, The Netherlands

Background: NO was shown to be the major blood vessel relaxant induced by LPS or cytokines like TNF, IL-1 or IL-2. However, while the inhibition of NO production can restore blood pressure, morbidity and/or mortality is often exacerbated. Even a phase III clinical trial in septic shock patients had to be prematurely terminated because of higher mortality in the treatment group. Previously, we have shown complete protection against TNF-induced bradycardia, hypotension and mortality by inhibition of sGC activation (1). However, inhibition of NO did not protect. This was found to be due to the Janus-faced role of NO during TNF shock: causing cardiovascular collapse on the one hand, but necessary to prevent oxidative stress and peroxidative damage on the other hand. Despite the suggested pivotal role of NO in regulating blood pressure changes, the question still remains whether NO is really exclusively responsible for (patho)physiological vessel relaxation. Endothelium produces three vasodilatory factors: $\mathrm{NO}$, prostacyclin $\left(\mathrm{PGI}_{2}\right)$ and "EDHF". The nature of EDHF varies among vascular beds and species, strains, sex and age, as well as with variable experimental conditions and between laboratories. Nevertheless, no consensus regarding the chemical identity of EDHF has been reached yet, even its very (patho)physiological existence remains obscure.

Objective: We examined the involvement of NO in a model of hyperacute shock induced by TNF in combination with the caspase inhibitor zVAD, causing death within 2.5 to $4 \mathrm{~h}$ (Cauwels et al., Nat. Immunol. 2003). By studying the cardiovascular changes in these mice, we found that mortality is preceded by a very sudden and steep drop in blood pressure, that can be observed as early as $1 \mathrm{~h}$ after TNF. This is very fast, causing us to wonder what might be the molecular mediator.

Methods and Results: To evaluate the role of NO, we used NOS inhibition and various NOS-deficient mice, but this accelerated rather than prevented death. The same was true for $\mathrm{PGI}_{2}$ inhibition by indomethacin. In addition, NO and cGMP levels were not increased during zVAD+TNF shock at all, on the contrary. What then, if not $\mathrm{NO} / \mathrm{cGMP}$ or $\mathrm{PGI}_{2}$, causes the hyperacute shock in this model? Generally, EDHF activity can be inhibited by apamin and charybdotoxin. When applied to the zVAD+TNF treated mice, the small-conductance calciumdependent $\mathrm{K}^{+}$channel (SK) inhibitor apamin could completely prevent the hyperacute shock. Interestingly, we have recently shown that excessive oxidative stress, originating from $\mathrm{PLA}_{2}$ signaling and mitochondria, mediates zVAD+TNF mortality. When blood pressure changes were recorded in conscious, permanently catheterized mice, we found that even in the absence of NO (L-NAME treatment) the abrupt hypotension still occured, while in the absence of intracellular superoxide (tempol treatment) the drastic drop in blood pressure never took place.

Conclusion: We therefore propose that intracellular superoxide (or an oxidant-sensitive factor) is responsible for the hypotension and shock in what we tentatively would like to call an "EDHF-dependent" shock model.

References :

1. Cauwels et al., Immunity 2000.

2. Cauwels et al., submitted.

3. Cauwels et al., Nat. Immunol. 2003. 
S107

RENOVASCULAR HYPERTENSION AND ACUTE PRESSURE ELEVATION SELECTIVELY IMPAIRS NO-MEDIATED VASODILATION IN RAT SMALL ARTERIES

\author{
F.H. Christensen ${ }^{a}$, E. Stankevicius ${ }^{b}$, T. Hansen ${ }^{c}$, M.M. Jørgensen ${ }^{a}$, V. L. Valverde ${ }^{a}$, N.H. Buus ${ }^{a}$ and \\ U. Simonsen ${ }^{a}$ \\ ${ }^{a}$ Department of Pharmacology, University of Aarhus, 8000 Aarhus C, Denmark \\ ${ }^{\mathrm{b}}$ Department of Physiology Kaunas University of Medicine, LT-44307 Kaunas, Lithuania \\ ${ }^{\mathrm{C}}$ Department of Physiology, University of Aarhus, 8000 Aarhus C, Denmark
}

Objective: The purpose of the present study was to investigate whether renovascular hypertension and high pressure per se alters flow and acetylcholine-induced vasodilation in rat mesenteric small arteries.

Methods: Sprague-Dawley rats were randomly allocated into three groups: uninephrectomized controls, and one-kidney one-clip hypertensive rats, which after 5 weeks were treated with either vehicle or tempol $(1 \mathrm{mmol} / \mathrm{L}$ in the drinking water).

Results: In pressurized mesenteric small arteries from renal hypertensive rats, dihydroethium fluorescence was increased and flow-evoked nitric oxide (NO)-mediated vasodilation was blunted, while acetylcholineevoked endothelium-derived hyperpolarizing factor (EDHF)-type vasodilation in the same preparations was unchanged. Microelectrode experiments revealed that NO concentration was reduced in small arteries, but expression of endothelial NO synthase and $\mathrm{p} 47$ phox was unchanged. Tempol treatment of renal hypertensive rats lowered systolic blood pressure and dihydroethidium fluorescence in the arterial wall, and restored flow-evoked NO-mediated vasodilation. In vitro a transient pressure rise from 50 to $120 \mathrm{~mm} \mathrm{Hg}$ for one hour increased dihydroethidium fluorescence and blunted flow and S-nitroso-N-acetylpenicillamine induced vasodilation, without changing acetylcholine-evoked vasodilation. NO-mediated vasodilation was restored by tempol, and an inhibitor of NADPH oxidase, apocynin, and in the presence of endothelin receptor antagonists.

Conclusion: The present study suggests that high pressure per se through activation of endothelin receptors selectively inhibits flow-induced NO-mediated vasodilation, while EDHF-type vasodilation is unaltered. Increased formation of superoxide derived from $\mathrm{NAD}(\mathrm{P}) \mathrm{H}$ oxidase seems to play an important role for the decreased flow-evoked NO-mediated vasodilation, and this is also supported by the observation that tempol corrects the blunted flow-evoked NO-mediated vasodilation in renal hypertensive rats. 
S1 O8

FLOW AUGMENTS THE CONTRACTIONS TO PHENYLEPHRINE IN THE RABBIT CAROTID ARTERY BY REDUCING THE RELEASE OF ENDOTHELIUM-DERIVED NO

\section{L.E. Rasmussen, B.L. Jensen, P.M. Vanhoutte and O. Skott.}

Physiology and Pharmacology, University of Southern Denmark, Winslowparken 21.3, Odense C, 5000 Denmark

Objective: The effect of endothelial shear stress on the reactivity of isolated rabbit carotid arteries was examined by measuring contractions of perfused and non-perfused arterial segments exposed to the $\alpha_{1}$ adrenoceptor agonist, phenylephrine.

Methods: Isometric force was measured, by means of force transducers, in non-perfused and perfused (5 or $50 \mathrm{ml} / \mathrm{min}$; Krebs-Henseleit solution) segments of the same rabbit carotid arteries. Contractions were obtained with increasing concentrations ( $30 \mathrm{nM}-30 \mu \mathrm{M})$ of phenylephrine, followed by addition of acetylcholine (ACh, 1 $\mu \mathrm{M})$, when the maximal contractile response was obtained.

Results: The maximal contractions caused by the $\alpha_{1}$-adrenergic agonist were similar in the absence and presence of flow. The concentration-response curve to phenylephrine was shifted significantly to the left in the presence of flow [either at $5\left(\mathrm{pEC}_{50}=6.2\right)$ or $50\left(\mathrm{pEC}_{50}=6.2\right) \mathrm{ml} / \mathrm{min}$ ] compared to the non-perfused rings $\left(\mathrm{pEC}_{50}=5.8\right)$. In the presence of $\mathrm{N}^{\omega}$-Nitro-l-Arginine Methyl Ester (L-NAME; $100 \mu \mathrm{M}$ ) or following removal of the endothelium no significant differences in the sensitivity to phenylephrine were observed between static rings and perfused segments. The perfused and non-perfused preparations with, but not those without endothelium relaxed when exposed to acetylcholine, a response that was significantly reduced by L-NAME.

Conclusions: These experiments demonstrate that in the rabbit carotid artery the constriction evoked by $\alpha_{1}$ adrenergic activation is potentiated in the presence of flow. This potentiation is due to a reduced release of endothelium-derived nitric oxide.

[Supported by the Danish Cardiovascular Research Academy and the Danish Heart Foundation]. 
S109

BLOOD PRESSURE IN MICE WITH A TARGETED DELETION OF THE SOLUBLE GUANYLYL CYCLASE ALPHA ${ }_{1}$ SUBUNIT

P. Brouckaert ${ }^{\text {a }}$, E. Buys ${ }^{a}$, P. Sips ${ }^{a}$, E. Rogge ${ }^{a}$, M. Dewerchin ${ }^{b}$ and A. Cauwels ${ }^{a}$

${ }^{a}$ Department of Molecular Biomedical Research, VIB and Ghent University, 9052 Gent, Belgium

${ }^{\mathrm{b}}$ Department of Transgene Technology and Gene Therapy, VIB and Catholic University of Leuven, Leuven, Belgium

Objective: Soluble guanylyl cyclase (sGC) is a heterodimeric heme containing enzyme of which two active isoforms have been identified, alpha beta $_{1}$ and alpha $_{2}$ beta $_{1}$. It is considered to be the major target protein activated by NO in the cardiovascular system and in the relaxation of vascular smooth muscle cells. The inhibitors of sGC that can be used in vivo are not highly specific and in addition not isoform-specific. To characterize the exact role of sGC in NO-mediated effects, to delineate the role of the isoforms and validate their potential as pharmacological targets, we opted for a mouse transgenic approach.

Methods: Mice deficient in the sGCalpha $1_{1}$ subunit $\left(\mathrm{sGCa}^{-/}\right)$were generated using homologous recombination in ES cells and Cre/lox technology. Non-invasive blood pressure measurements were performed in male and female $\mathrm{sGCa}^{-/-}$mice and littermate controls using a computerized tail cuff method (Visitech).

Results: $\mathrm{sGCa1}^{-/}$mice were viable and reproduce normally. The deleted allele is transmitted with Mendelian ratios. Presence of the mutation (exon 6 deletion in the catalytic domain) was verified using Southern blotting, RT-PCR, Northern and Western blotting. Systolic blood pressure was higher in adult (from 10-14 weeks of age on) $\mathrm{sGCa}^{-/}$mice than in controls ( $150 \pm 3$ vs $\left.122 \pm 2 \mathrm{mmHg}, \mathrm{P}<0.0001\right)$. In female mice the blood pressure was not different between the two groups (112 \pm 2 vs $109 \pm 1 \mathrm{mmHg}$ ).

Conclusions: In $\mathrm{sGCa}^{-1 /}$ mice a gender specific hypertension can be observed. Either the isoform involvement is gender dependent or the NOS-3 dependent vasorelaxation is independent of sGC, and the hypertension in males is not smooth muscle dependent. 


\section{Integration of Dynamic Vascular Control Mechanisms}

by

Professor Tudor M Griffith

Acting Head Diagnostic Radiology,

University of Wales College of Medicine,

Cardiff, Wales

UK

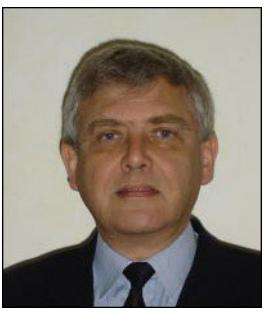

"I have always been impressed by the way in which truly interdisciplinary research is capable of generating novel scientific hypotheses and concepts. In this context, vascular biology is a particularly exciting field of investigation as it necessarily brings together disciplines as diverse as molecular biology, fluid dynamics and mathematical modelling in order to understand the mechanisms governing blood flow."

\begin{tabular}{|c|c|c|c|}
\hline $14.00-14.45$ & $\begin{array}{l}\text { 4th David Bohr Lecture } \\
\text { Integration of Dynamic Vascular Control Mechanisms }\end{array}$ & Tudor M Griffith & $\begin{array}{l}\text { Invited } \\
\text { Lecture }\end{array}$ \\
\hline $14.45-15.00$ & $\begin{array}{l}\text { The role of pertussis toxin sensitive pathways in de EDHF } \\
\text { mediated relaxation in porcine coronary arteries }\end{array}$ & $\mathrm{Ng}$, Jacobus & S2 010 \\
\hline $15.00-15.15$ & $\begin{array}{l}\text { Functional evaluation of epoxyeicosatrienoic acids as } \\
\text { endothelium-derived hyperpolarizing factor in rat mesenteric } \\
\text { arterial bed }\end{array}$ & Adeagbo, Ayotunde & S2 011 \\
\hline $15.15-15.30$ & $\begin{array}{l}\text { EDHF- but not NO-mediated relaxation is abolished in the } \\
\text { isolated mesenteric arteries of hypertensive rats chronically } \\
\text { treated with angiotensin II }\end{array}$ & $\begin{array}{l}\text { Chataigneau, } \\
\text { Thierry }\end{array}$ & S2 012 \\
\hline $15.30-16.00$ & $\begin{array}{l}\text { POSTER SESSION } 1 \\
- \\
\text { coffee break }\end{array}$ & & \\
\hline $16.00-16.15$ & $\begin{array}{l}\text { The role of endothelial connexin } 40 \text { and connexin } 43 \text { mRNA } \\
\text { expression in relation to hyperhomocysteinemia }\end{array}$ & Heil, Sandra & S2 013 \\
\hline $16.15-16.30$ & $\begin{array}{l}\text { Smaller windows in internal elastic lamina, fewer routes for } \\
\text { myoendothelial junctions, less EDHF response }\end{array}$ & McGrath, John & S2 014 \\
\hline $16.30-16.45$ & $\begin{array}{l}\text { Endothelium-dependent responses of carotid, femoral and } \\
\text { mesenteric arteries of streptozotoxin-induced diabetic rats }\end{array}$ & Shi, Yi & S2 015 \\
\hline $16.45-17.00$ & $\begin{array}{l}\text { Impaired EDHF-dilation correlated with increased myogenic } \\
\text { constriction in mesenteric resistance arteries during } \\
\text { progression of heart failure }\end{array}$ & Xu, Ying & S2 016 \\
\hline $17.00-17.15$ & $\begin{array}{l}\text { Impaired EDHF responses in renal arteries from the obese } \\
\text { Zucker rat: involvement of Gap junctions and connexins }\end{array}$ & Reid, Julianne & S2 017 \\
\hline $17.15-17.30$ & $\begin{array}{l}\text { Regional differences in endothelial hyperpolarization and } \\
\text { endothelium-derived hyperpolarizing factor impairment in } \\
\text { diabetes mellitus }\end{array}$ & Tare, Marianne & S2 018 \\
\hline
\end{tabular}


$\mathrm{S} 2 \mathrm{O} 10$

THE ROLE OF PERTUSSIS TOXIN SENSITIVE PATHWAYS IN EDHF MEDIATED RELAXATION IN PORCINE CORONARY ARTERIES

\section{K.F.J Ng, P.M Vanhoutte and R.Y.K Man}

Department of Anaesthesiology \& Department of Pharmacology, the University of Hong Kong

Objective: Endothelium-dependent hyperpolarizations contribute to endothelium-dependent relaxations. However, the intracellular signalling cascade leading to the release of EDHF remains unknown. This study examines the effect of pertussis toxin, a selective inhibitor of Gi-proteins, on EDHF-mediated relaxations.

Methods: Porcine right coronary artery rings $(4-5 \mathrm{~mm})$ were placed in organ chambers containing KrebsRinger solution ( $\mathrm{NaCl} 118.3, \mathrm{KCl} 4.7, \mathrm{MgSO}_{4}$ 1.2, $\mathrm{KH}_{2} \mathrm{PO}_{4} 1.2, \mathrm{CaCl}_{2} 2.5, \mathrm{NaHCO}_{3} 25.0$, glucose 11.1) and indomethacin $\left(10^{-5} \mathrm{M}\right)$. The rings were incubated for two hours with or without pertussis toxin [PTx (200 ng.ml $\left.\left.{ }^{-1}\right)\right]$. L-NAME $\left(10^{-4} \mathrm{M}\right)$, or charybdotoxin $\left(10^{-7} \mathrm{M}\right)$ plus apamin $\left(10^{-7} \mathrm{M}\right)$ were added to some rings after the incubation with pertussis toxin. All rings were then contracted with prostagladin $F_{2 \alpha}\left(2-4 \times 10-{ }^{6} \mathrm{M}\right)$ and subsequently relaxed with increasing concentrations of either substance $\mathrm{P}\left(10^{-13}\right.$ to $\left.10^{-8} \mathrm{M}\right)$, thrombin $\left(10^{-3}\right.$ to 1 U.mL $\left.{ }^{-1}\right)$ or the $\alpha 2$-adrenoceptor agonist UK14304 $\left(10^{-9}\right.$ to $\left.10^{-5} \mathrm{M}\right)$.

Results: Six arterial rings were used for each experiment. Incubation with PTx caused a rightward shift of the concentration-effect curve of EDHF-mediated relaxations caused by thrombin while those to substance P were unaffected. No relaxation to UK14304 was observed after L-NAME incubation.
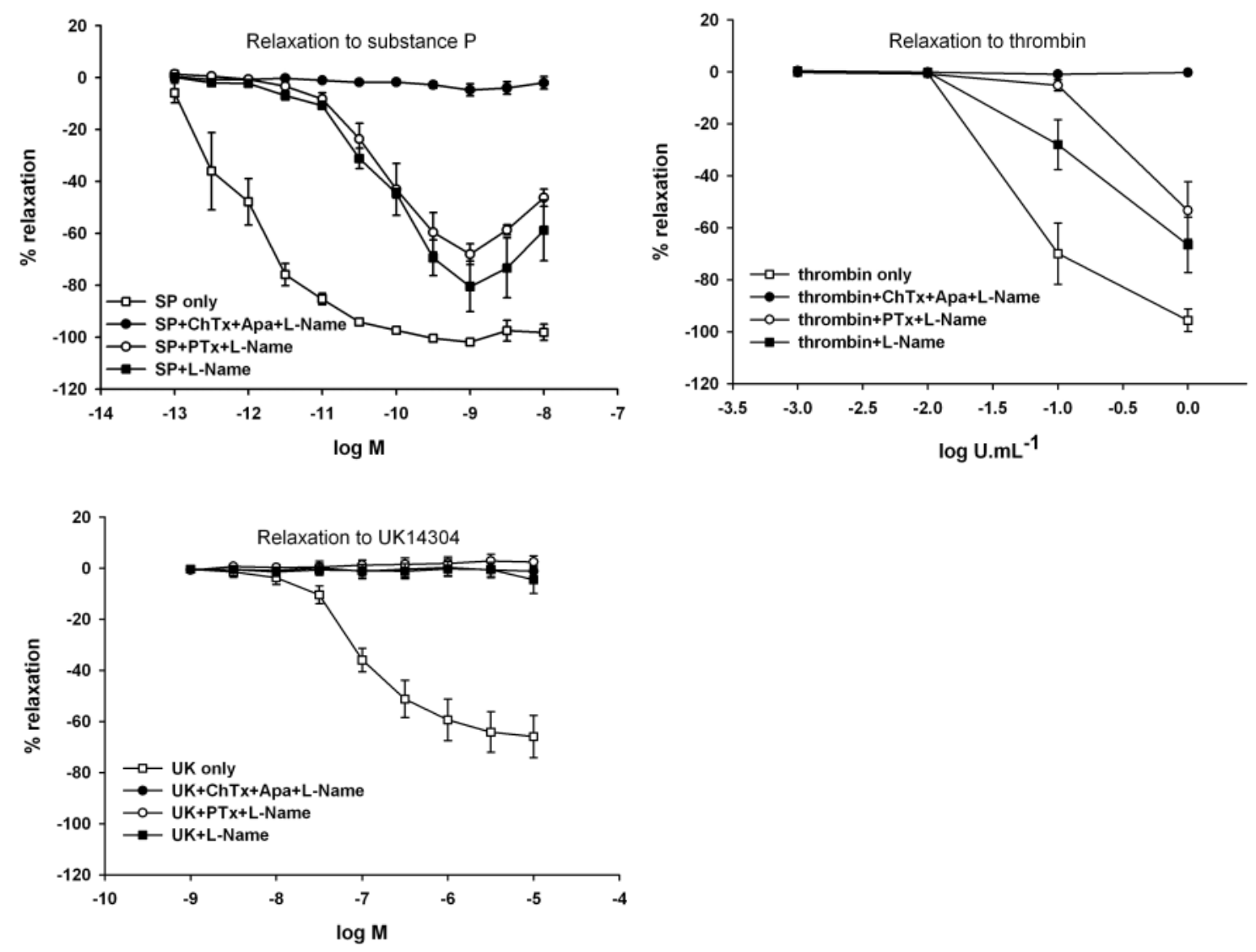

Conclusion: EDHF-mediated relaxations induced by some (e.g. thrombin) but not all (e.g. substance P) agonists involve Gi-proteins for signal transduction. 
S2O11

FUNCTIONAL EVALUATION OF EPOXYEICOSATRIENOIC ACIDS AS ENDOTHELIUM- DERIVED HYPERPOLARIZING FACTOR IN RAT MESENTERIC ARTERIAL BED

\author{
A.S. Adeagbo ${ }^{a}$, S.O. Awe ${ }^{\text {a }}$, H. Wulff ${ }^{\text {b }}$ and I.G. Joshua ${ }^{a}$ \\ ${ }^{a}$ Department of Physiology \& Biophysics, University of Louisville, Louisville, KY, U.S.A. \\ ${ }^{\mathrm{b}}$ Department of Pharmacology \& Toxicology, University of California, Davis, CA., U.S.A.
}

Epoxyeicosatrienoic acids (EETs) are epoxygenase-derived metabolites of arachidonic acid that hyperpolarize smooth muscle cells via the opening of calcium-activated potassium $\left(\mathrm{K}_{\mathrm{Ca}}\right)$ channels to initiate vascular relaxation. EETs are considered candidates for endogenous EDHF (endothelium-derived hyperpolarizing factor) in some vascular beds.

Objectives: This study evaluates the relative contribution of (1) $\mathrm{K}_{\mathrm{Ca}}$ channel subtypes [large-conductance $\left(\mathrm{BK}_{\mathrm{Ca}}\right)$; intermediate-conductance $\left(\mathrm{IK}_{\mathrm{Ca}}\right)$, and small-conductance $\left.\left(\mathrm{SK}_{\mathrm{Ca}}\right)\right]$ to dilations elicited by EETs and acetylcholine, and (2) endogenously produced EETs to arterial tone. We employed the selective blockers of $\mathrm{BK}_{\mathrm{Ca}}$ (Iberiotoxin or IBTX), IK $\mathrm{Ca}$ (TRAM-34), $\mathrm{SK}_{\mathrm{Ca}}$ (UCL-1648), and epoxygenases (2-(2-propynyoxy)benzenehexanoic acid (PPOH) as investigational tools.

Methods: Bolus injections of acetylcholine and EETs were administered to phenylephrine-constricted rat mesenteric arterial beds perfused $(5 \mathrm{ml} / \mathrm{min})$ in vitro with physiological salt solution (PSS; $\left.37^{\circ} \mathrm{C}\right)$ containing nitro-L-arginine methyl ester $(100 \mu \mathrm{M})$ plus indomethacin $(5 \mu \mathrm{M})$, and gassed with carbogen. Changes in perfusion pressure initiated by bolus application of agonists, or by infusion of inhibitors were measured with Statham pressure transducer and recorded on a Grass polygraph.

Results: 11,12-EET, and 5,6-EET decreased perfusion pressures (indices of vasodilation) concentrationdependently while 8,9- and 14,15-EETs failed to dilate the arteries. Vasodilation elicited by 5,6- or 11,12-EETs was abolished by excess $\mathrm{K}^{+}$PSS, or by tetrabutylammonium $(1 \mathrm{mM})$ suggesting the involvement of $\mathrm{K}_{\mathrm{Ca}}$ channels in this response. The selective $\mathrm{BK}_{\mathrm{Ca}}$ inhibitor, iberiotoxin (IBTX, $0.5 \mu \mathrm{M}$ ), inhibited the dilator effect of 11,12EET (300 ng) by $88 \pm 5 \%$. The remnant vasodilator effect was abolished by a combination of IBTX plus TRAM$34(0.1 \mu \mathrm{M})$, but not with UCL-1648. Acetylcholine $\left(10^{-12}-10^{-7}\right.$ mole) initiated EDHF-mediated dilation of the perfused arterial beds. Two structurally distinct specific blockers of $\mathrm{SK}_{\mathrm{Ca}}$, apamin $(0.5 \mu \mathrm{M})$ or UCL-1648 $(0.1 \mu \mathrm{M})$ each partially, but significantly reduced acetylcholine responses. Neither TRAM-34 nor IBTX altered acetylcholine responses. However, combinations of UCL-1648 plus TRAM-34 (each at $0.1 \mu \mathrm{M}$ ) or UCL-1648 plus IBTX further significantly reduced acetylcholine-induced EDHF responses. The epoxygenase inhibitor PPOH $(1-3 \mu \mathrm{M})$ also concentration-dependently inhibited acetylcholine-induced EDHF dilator responses. Infusion of epoxide hydrolase inhibitors N,N'-dicyclohexylurea (DCU; 30-100 nM) or 4-phenylchalcone (4PCO; 1-3 $\mu \mathrm{M})$ attenuated phenylephrine-induced tone, but failed to enhance acetylcholine-induced EDHF vasodilation.

Conclusions: (1) EDHF-mediated vasodilation in response to acetylcholine exhibit distinct pharmacological profiles from that elicited by 11,12-EET; $\mathrm{BK}_{\mathrm{Ca}}$ and $\mathrm{IK}_{\mathrm{Ca}}$ channels mediate 11,12-EET while $\mathrm{SK}_{\mathrm{Ca}}$ and $\mathrm{IK}_{\mathrm{Ca}}$ channels mediate acetylcholine-induced vasodilation. (2) Mesenteric arterial wall synthesizes/releases EETs, which modulates agonist-induced tone; however, it is doubtful that an EET is the physiological EDHF in rat mesenteric arteries.

[Supported by American Heart Association Grant-in-Aid to ASA] 
$\mathrm{S} 2 \mathrm{O} 12$

EDHF- BUT NOT NO-MEDIATED RELAXATION IS ABOLISHED IN THE ISOLATED MESENTERIC ARTERIES OF HYPERTENSIVE RATS CHRONICALLY TREATED WITH ANGIOTENSIN II

\author{
S. Dal, M. Oumy-Kane, C. Schott, V.B. Schini-Kerth and T. Chataigneau
}

Pharmacologie et Physico-Chimie des Interactions Moléculaires et Cellulaires, UMR CNRS 7034, Faculté de Pharmacie, Université Louis Pasteur de Strasbourg, Illkirch, France

Objective: Red wine polyphenols (RWPs) induce potent endothelium-dependent relaxations of the coronary artery by stimulating the formation of both NO and EDHF through the redox-sensitive activation of the PI3kinase pathway in endothelial cells. These effects could contribute to the cardiovascular protective properties of red wine polyphenols. The present study aimed to determine whether RWPs-induced NO and EDHF formation in arteries is altered in experimental hypertension.

Methods: Male Wistar rats were treated with angiotensin II $(0.4 \mathrm{mg} / \mathrm{kg} /$ day $)$ during 21 days using osmotic mini-pumps. Arterial pressure was measured by tail-cuff plethysmography. Reactivity of mesenteric artery rings was measured in organ chambers. Experiments were performed in the presence of indomethacin to prevent the formation of prostanoids. The NO-mediated component of relaxation was determined in the presence of charybdotoxin plus apamin, and that of EDHF in the presence of $\mathrm{N}^{\omega}$-nitro-L-arginine (L-NA). The expression level of the gap junction proteins in segments of mesenteric artery from control and angiotensin II-treated rats was quantified by immunohistochemistry using antibodies directed against connexin 37 (Cx37), connexin 40 (Cx40) and connexin 43 (Cx43).

Results: Angiotensin II administration increased the mean systolic blood pressure from about $120 \mathrm{mmHg}$ to about $175 \mathrm{mmHg}$. RWPs and acetylcholine (ACh) induced concentration-dependent relaxations of mesenteric arteries, which were partially reduced by either L-NA or charybdotoxin plus apamin, and abolished by the combination of all inhibitors in the control and angiotensin II group. Angiotensin II treatment did not alter the global (NO plus EDHF) and the NO-mediated component of relaxation but abolished that to EDHF, in response to ACh. Angiotensin II administration did not affect the NO-mediated component of relaxation in response to RWPs but abolished that to EDHF and reduced the global component. The expression of the three connexins $\mathrm{Cx} 37, \mathrm{Cx} 40$ and $\mathrm{Cx} 43$ was decreased in the mesenteric arteries from angiotensin II-treated rats.

Conclusions: These findings indicate that RWPs and ACh induce both NO- and EDHF-mediated relaxation in the rat mesenteric artery. Angiotensin II-induced hypertension is associated with a selective suppression of the EDHF-mediated component of relaxation without affecting that to NO. They further suggest that NO may compensate for EDHF loss in order to maintain a normal endothelial function in the mesenteric artery of hypertensive rats. The suppression of EDHF-mediated responses could be partly attributed to a decreased expression of connexins, which compose the myoendothelial gap junctions. 
$\mathrm{S} 2 \mathrm{O} 13$

THE ROLE OF ENDOTHELIAL CONNEXIN 40 AND CONNEXIN 43 mRNA EXPRESSION IN RELATION TO HYPERHOMOCYSTEINEMIA

\author{
S.G. Heil ${ }^{a}$, A.S. De Vriese ${ }^{b}$, L.A.J. Kluijtmans ${ }^{a}$, B.J.M. van der Rijt-Pisa ${ }^{a}$, J.M.F. Trijbels ${ }^{a}$ and H.J. \\ Blom $^{a}$ \\ ${ }^{a}$ Radboud University Nijmegen Medical Centre, Laboratory of Pediatrics and Neurology, Nijmegen, \\ The Netherlands. \\ ${ }^{\mathrm{b}}$ University of Ghent, Renal Unit, Ghent, Belgium.
}

Objective: Hyperhomocysteinemia is associated with increased risk of cardiovascular diseases. Recently, we demonstrated that the endothelium-derived hyperpolarizing factor (EDHF)-mediated vasodilatation was impaired in hyperhomocysteinemia. Previously, evidence for a role of gap junctions in relation to the EDHF-mediated vasodilatation was provided as we demonstrated that blocking of the structural subunits of gap junctions [i.e. connexin $40(\mathrm{Cx} 40)$ and connexin $43(\mathrm{Cx} 43)]$ led to a decreased EDHF-mediated vasodilatation. We, therefore, hypothesized that the impaired EDHF-mediated vasodilatation in hyperhomocysteinemia might be caused by decreased mRNA expression of $\mathrm{Cx} 40$ and/or Cx43.

Methods: Rats were fed either a high methionine diet with low levels of B vitamins (HMLB) or standard rodent chow for 8 weeks. Endothelial cells were dissected from renal arterioles by lasermicrodissection and realtime quantitative PCR was applied to quantify $\mathrm{Cx} 40$ and $\mathrm{Cx} 43$ mRNA levels.

Results: Rats fed the HMLB diet had significantly elevated homocysteine levels as compared to those fed the control diet. $\mathrm{Cx} 40 \mathrm{mRNA}$ levels were 1.7-fold down regulated $(\mathrm{P}<0.10)$ in endothelial cells dissected from renal arterioles of hyperhomocysteinemic rats $(n=7)$ as compared to those fed the control diet $(n=7)$. No differences could be observed in Cx43 mRNA expression.

Conclusion: These preliminary findings suggest that the impaired renal EDHF-mediated vasodilatation of hyperhomocysteinemic rats might be due to decreased expression of $\mathrm{Cx} 40$. 
S2O14

SMALLER WINDOWS IN INTERNAL ELASTIC LAMINA, FEWER ROUTES FOR MYOENDOTHELIAL JUNCTIONS, LESS EDHF RESPONSE.

\section{J.C. McGrath, J.M. Gonzalez, A.M. Briones, E. Vila, M.C. Gonzalez, S.M Arribas and C.J Daly}

Autonomic Physiology Unit, University of Glasgow, Glasgow, UK.

Objective: To test the hypothesis that, in spontaneously hypertensive rats (SHR), smaller windows in the internal elastic lamina (IEL) will result in a reduced number of myoendothelial junctions and explain attenuation of EDHF in resistance arteries.

Methods: Pressure fixed, third generation, small mesenteric arteries from WKY and SHR at 6 months old showed the known, characteristically different, structural phenotypes of normotensives and hypertensives. Confocal microscopy generated 3D models of the arteries. Cell nuclei and membranes were labeled with specific fluorescent dyes and the IEL was delineated by its inherent fluorescence. Measurements were made using MetaMorph Image analysis software.

Results: SHR arteries, which have smaller windows in the IEL (1) have a significantly reduced number of myoendothelial bridges across the IEL compared with the WKY. The bridges are of similar diameter in the two strains but the windows are, on average, smaller in SHR so that the number of sufficient size to carry the myoendothelial connections is reduced. Thus, the smaller average size of fenestrae reduces the number of physical possibilities for maintaining or forming effective bridges

Conclusions: Several independent laboratories have shown that mesenteric arteries in SHR have defective EDHF signaling at 6-8 months compared with aged matched normotensives (e.g. Fujii et al. (2)). It has been shown in various experimental conditions that EDHF signalling is dependent on the integrity and extent of myoendothelial connections (reviewed by Griffith et al. (3)). The dense structure of the IEL dictates that the only route available for myoendothelial junctions is via discrete windows (fenestrae) whose average size is normally larger than that of the average myoendothelial connection. We have now shown that in adult SHR, where the average size of the windows is reduced by over $60 \%$, the number of myoendothelial connections is reduced by one third. We propose that this is responsible for the loss of EDHF function. This change in elastin structure is also responsible for the decreased distensibility of these arteries since its digestion by elastase removes the difference in distensibility between SHR and WKY (1). We do not yet know whether this is a defensive reaction that enables the vessel to cope with increased blood pressure or is an inherent genetic property of this strain which contributes to its hypertension, posing another of the great "chicken and egg" questions in hypertension. Our present conclusion is that, in this artery, widely taken as a model for hypertensive "remodelling", loss of myoendothelial bridges, due to restricted window size, explains reduced EDHF function. Therefore, we propose that the loss of EDHF function is secondary to the structural change that reduces the number of myoendothelial connections.

1. Briones et al, 2003, Journal of Physiology 552, 185-195.

2. Fujii et al. Circ. Res. 1992; 70: 6609.

3. Griffith et al. 2004, Pharmacol Res. 2004;49:551-64. 
S2O15

ENDOTHELIUM-DEPENDENT RESPONSES OF CAROTID, FEMORAL AND MESENTERIC ARTERIES OF STREPTOZOTOCIN-INDUCED DIABETIC RATS

\section{Y.Shi, D.D.Ku, R.K.Y.Man and P.M.Vanhoutte}

Department of Pharmacology, Faculty of Medicine, University of Hong Kong

Objective: Diabetes causes endothelial dysfunction. The present experiments were designed to study endothelial function in carotid, femoral and main mesenteric arteries from rats with type I diabetes, as obtained by the injection of streptozotocin.

Methods: Rings with and without endothelium of carotid, femoral and main mesenteric arteries were suspended in organ chamber for the recording of isometric tension.

Results: In carotid arteries, L-NAME (inhibitor to NO synthase) abolished endothelium-dependent relaxations to acetylcholine, suggesting that nitric oxide is the sole mediator in this artery. Streptozotocininduced diabetes impaired the endothelium dependent relaxations to acetylcholine, an impairment which was restored by L-arginine, suggesting that in this artery type I diabetes resulted in a blunted production of NO possibly because of a limited availability of substrate for NO synthase.

In femoral arteries, the endothelium-dependent relaxations to acetylcholine were comparable in arteries from control and streptozotocin-treated rats and were abolished by L-NAME. The relaxations to acetylcholine were slightly but significantly augmented by both indomethacin (inhibitor to cyclooxygenase) and S18886 (antagonist at $\mathrm{TP}$ receptor), suggesting that the endothelium-derived contracting factor is released concomitantly with NO under control conditions. In rings treated with L-NAME, acetylcholine induced a further endothelium-dependent contraction which was inhibited by S18886, confirming the release of EDCF. Indomethacin reversed this contraction to a relaxation which was inhibited by charybdotoxin plus apamin, suggesting the release of an endothelium-dependent hyperpolarizing factor (EDHF). This EDHF-mediated component was larger in arteries from type I diabetic rats.

Mesenteric arteries from control and streptozotocin-treated rats exhibited comparable endothelium-dependent relaxations to acetylcholine. L-NAME shifted the concentration-relaxation curve to the right, suggesting that nitric oxide only partially mediates endothelium-dependent relaxation in this artery. The effect of L-NAME was reduced by the streptozotocin-treatment, suggesting a reduced release of NO. The L-NAME resistant relaxation to acetylcholine was blocked by apamin plus charybdotoxin, suggesting the involvement of EDHF. This EDHFmediated component was larger in arteries from streptozotocin-treated animals. At lower concentration of acetylcholine, indomethacin alone or combined with L-NAME did not affect endothelium-dependent relaxations. In the presence of L-NAME plus indomethacin, higher concentrations of acetylcholine induced an endotheliumdependent contraction in the arteries from control, but not those from diabetic rats. This contraction was inhibited by esculetin (inhibitor to lipoxygenase) suggesting that, in the presence of inhibitors of cyclooxygenase, arachidonic acid is shunted to the lipoxygenase pathway in the endothelial cells.

Conclusion: The present experiments illustrate both in control rats and in the animals with type I diabetes, the heterogeneity of endothelium-dependent responses in arteries of different anatomical origin.

[Supported in part by RGC grant HKU 7524] 
S2O16

IMPAIRED EDHF-DILATION CORRELATED WITH INCREASED MYOGENIC CONSTRICTION IN MESENTERIC RESISTANCE ARTERIES DURING PROGRESSION OF HEART FAILURE

\author{
Y. Xu, R.H. Henning, W.H. van Gilst and H. Buikema \\ Clinical Pharmacology, University Medical Centrum Groningen, A. Deusinglaan 1, 9713 AV, \\ Groningen, The Netherlands
}

Objective: Increased peripheral resistance in chronic heart failure (CHF) involves activation of neurohumoral systems, but local vascular mechanisms of impaired dilation and enhanced constriction also contribute importantly. We investigated the vascular reactivity of isolated mesenteric resistance arteries obtained from CHF-rats at 9 weeks after induction of experimental myocardial infarction (MI).

Methods: The internal circumference of the arteries was studied in a small wire setup for stretch-induced myogenic tension (MT) by stepwise increasing the diameter from $0.5 \mathrm{~L} 100$ to $1.2 \mathrm{~L} 100$ in the absence and presence of calcium-containing buffer solution. Agonist-induced tension was assessed by stimulating artery preparations with a combination of $\mathrm{KCl} / \mathrm{U} 46619$ over the same length-range. In addition to that, endothelium dependent relaxation was assessed using acetylcholine (Ach).

Results: We found that MT developed in arteries from CHF-rats, but not in those from sham operated rats. Also, active tension responses induced by $\mathrm{KCl} / \mathrm{U} 46619$ were significantly increased in the CHF group. In the presence of indomethacin to rule out interference of vasoactive prostanoids, Ach-induced dilation (calculated as the area under the curve) was smaller in CHF rats (-9.5\% compared to sham) but this reached no statistical significance. Interestingly, the response to Ach was reduced twice as much in arteries from CHF rats $(-23.9 \%$, $\mathrm{P}=0.0018)$ as compared to sham operated rats $(-9.6 \%, \mathrm{P}=\mathrm{NS})$ by additional NOS-inhibition with L-NMMA; the remainder non-prostanoid non-NO mediated-response was significantly smaller in CHF. Furthermore, this decreased non-prostanoid non-NO (EDHF-)mediated-response was correlated with increased MT in CHF rats $(\mathrm{r}=0.76 ; \mathrm{P}=0.04)$.

Conclusions: Our data demonstrate that CHF increased active tension and induced MT which correlated with decreased EDHF. Other investigators previously reported a minor decrease in total dilation to Ach in mesenteric arteries at 4 weeks after MI, with a marked down-regulation of NO-mediated dilation and upregulation of EDHF-dilation (1). These authors suggested that increased EDHF-activity in CHF may represent a compensatory response to decreased NO-activity to preserve endothelial function and tissue perfusion. Our present findings may extent these data by suggesting that at 9 weeks after MI during progression of CHF, this initial compensatory EDHF-dilation is lost and in fact is reversed into a EDHF-deficit that is accompanied by an increased MT development (2). These data illustrate the transition of early compensatory changes in endothelial mediators to maintain endothelial function and tissue perfusion after MI towards enhanced vasoconstrictor mechanisms during progression of $\mathrm{CHF}$.

1 Malmsjo M, et al. Cardiovasc Res 1999;43:200-209.

2 Gschwend S, et al. Hypertension 2003;41:912-918. 
S2O17

IMPAIRED EDHF RESPONSES IN RENAL ARTERIES FROM THE OBESE ZUCKER RAT: INVOLVEMENT OF GAP JUNCTIONS AND CONNEXINS

\author{
J.J. Reid ${ }^{a}$, E.J. Young ${ }^{a}$, W.B. Wiehler ${ }^{b}$ and W. A.K. Lau ${ }^{a}$ \\ ${ }^{a}$ School of Medical Sciences, RMIT University, Melbourne, Australia. \\ ${ }^{\mathrm{b}}$ Faculty of Medicine, University of Calgary, Calgary, Canada.
}

Objective: The obese Zucker rat (OZR) is a well accepted animal model of insulin resistance, and we have previously shown that the 25-week OZR exhibits various risk factors (glucose intolerance, hypertension, hyperlipidaemia and proteinuria) associated with the insulin resistance syndrome and type 2 diabetes (1). Additionally, we have demonstrated endothelial dysfunction in renal arteries from the 25 -week OZR that can be attributed to an impaired response to endothelium-derived hyperpolarizing factor (EDHF) (2). Since there is increasing evidence for a role of myoendothelial gap junctions in EDHF-mediated effects, the objective of the present study was to compare the potential involvement of gap junctional communication and associated connexins in the EDHF-mediated relaxations in renal arteries from the OZR and from the lean littermate control Zucker rat (LZR).

Methods: Endothelium-intact renal arteries (ID $450-500 \mu \mathrm{m}$ ) were mounted in a wire Mulvany-Halpern myograph for isometric force recordings in the presence of nitro-L-arginine methyl ester $(100 \mu \mathrm{M})$, ODQ $(10 \mu \mathrm{M})$ and indomethacin $(10 \mu \mathrm{M})$ to block NO and prostacyclin production. mRNA expression of connexins in renal artery homogenates from the LZR and OZR was also assessed using RT-PCR; primers specific for connexins 37, 40,43 and 45 were synthesised and beta actin was used as the housekeeping gene.

Results: EDHF-mediated relaxations to acetylcholine $(1 \mathrm{nM}-10 \mu \mathrm{M})$ were significantly smaller $(\mathrm{P}<0.05$, ANOVA) in phenylephrine-constricted renal arteries from the OZR compared to the LZR; these responses were blocked by apamin $(1 \mu \mathrm{M})$ and charybdotoxin $(0.1 \mu \mathrm{M})$ in both lean and obese rats. The gap junction uncoupler 43Gap27 $(300 \mu \mathrm{M}$, which targets connexin 43$)$ had no significant effect ( $>0.05$, ANOVA) on the EDHFmediated relaxations evoked by acetylcholine in renal arteries from both the OZR and LZR. In contrast, 40Gap27 $(300 \mu \mathrm{M}$, which targets connexin 40$)$ partially inhibited ( $\mathrm{P}<0.05$, ANOVA) the EDHF-mediated relaxations in renal arteries from the LZR but did not affect those from the OZR, such that renal EDHF-mediated relaxations were no longer different between lean and obese rats. Carbenoxolone $(300 \mu \mathrm{M})$ or a combination of 40Gap27 and 43Gap27 had a similar effect to that of 40Gap27 alone. None of the inhibitors had any effect on endothelium-independent relaxations to sodium nitroprusside. mRNA levels showed a significant decrease ( $\mathrm{P}<0.05$, Student's t-test) of 3.5-fold in connexin 37 expression, 2.9-fold in connexin 40 expression, and 2.0-fold in connexin 45 expression in the OZR compared with the LZR, with no significant change in connexin 43 expression.

Conclusions: These results suggest that endothelial dysfunction in OZR renal arteries is associated with reduced connexin 40 function and mRNA expression, providing evidence that connexin 40-associated gap junctions are defective in the OZR, contributing to renal endothelial dysfunction in insulin resistance.

1 Karagiannis J, Reid JJ, Darby I et al (2003) J Cardiovasc Pharmacol 42: 497-505.

2 Reid JJ, Lau WAK (2002) J Hypertens 20 (Suppl 4): S276. 
S2O18

REGIONAL DIFFERENCES IN ENDOTHELIAL HYPERPOLARIZATION AND ENDOTHELIUMDERIVED HYPERPOLARIZING FACTOR IMPAIRMENT IN DIABETES MELLITUS

\section{Tare, H.A. Coleman and H.C. Parkington}

Department of Physiology, Monash University, Victoria, 3800, Australia

Objective: The endothelium plays a central role in vascular relaxation, and endothelium-dependent vasodilator function is compromised in diabetes. In many resistance arteries and arterioles, endothelium-derived hyperpolarizing factor (EDHF) contributes significantly to endothelium-dependent vasodilation. In mesenteric arteries of rats with streptozotocin (STZ)-induced diabetes, EDHF-mediated smooth muscle hyperpolarization and relaxation are impaired. A significant proportion of the EDHF response in the smooth muscle in this vessel is initiated by the generation of hyperpolarization in the endothelial cells which spreads to the smooth muscle via myoendothelial gap junctions (MEGJs). Here we investigated the influence of diabetes on endothelial cell hyperpolarization and endothelial-smooth muscle cell electrical cross-talk in intact segments of artery. These were compared with responses in the femoral artery, in which endothelium-dependent relaxation is resistant to diabetes.

Methods: Male Wistar rats were injected with either $60 \mathrm{mg} / \mathrm{kg} \mathrm{STZ}$ in citrate buffer, or buffer alone, into the tail vein. Eight weeks later, mesenteric and femoral arteries were isolated, segments were placed in a recording chamber and cut longitudinally for half of their length (endothelium pinned uppermost), with the remainder left intact. Tissues were superfused with warmed, oxygenated physiological saline at $35^{\circ} \mathrm{C}$. EDHF responses were isolated with nitro-L-arginine methyl ester $(100 \mu \mathrm{M})$ and indomethacin $(1 \mu \mathrm{M})$ to inhibit nitric oxide synthase and cyclooxygenase. Intracellular microelectrodes were used to record the membrane potentials of endothelial and smooth muscle cells, and electrode tips were filled with $2 \%$ Lucifer Yellow to permit identification of each cell from which recordings were made.

Results: Acetylcholine evoked concentration-dependent hyperpolarization in endothelial and smooth muscle cells of mesenteric preparations from both control and diabetic rats. Maximal EDHF-attributed smooth muscle hyperpolarization was halved in mesenteric arteries from diabetic rats and accounts for the reduced EDHFmediated relaxation in these vessels. Whether the impairment of the EDHF response resides in the smooth muscle or endothelium was investigated by recording hyperpolarizations in endothelial cells of the same preparations. Generation of endothelial cell hyperpolarization was impaired, with maximal hyperpolarization halved in diabetic vessels. Hyperpolarization evoked selectively in the smooth muscle by levcromakalim is conducted to endothelial cells via MEGJs in control vessels and was not altered by diabetes. In femoral arteries, the absence of MEGJs accounts for the lack of involvement of EDHF in endothelium-dependent relaxation, despite the profound endothelial cell hyperpolarization. The ability of the endothelial cells to generate hyperpolarization was unaltered in femoral arteries of diabetic rats.

Conclusions: The reduction in EDHF-mediated smooth muscle hyperpolarization and relaxation in the mesenteric artery in diabetes is caused by impaired generation of hyperpolarization in the endothelial cells. Electrical cross talk between endothelial and smooth muscle cells via MEGJs remains functional. In contrast, endothelial cell hyperpolarization was preserved in femoral arteries of diabetic animals. It is tempting to speculate that the presence or absence of functional contacts between endothelial and smooth muscle cells may contribute to the regionality of endothelium-dependent vasodilator dysfunction in diabetes. 


\section{Oxidant-induced protein modifications mediating vascular relaxation and signalling}

by

Professor Richard A Cohen,

Vascular Biology Unit, X708

Department of Medicine

Boston University School of Medicine

USA

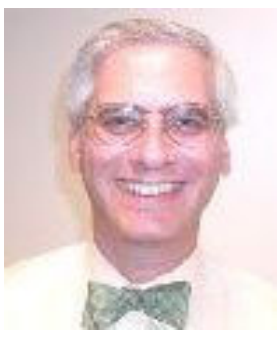

"The most exciting part of contemporary science for me is the possibility to apply molecular tools and technologies to establish new insights into physiology and disease. The ability to establish new integrative understanding of complex problems and systems has grown enormously as a result."

\begin{tabular}{|c|c|c|c|}
\hline $09.00-09.45$ & $\begin{array}{l}\text { 6th John T. Shepherd Lecture } \\
\text { Oxidant-Induced Protein Modifications Mediating Vascular } \\
\text { Relaxation and Signalling }\end{array}$ & Richard Cohen & $\begin{array}{l}\text { Invited } \\
\text { Lecture }\end{array}$ \\
\hline $09.45-10.00$ & $\begin{array}{l}\text { Raloxifene attenuates endothelial dysfunction induced by } \\
\text { oxidized low-density lipoprotein }\end{array}$ & Huang, Yu & S3 019 \\
\hline $10.00-10.15$ & $\begin{array}{l}\text { Calcium handling in aortic smooth muscle cells of } \\
\text { apolipoprotein E-deficient mice transfected with } \\
\text { paraoxonase-1 }\end{array}$ & Van Assche, Tim & S3 O20 \\
\hline $10.15-10.30$ & $\begin{array}{l}\text { Endothelium-dependent contractions in the SHR aorta: the } \\
\text { Janus face of prostacyclin }\end{array}$ & Félétou, Michel & S3 O21 \\
\hline $10.30-11.00$ & $\begin{array}{l}\text { POSTER SESSION } 1 \\
- \\
\text { coffee break }\end{array}$ & & \\
\hline $11.00-11.15$ & $\begin{array}{l}\text { The lipid peroxidation inhibitor butylated hydroxytoluene } \\
\text { (BHT) annuls bradykinin induced vasodilation resistant to } \\
\text { NOS \& COX inhibitors in the rat mesenteric and coronary beds }\end{array}$ & Ballejo, Gustavo & S3 022 \\
\hline $11.15-11.30$ & $\begin{array}{l}\text { Rosuvastatin's protection against the development of nitrate } \\
\text { tolerance in wild-type and eNOS-/- mice seems to implicate } \\
\text { the NAD }(P) \text { H oxidase pathway }\end{array}$ & Otto, Anne & S3 023 \\
\hline $11.30-11.45$ & $\begin{array}{l}\text { Acetylcholine and sodium nitroprusside cause long-term } \\
\text { inhibition of EDCF-mediated contractions }\end{array}$ & Tang, Eva H.C. & S3 O24 \\
\hline $11.45-12.00$ & $\begin{array}{l}\text { Effects of ascorbate on endothelium-derived hyperpolarizing } \\
\text { factor (EDHF)-mediated vasodilatation in the perfused rat } \\
\text { mesentery and hindlimb }\end{array}$ & Stirrat, Alison & S3 O25 \\
\hline
\end{tabular}


S3O19

RALOXIFENE ATTENUATES ENDOTHELIAL DYSFUNCTION INDUCED BY OXIDIZED LOWDENSITY LIPOPROTEIN

\author{
C-H. Ng, Z-Y. Chen, X. Yao, C-L. Au, L. Yung, P.M. Vanhoutte and Y. Huang
}

Department of Biochemistry and Department of Physiology, Chinese University of Hong Kong, China Department of Pharmacology, University of Hong Kong, Hong Kong SAR, China

Objective: Hypercholesterolemia and atherosclerosis are closely associated with unfavorable alterations in vascular reactivity, such as diminished endothelial nitric oxide-dependent vasodilatation, which is characterized as endothelial dysfunction. Oxidative modification of low-density lipoprotein (LDL) is believed to be an important event in the development of endothelial dysfunction. Raloxifene, the second generation selective estrogen receptor modulator, is known to improve lipid profiles in human subjects. But its effect on endothelial function in the presence of oxidized LDL is not clear. The aim of the present study was to investigate the hypothesis that raloxifene treatment could ameliorate the impairment of endothelium-mediated vasorelaxation induced by oxidized human LDL in the isolated aortas from Sprague-Dawley rats.

Results: In phenylephrine-contracted aortic rings with endothelium, oxidized LDL attenuated acetylcholineor thapsigargin-induced relaxation in a concentration- and time-dependent manner, while native human LDL $(100 \mu \mathrm{g} / \mathrm{ml})$ was without effect. Co-incubation of rings with native LDL plus $5 \mu \mathrm{M}$ copper also reduced the relaxation to acetylcholine. Treatment with raloxifene concentration-dependently inhibited the effect of oxidized LDL on endothelial function and this effect was antagonized by ICI 182,780, a classic estrogen receptor blocker. Estrogen but not tamoxifen (the first generation selective estrogen receptor modulator) showed a similar effect as to raloxifene. Treatment with PI3 kinase inhibitors (wortmannin and LY 294002) reversed the effect of raloxifene on the impaired relaxation to acetylcholine. Raloxifene did not possess acute free radical scavenging activity.

Conclusions: The present results indicate that raloxifene ameliorates endothelial dysfunction in oxidized LDL-treated aortic rings by improving endothelial NO production probably via a PI3 kinase-dependent mechanism and this effect is associated with ICI 182,780-sensitive estrogen receptors on the endothelium. This study has thus provided evidence for additional vascular benefits of raloxifene. Whether this favorable effect of raloxifene on endothelial function translates into clinical benefits in hypercholesterolemia remains to be confirmed. [Supported by Research Grants Council of Hong Kong SAR] 
S3O20

CALCIUM HANDLING IN AORTIC SMOOTH MUSCLE CELLS OF APOLIPOPROTEIN E-DEFICIENT MICE TRANSFECTED WITH PARAOXONASE-1

\author{
T. Van Assche ${ }^{a}$, P. Fransen ${ }^{a}$, P-J. Guns ${ }^{a}$, C. Van Hove ${ }^{a}$, B. Mackness ${ }^{b}$, M. Mackness ${ }^{b}$, E. Ninio ${ }^{c}$, \\ W. Verreth ${ }^{d}, P$. Holvoet ${ }^{d}$ and H. Bult ${ }^{a}$ \\ a Department of Pharmacology, University of Antwerp, Belgium \\ ${ }^{\mathrm{b}}$ University Department of Medicine, Manchester Royal Infirmary, Manchester, UK. \\ c INSERM U525, IFR14 Coeur Muscle Vaisseaux and Université P.M. Curie, Faculté de Médecine, \\ Paris, France. \\ ${ }^{d}$ CEHA, Catholic University of Louvain, Belgium
}

Objective: Transfer of genes that reduce oxidative stress, like paraoxonase 1 (PON1), platelet-activating factor acetylhydrolase (PAF/AH) and lecithin-cholesterol transferase (LCAT), retards the progression of atherosclerosis in apolipoprotein E-deficient mice $\left(\mathrm{apoE}^{-/}\right)$. Oxidative stress modulates calcium handling of smooth muscle cells. Therefore, we investigated the effect of apoE $\mathrm{E}^{-/}$and the effect of PON1, PAF/AH and LCAT gene transfer in apoE $^{-/}$mice on calcium-handling and force development in aortic smooth muscle cell (SMC) rings.

Methods: C57Bl/6 WT, apoE ${ }^{-/}$and apoE ${ }^{-/}$mice transfected three weeks in advance with PON1, PAF/AH, LCAT or a control virus RR5, were used (18 months, regular chow). Plaque-free endothelium-denuded aortic rings (width $1 \mathrm{~mm}$ ) were mounted in a wire myograph and loaded with the calcium sensitive dye Fura-2 AM. Isometric force development and free intracellular calcium $\left(\left[\mathrm{Ca}^{2+}\right]_{\mathrm{i}}\right)$ were simultaneously measured. The 340/380 $\mathrm{nm}$ excitation emission ratio was used as a relative measure of $\left[\mathrm{Ca}^{2+}\right]_{\mathrm{i}}$ (relative units, $\mathrm{RU}$ ). $\mathrm{ApoE}^{-/-}$mice and apoE $E^{-/-}$mice transfected with the control virus RR5 showed similar responses to experimental interventions, therefore both groups were combined and referred to as $\mathrm{apoE}^{-/-}$mice in the results.

Results: In comparison with $\mathrm{WT}$, apoE ${ }^{-/-}$mice showed a significantly reduced calcium release after treatment with $10 \mu \mathrm{M}$ cyclopiazonic acid (CPA), a sarco-endoplasmic calcium ATPase (SERCA) inhibitor (1.97 \pm 0.50 , $\mathrm{n}=4$, versus $0.69 \pm 0.08 \mathrm{RU}, \mathrm{n}=11)$. CPA-sensitive $\left[\mathrm{Ca}^{2+}\right]_{\mathrm{i}}$ release was restored by transfecting apoE ${ }^{-/}$mice with PON1 (1.68 $\pm 0.28 \mathrm{RU}, \mathrm{n}=5)$, but not with LCAT $(0.97 \pm 0.16 \mathrm{RU}, \mathrm{n}=6)$ or PAF/AH $(0.80 \pm 0.28 \mathrm{RU}, \mathrm{n}=6)$. CPA-sensitive $\left[\mathrm{Ca}^{2+}\right]_{\mathrm{i}}$ release $(>0.80 \mathrm{RU})$ was much higher than the $\left[\mathrm{Ca}^{2+}\right]_{\mathrm{i}}$ release evoked with $50 \mathrm{mM} \mathrm{KCl}$ or $1 \mu \mathrm{M}$ phenylephrine (PE) $(<0.60 \mathrm{RU})$. Yet CPA only elicited a small contraction $(<1.40 \mathrm{mN} / \mathrm{mm})$ in comparison with high external $\mathrm{K}^{+}$or PE $(>3.60 \mathrm{mN} / \mathrm{mm})$. This weak CPA-contraction was comparable between all groups. PON1-transfected $\mathrm{apoE}^{-/-}$mice, however, developed significantly higher force than apoE $\mathrm{E}^{-/-}$mice after depolarization with $50 \mathrm{mM} \mathrm{K}^{+}(4.82 \pm 0.23, \mathrm{n}=7$ versus $3.61 \pm 0.19 \mathrm{mN} / \mathrm{mm}, \mathrm{n}=13)$ or stimulation with $1 \mu \mathrm{M} \mathrm{PE}$ $(4.32 \pm 0.20, \mathrm{n}=7$ versus $3.86 \pm 0.16 \mathrm{mN} / \mathrm{mm}, \mathrm{n}=13)$.

Conclusions: ApoE ${ }^{-/-}$mice showed reduced CPA-sensitive $\left[\mathrm{Ca}^{2+}\right]_{\mathrm{i}}$ release in comparison with WT. PON1, but not PAF/AH and LCAT gene transfer restores this CPA-sensitive $\left[\mathrm{Ca}^{2+}\right]_{\mathrm{i}}$ release in apoE $\mathrm{E}^{-/-}$mice. Normalization of CPA-sensitive $\left[\mathrm{Ca}^{2+}\right]_{i}$ release is accompanied by an increase in force development. Modulation of SMC sarcoplasmic reticulum function may contribute to the beneficial effect of PON1 gene transfer on the progression of atherosclerosis in $\mathrm{apoE}^{-/-}$mice. 
$\mathrm{S} 3 \mathrm{O} 21$

ENDOTHELIUM-DEPENDENT CONTRACTIONS IN THE SHR AORTA: THE JANUS FACE OF PROSTACYCLIN

\section{P. Gluais ${ }^{a}$, P.M. Vanhoutte ${ }^{b}$ and M. Feletou ${ }^{a}$}

${ }^{a}$ Institut de Recherches Servier, Suresnes, France

${ }^{\mathrm{b}}$ Department of Pharmacology, Faculty of Medicine, University of Hong Kong

Objectives: In arteries of spontaneously hypertensive (SHR) and aging Wistar Kyoto rats (WKY), acetylcholine causes endothelium-dependent contractions, which are mediated by a diffusible product(s) [endothelium-derived contracting factor, EDCF] of the metabolism of arachidonic acid by cyclooxygenase-1 (COX-1) which activate(s) smooth muscle TP receptors. The present experiments were designed to identify the nature of EDCF.

Methods: Rings of SHR and WKY aorta were suspended in oxygenated Krebs-Ringer bicarbonate solution for the measurement of isometric force and, in separate experiments, of the release of thromboxane $B_{2}$ (index of thromboxane $\left.\mathrm{A}_{2}, \mathrm{TXA}_{2}\right)$, 8-isoprostane, prostaglandin $\mathrm{E}_{2}, \mathrm{D}_{2}$ and $\mathrm{F}_{2 \alpha}\left(\mathrm{PGE}_{2}, \mathrm{PGD}_{2}\right.$ and $\left.\mathrm{PGF}_{2 \alpha}\right)$, and 6-keto$\mathrm{PGF}_{1 \alpha}$ (index of prostacyclin, $\mathrm{PGI}_{2}$ ).

Results: In isolated aortic rings of SHR (40-65 weeks old), acetylcholine produced a TP-receptor mediated, endothelium-and COX-1-dependent contraction which was potentiated by NO-synthase inhibitors. The various prostaglandin derivatives tested produced contractions that were also TP-receptor mediated and which were enhanced by either a NO-synthase inhibitor or by endothelium-removal (order of potency U 46619 >> 8isoprostane $=\mathrm{PGF}_{2 \alpha}=\mathrm{PGH}_{2}>\mathrm{PGE}_{2}=\mathrm{PGD}_{2}>\mathrm{PGI}_{2}>>$ iloprost $=6$-keto- $\left.\mathrm{PGF}_{1 \alpha}\right)$. Acetylcholine induced an endothelium- and COX-1-dependent release of $\mathrm{PGI}_{2}>>>\mathrm{PGE}_{2}=\mathrm{PGF}_{2 \alpha}>\mathrm{TXA}_{2}>\mathrm{PGD}_{2}>8$-isoprostane. Dazoxiben did not affect acetylcholine-induced contraction but prevented the $\mathrm{TXA}_{2}$ release without influencing that of other prostaglandins. The acetylcholine-dependent production of $\mathrm{PGI}_{2}$ was 2 to 5 times larger in the aortic rings from SHR than WKY and was not influenced by NO-synthase inhibition. In both strains, the curves of the concentration-dependent release of $\mathrm{PGI}_{2}$ and of the endothelium-dependent contractions were superimposable. The release of $\mathrm{PGI}_{2}$ was fast and consistent with the time-course of endothelium-dependent contractions. $\mathrm{PGI}_{2}$ and $\mathrm{PGH}_{2}$-induced contractions were transient, as were those to $\mathrm{EDCF}$, while the contractions to the other prostaglandin derivatives were sustained. $\mathrm{PGH}_{2}$, but not $\mathrm{PGI}_{2}$, was more potent in SHR than in WKY aortic rings.

Conclusions: These results suggest that in the SHR aorta various endothelium-derived prostaglandins, can act as EDCF but that $\mathrm{PGH}_{2}$ and $\mathrm{PGI}_{2}$ are the most suitable candidates. 
$\mathrm{S} 3 \mathrm{O} 22$

THE LIPID PEROXIDATION INHIBITOR BUTYLATED HYDROXYTOLUENE (BHT) ANNULS BRADYKININ INDUCED VASODILATION RESISTANT TO NOS \& COX INHIBITORS IN THE RAT MESENTERIC AND CORONARY BEDS.

\section{G. Ballejo, M.C.O. Salgado, O.Vettore and O. Mesquita jr.}

Departamento de Farmacologia, Faculdade de Medicina de Ribeirao Preto-Universidade de São Paulo, Ribeirão Preto, SP Brasil.

Objective: The mechanisms involved in the NOS/COX inhibitors-resistant endothelial-dependent vasodilation elicited by bradykinin (BK) remain to be fully elucidated.

Methods: In the present study the potential mechanisms were further investigated using the isolated and perfused rat mesenteric and coronary beds.

Results: In phenylephrine pre-constricted isolated mesenteric bed (Krebs containing diclofenac, DF, $10 \mu \mathrm{M}$, L-NOARG $200 \mu \mathrm{M}$ \& guanethidine $7.5 \mu \mathrm{M}, 4 \mathrm{~mL} / \mathrm{min}$ ) BK (5-100ng) and ACh (10-40 ng) induced concentration-dependent vasodilation. BK-induced vasodilation was abolished by the combination of apamin $(1 \mu \mathrm{M})$ and charybdotoxin $(0.1 \mu \mathrm{M})$ but was unaffected by the cytochrome P450 inhibitor sulfaphenazole (SPZ, $30 \mu \mathrm{M})$, the VR1 antagonist capsazepine $(1 \mu \mathrm{M})$, the CGRP receptor antagonist CGRP8-37 $(1 \mu \mathrm{M})$, the gap junction inhibitor 18- $\alpha$ Glycyrrhetinic acid $(100 \mu \mathrm{M})$, the CB1R antagonist SR141716A $(1 \mu \mathrm{M})$, catalase $(1200 \mathrm{U} / \mathrm{mL})$ or the combination of $\mathrm{Ba}^{2+}(100 \mu \mathrm{M})$ and ouabain $(100 \mu \mathrm{M})$. In contrast, BK-induced vasodilation was greatly reduced by the $\mathrm{NO}$ scavenger hydroxocobalamin $(\mathrm{B} 12 \mathrm{a}, 100-300 \mu \mathrm{M})$ and practically abolished by the lipid peroxidation inhibitor butylated hydroxytoluene (BHT, $25 \mu \mathrm{M}$ ). In the vasopressin pre-constricted isolated coronary bed (Krebs-Henseleit containing L-NOARG+DF, $13 \mathrm{ml} / \mathrm{min}$ ) BK (0.3-10 pmol) caused concentration-dependent vasodilation which was marginally reduced by SPZ (10-30 $\mu \mathrm{M})$. In contrast, BK induced coronary vasodilation was greatly reduced by B12a $(100 \mu \mathrm{M})$ and abolished by BHT $(10 \mu \mathrm{M})$. In the mesenteric bed, bolus injections of $\mathrm{HgCl}_{2}$ (5nmoles) caused vasodilation which desensitized after repeated administration. In $\mathrm{Hg}^{2+}$-desensitized preparations BK failed to produce vasodilation. Nitrosothiols (determined by the triiodine method) were present in the low nanomolar range in mesenteric bed homogenates. Considering that nitrosothiols have been proposed as mediators of the EDHF phenomenon and that NO is released from these compounds by $\mathrm{Hg}$ or light, together with the fact that lipid peroxidation is accompanied by low level luminiscenc,e we explored whether lipid peroxidation reactions activated by BK could be associated with photon emission. To this aim we took advantage of the properties of a nitrofurylvynilquinoline derivative (NFQ) which releases NO when irradiated with light $(420-430 \mathrm{~nm})$ but not when in contact with biological tissues. Intriguingly, the magnitude of BK induced vasodilation under ambient illumination of $<5$ Lux, but not those induced by Ach, was enhanced in the presence of NFQ $(0,5-1,0 \mu \mathrm{M})$ in a B12a $(200 \mu \mathrm{M})$ and BHT $(25 \mu \mathrm{M})$ sensitive manner.

Conclusions: The NOS/COX inhibitors-resistant vasodilation induced by BK in rat coronary and mesenteric beds exhibits properties consistent with an EDHF-dependent response which appears to involve none of the following proposed mechanisms: $\mathrm{H}_{2} \mathrm{O}_{2}$, a SPZ-sensitive EDHF, the activation of VR1 or CB1R, gap junctions or inward rectifying $\mathrm{K}^{+}$channels. In contrast, the present findings suggest that $\mathrm{BK}$ induced EDHF-like vasodilation in mesenteric and coronary beds could be mediated by NO itself derived from sources other than NOS activity and requires a lipid peroxidation step which is associated with the emission of photons. 
$\mathrm{S} 3 \mathrm{O} 23$

ROSUVASTATIN'S PROTECTION AGAINST THE DEVELOPMENT OF NITRATE TOLERANCE IN WILD-TYPE AND ENOS ${ }^{-1}$ MICE SEEMS TO IMPLICATE THE NAD(P)H OXIDASE PATHWAY.

A. Otto ${ }^{b}$, D. Fontaine ${ }^{b}$, J. Fontaine ${ }^{b}$ and G. Berkenboom ${ }^{a}$

${ }^{a}$ Cardiology Department, Erasme Hospital, Brussels, Belgium

${ }^{\mathrm{b}}$ Pharmacology Department, Institute of Pharmacy, Université Libre de Bruxelles, Brussels, Belgium

Objective: Nitrate tolerance is associated with an enhanced superoxide anion production and could be attenuated by statins as they interact with the two main (eNOS and NAD(P)H oxidase) pathways involved in this oxidative stress.

Methods: Therefore, in wild-type (WT) and eNOS deficient mice $\left(\mathrm{eNOS}^{-/}\right), 3$ types of treatment were given : group 1 received rosuvastatin $(20 \mathrm{mg} / \mathrm{kg} / \mathrm{d}$ p.o.) for 5 weeks and the last 3 days a co-treatment with the statin plus nitroglycerin (NTG, $30 \mathrm{mg} / \mathrm{kg} / \mathrm{d}$, sub-cutaneous injections b.i.d); group 2 received only NTG (30 $\mathrm{mg} / \mathrm{kg} / \mathrm{d}$, b.i.d for 3 days) and group 3 served as control. Rings of thoracic aortas from these groups were studied in organ baths.

Results: Relaxations to NTG $(0.1 \mathrm{nM}$ to $0.1 \mathrm{mM})$ were determined on U44619, a thromboxane analogue, preconstricted rings and $\mathrm{O}^{2-}$ production (counts $/ 10 \mathrm{~s} / \mathrm{mg}$ ) was assessed on aorta homogenates with the lucigenin enhanced chemiluminescence technique. In WT group 2, the concentration-response curves to NTG were significantly shifted to the right: the $\mathrm{pD}_{2}$ (-log NTG concentration evoking a half maximal relaxation) was $6.27 \pm$ $0.06(\mathrm{n}=7)$ vs. $6.70 \pm 0.05(\mathrm{n}=8)$ in WT group 3 (not exposed to NTG) and $\mathrm{O}^{2-}$ production was enhanced from $6,845 \pm 1,313(\mathrm{n}=9)$ to $24,477 \pm 4,927(\mathrm{n}=8 \mathrm{P}<.01)$. In contrast, in WT group 1 , the rightward shift was abolished: the $\mathrm{pD}_{2}$ value was $6.68 \pm 0.04(\mathrm{n}=8)(\mathrm{P}<.001$ vs. group $2, \mathrm{WT})$ and $\mathrm{O}^{2-}$ production was $12,171 \pm 780$ $(\mathrm{n}=6$, NS vs. group $3 \mathrm{WT})$. In eNOS ${ }^{-/}$mice similar protection was observed: the $\mathrm{pD}_{2}$ values in groups 1 and 3 were $7.66 \pm 0.12$ and $7.87 \pm 0.17$ (NS) vs. $7.21 \pm 0.09$ in eNOS $^{-/-}$group $2(n=5, P<.05)$. In both strains, this rosuvastatin-induced protection was abolished after incubation with mevalonate $(100 \mu \mathrm{M})$, the product of HMGCoA reductase enzyme reaction. Moreover, before NTG exposure, rosuvastatin treatment decreased p22phox (an essential NAD(P)H oxidase subunit) mRNA.

Conclusions: Long-term rosuvastatin treatment protects against nitrate tolerance by counteracting NTGinduced increase in $\mathrm{O}^{2-}$ production. This protection involves a direct interaction with the $\mathrm{NAD}(\mathrm{P}) \mathrm{H}$ oxidase pathway and seems to be completely independent of the eNOS pathway. 
S3O24

ACETYLCHOLINE AND SODIUM NITROPRUSSIDE CAUSE LONG-TERM INHIBITION OF EDCFMEDIATED CONTRACTIONS

\author{
E.H.C. Tang ${ }^{a}$, M. Feletou ${ }^{b}$, Y. Huang ${ }^{\text {c }}$, R.Y.K. Man ${ }^{a}$ and P. M. Vanhoutte ${ }^{a}$ \\ a Department of Pharmacology, Faculty of Medicine, University of Hong Kong \\ ${ }^{\mathrm{b}}$ Institut de Recherches Internationales Servier, Paris, France \\ ${ }^{c}$ Department of Physiology, Faculty of Medicine, Chinese University of Hong Kong
}

Background: Acute inhibition of nitric oxide synthase or guanylyl cyclase enhances endothelium-dependent contractions in the aorta of spontaneously hypertensive rat (SHR), indicating that the presence of nitric oxide acutely suppresses the production and/or the action of endothelium-dependent contracting factors (EDCF). Preliminary studies in the laboratory suggested that previous exposure to acetylcholine exerts a delayed inhibitory effect on subsequent EDCF-mediated contractions.

Objective: The present studies were designed to confirm the long-term inhibitory effect of acetylcholine and to determine whether or not nitric oxide is the sole mediator of the phenomenon. The role of soluble guanylyl cyclase was also determined.

Methods: Rings of SHR aorta were suspended in conventional organ chambers for recording of isometric force. Rings with endothelium were incubated in the absence or presence of $\mathrm{N}^{\omega}$-nitro-L-arginine methyl ester (an inhibitor of NO synthases) or ODQ (an inhibitor of soluble guanylyl cyclase) before exposure to progressively increasing concentrations of sodium nitroprusside or acetylcholine in rings contracted with phenylephrine. Thereafter, the rings were washed and assessed for the ability to produce EDCF-mediated contractions to increasing concentration of acetylcholine or the calcium ionophore A23187 (in the presence of $\mathrm{N}^{\omega}$-nitro-Larginine methyl ester).

Results: The results show that if at the beginning of the experiments, rings are exposed to increasing concentration of acetylcholine or sodium nitroprusside, the subsequent acetylcholine-induced EDCF-mediated contractions are reduced compared to rings of the same arteries not previously exposed to the muscarinic agonist or the nitric oxide donor. This inhibitory effect can be partially prevented by incubation with ODQ before the application of acetylcholine and almost abolished in rings incubated with ODQ before the application of sodium nitroprusside. Previous exposure to sodium nitroprusside likewise reduced but previous exposure to acetylcholine did not affect endothelium-dependent contractions to the calcium ionophore A23187.

Conclusions: These data suggest that acetylcholine and sodium nitroprusside both can inhibit EDCFmediated contractions but via distinct pathways. Previous exposure to acetylcholine prevents EDCF-mediated responses by interfering with an early step of the signalling cascade which is nitric oxide and cyclic GMPindependent, most likely through changes at the level of the muscarinic receptors. A large prior discharge of nitric oxide, as demonstrated by high concentrations of sodium nitroprusside suppresses EDCF-mediated responses in a cyclic GMP-dependent manner. The cyclic nucleotide most likely acts at a level downstream of the increase in calcium concentration. Changes in sensitivity of the vascular smooth muscle are not involved. Thus, acetylcholine and nitric oxide can exerts distinct long-term modulatory effects on EDCF-mediated responses. 
S3O25

EFFECTS OF ASCORBATE ON ENDOTHELIUM-DERIVED HYPERPOLARIZING FACTOR (EDHF)MEDIATED VASODILATATION IN THE PERFUSED RAT MESENTERY AND HINDLIMB

\section{A. Stirrat, W.S. Wilson and W. Martin}

Institute of Biomedical and Life Sciences, University of Glasgow, Glasgow, G12 8QQ.

Objective: Ascorbate inhibits endothelium-derived hyperpolarizing factor (EDHF)-mediated vasodilatation in the bovine perfused ciliary circulation in a flow-dependent manner $(1)$. The aim of this study was to determine if ascorbate similarly inhibits EDHF-mediated relaxation in the perfused rat mesentery and hindlimb preparations.

Methods: The mesenteric and hindlimb vascular beds of male Wistar rats were perfused via the mesenteric artery and descending aorta respectively at flow rates of 5, 10 or $15 \mathrm{ml} \mathrm{min}^{-1}$ with Krebs solution gassed with $95 \% \mathrm{O}_{2} / 5 \% \mathrm{CO}_{2}$ at $37^{\circ} \mathrm{C}$. The thromboxane A2-mimetic $\mathrm{U} 46619(80 \mathrm{nM})$ was used to constrict the mesenteric vascular bed while the hindlimb preparation was constricted with the $\alpha_{1}$-agonist phenylephrine (100-200 nM). All experiments were conducted in the presence of L-NAME $(100 \mu \mathrm{M})$ and indomethacin $(10 \mu \mathrm{M})$ to ensure ACh-induced (10 nmol) vasodilatations were EDHF-mediated. When consistent ACh-induced relaxations were established, ascorbate $(50 \mu \mathrm{M})$ was added and its effects on ACh-induced dilatation assessed during the following $180 \mathrm{~min}$. Time-matched control experiments were also conducted. Data are expressed as mean \pm s.e.m., $\mathrm{n} \geq 8$, with differences determined using one-way ANOVA with Bonferroni's post-test.

Results: In rat mesenteric vascular beds perfused at $15 \mathrm{ml} \mathrm{min}^{-1}$ and constricted with U46619, ACh (10 nmol) elicited a powerful EDHF-mediated vasodilatation $(64.6 \pm 5 \%, \mathrm{n}=10$ at $0 \mathrm{~min})$ which was maintained over the 180 min experimental period $(54.4 \pm 5.1 \%, \mathrm{n}=10$ at $180 \mathrm{~min})$. When ascorbate was added to the mesenteric perfusate for $180 \mathrm{~min}$, the $\mathrm{ACh}$-induced vasodilatation was not affected at a flow rate of $5 \mathrm{ml} \mathrm{min}^{-1}$ but was significantly inhibited at $10(26.5 \pm 4.2 \%, \mathrm{n}=8$ at $180 \mathrm{~min}, \mathrm{P}<0.001)$ and $15 \mathrm{ml} \mathrm{min}^{-1}(13.6 \pm 4.1 \%, \mathrm{n}=10$ at $180 \min , \mathrm{P}<0.001)$.

In rat hindlimb preparations perfused at $15 \mathrm{ml} \mathrm{min}^{-1}$ and constricted with phenylephrine, ACh (10 nmol) elicited a powerful vasodilatation $(55.9 \pm 5.5 \%, \mathrm{n}=11$ at $0 \mathrm{~min})$ which was maintained over the $180 \mathrm{~min}$ experimental period $(51.2 \pm 8 \%, \mathrm{n}=11$ at $180 \mathrm{~min})$. Ascorbate did not significantly inhibit the ACh-induced vasodilatation in the hindlimb at any flow rate.

Conclusions: These results show that ascorbate inhibits ACh-induced EDHF-mediated vasodilatation in the perfused rat mesentery at high (10 and $\left.15 \mathrm{ml} \mathrm{min}^{-1}\right)$ but not low $\left(5 \mathrm{ml} \mathrm{min}^{-1}\right)$ rates of flow. This outcome is similar to the requirement of flow in the ability of ascorbate to block EDHF-mediated vasodilatation in the bovine perfused long posterior ciliary artery (1). Basal blood flow in the rat mesentery and hindlimbs are $9.8 \pm$ 1.3 and $15.5 \pm 1.7 \mathrm{ml} \mathrm{min}^{-1}$ respectively $(2,3)$ and the viscosity of blood is $\sim 4$ times that of Krebs solution. The possibility that the shearing forces generated by perfusion with Krebs solution were insufficient to uncover the ability of ascorbate to block EDHF in the hindlimb preparation remains to be determined.

1 Nelli, S. et al. (2004) Br. J. Pharmacol. 142, 1081-1090.

2 Parai, K. \& Tabrizchi, R. (2002) Eur. J. Pharmacol. 448, 59-66.

3 Sheriff, D. D. (2003) Am. J. Physiol. 284, H2185-H2191. 


\section{Mechanisms of Structural Vasodilatation / Outward Arterial Remodeling}

by

Professor Jo De Mey,

Departement of Medicine

Universiteit Maastricht

Maastricht

The Netherlands

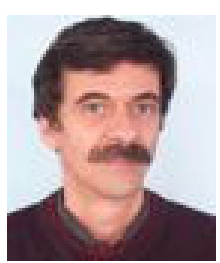

" What excites me in science includes the interplay between hemodynamics, vascular function and vascular structure in the control of tissue perfusion, the pathogenesis (inc. epigenetics!) of cardiovascular disease and the treatment and prevention of CVD. "

\begin{tabular}{|c|c|c|c|}
\hline $09.00-09.45$ & $\begin{array}{l}\text { 3rd Björn Folkow Lecture } \\
\text { Mechanisms of Structural Vasodilatation / Outward Arterial } \\
\text { Remodeling }\end{array}$ & Jo De Mey & $\begin{array}{l}\text { Invited } \\
\text { Lecture }\end{array}$ \\
\hline $09.45-10.00$ & $\begin{array}{l}\text { Characterization of purinergic P2Y receptors on endothelial } \\
\text { cells of the mouse aorta }\end{array}$ & Guns, Pieter-Jan & S4 O26 \\
\hline $10.00-10.15$ & $\begin{array}{l}\text { Neuropeptide Y2 receptors are involved in enhanced } \\
\text { neurogenic vasoconstriction in spontaneously hypertensive } \\
\text { rats }\end{array}$ & Simonsen, Ulf & S4 O27 \\
\hline $10.15-10.30$ & $\begin{array}{l}\text { Study on the identity and the characteristics of the Retinal } \\
\text { Relaxing Factor (RRF) }\end{array}$ & Boussery, Koen & $\mathrm{S} 4 \mathrm{O} 28$ \\
\hline $10.30-11.00$ & $\begin{array}{c}\text { POSTER SESSION } 2 \\
- \\
\text { coffee break }\end{array}$ & & \\
\hline $11.00-11.15$ & $\begin{array}{l}\text { Apolipoprotein E-deficient mice show enhanced calcium- } \\
\text { dependent relaxation to acetylcholine before development of } \\
\text { atherosclerotic lesions. }\end{array}$ & Fransen, Paul & S4 O29 \\
\hline $11.15-11.30$ & $\begin{array}{l}\text { Rho-kinase and calcium signaling in alpha-1 adrenergic } \\
\text { contraction of resistance arteries of Lyon genetically } \\
\text { hypertensive rats }\end{array}$ & Stoclet, Jean-Claude & S4 O30 \\
\hline $11.30-11.45$ & $\begin{array}{l}\text { Exercise and vasorelaxing effects of carbon monoxide- } \\
\text { releasing molecules in hypertensive rats }\end{array}$ & Boissiere, Julien & S4 O31 \\
\hline $11.45-12.00$ & $\begin{array}{l}\text { The decreased production of collagen type III in cultured } \\
\text { smooth muscle cells from varicose vein patients is due to a } \\
\text { degradation by MMPs: possible implication of MMP-3 }\end{array}$ & $\begin{array}{l}\text { Sansilvestri-Morel, } \\
\text { Patricia }\end{array}$ & S4 O32 \\
\hline
\end{tabular}


S4O26

CHARACTERIZATION OF PURINERGIC P2Y RECEPTORS ON ENDOTHELIAL CELLS OF THE MOUSE AORTA

\author{
P-J.D.F. Guns ${ }^{a}$, A. Korda ${ }^{a}$, H.M. Crauwels ${ }^{a}$, T. Van Assche ${ }^{a}$, B. Robaye ${ }^{b}$, J-M. Boeynaems ${ }^{c}$ and \\ H. Bult ${ }^{a}$ \\ ${ }^{a}$ Division of Pharmacology, University of Antwerp, 2610 Wilrijk, Belgium \\ ${ }^{b}$ Institute of Interdisciplinary Research, Institute of Biology and Molecular Medicine, Free University of \\ Brussels, 6041 Gosselies, Belgium \\ ${ }^{\mathrm{C}}$ Institute of Interdisciplinary Research, School of Medicine, Free University of Brussels, 1070 \\ Brussels, Belgium
}

Objective: Purinergic receptors mediate various effects including regulation of vasomotor responses. The aim of this study was to characterize endothelial P2Y receptors mediating vasodilatation of the aorta of C57BL6 mice.

Methods: With reverse transcriptase polymerase chain reaction (RT-PCR) the expression of different P2Y receptor subtypes was investigated at mRNA level. On the other hand functional vasodilatation studies were performed. Five adjacent segments (width $2 \mathrm{~mm}$ ) of the thoracic aorta were mounted in organ baths and force development was measured. Results are expressed as mean \pm s.e.m. of 5 mice.

Results: RT-PCR studies revealed mRNA expression of $\mathrm{P}_{2} \mathrm{Y}_{1}, \mathrm{P}_{2} \mathrm{Y}_{2}, \mathrm{P}_{2} \mathrm{Y}_{4}$ and $\mathrm{P}_{2} \mathrm{Y}_{6}$ receptor subtypes in the vessel wall. Purinergic agonists evoked complete (ATP, UTP, UDP) or partial (ADP) relaxation of phenylephrine pre-contracted aortic rings of C57BL6 mice. Moreover relaxation was abolished by removal of the endothelium from the aorta proving that purinergic receptors present on the endothelium mediate these relaxations. The rank order of dilatation potency was: $\mathrm{UDP} \sim \mathrm{UTP}>\mathrm{ADP}>\mathrm{ATP} \gamma \mathrm{S}>\mathrm{ATP}$, with respective $\mathrm{pD} 2$ values of 6.31, 6.24, 6.22, 5.82 and 5.40. Furthermore $\mathrm{P}_{2} \mathrm{Y}_{4}$-deficient (CD1/129SV) mice did not show impaired UTP- or ATP- induced relaxation indicating that the $\mathrm{P} \mathrm{Y}_{4}$ receptor subtype is not involved in ATP- or UTPevoked vasodilatation. These agonist results are compatible with the presence of functional $\mathrm{P}_{2} \mathrm{Y}_{1}$ (ADP $\left.>\mathrm{ATP}\right)$, $\mathrm{P}_{2} \mathrm{Y}_{2}$ (ATP and UTP) and P2Y 6 (UDP) receptors. To further characterize the receptors, the effect of purinergic receptor antagonists on nucleotide induced vasodilatation was studied. The $\mathrm{P}_{2} \mathrm{Y}_{1}$ selective antagonist $2^{\prime}-$ deoxy-N $\mathrm{N}^{6}$-methyladenosine3', 5'-bisphosphate (MRS2179) inhibited ADP-evoked relaxation only. In contrast suramin, a non-selective competitive purinergic antagonist, exerted a surmountable antagonism for all agonists. The apparent $\mathrm{pKb}$ values were similar for UTP and UDP $(5.19 \pm 0.03$ and $5.26 \pm 0.06)$, but were significantly different from those of ATP $(4.53 \pm 0.07 ; \mathrm{P}<0.05)$ and ADP $(5.55 \pm 0.11 ; \mathrm{P}<0.05)$.

Conclusions: At least three functional P2Y receptors are present in endothelial cells of the mouse aorta. $\mathrm{P}_{2} \mathrm{Y}_{1}$ is activated by ADP and selectively antagonized by MRS2179. ATP and UTP probably act on P2 $\mathrm{Y}_{2}$ receptors and UDP activates $\mathrm{P}_{2} \mathrm{Y}_{6}$ receptors. Though $\mathrm{P}_{2} \mathrm{Y}_{4}$ mRNA was detected in whole aortic tissue, this receptor subtype was apparently not involved in nucleotide-mediated relaxation of aortic rings. 
$\mathrm{S} 4 \mathrm{O} 27$

NEUROPEPTIDE Y2 RECEPTORS ARE INVOLVED IN ENHANCED NEUROGENIC VASOCONSTRICTION IN SPONTANEOUSLY HYPERTENSIVE RATS

\author{
K.A. Gradin ${ }^{a}, C$. Buus $^{b}, J-Y L i^{c}$, O. Frøbert ${ }^{b}$ and U. Simonsen ${ }^{b}$ \\ ${ }^{a}$ Department of Physiology and Pharmacology, University of Göteborg, Sweden \\ ${ }^{\mathrm{b}}$ Department of Pharmacology, University of Aarhus, 8000 Århus C, Denmark \\ ${ }^{c}$ Institute of Anatomy and Cell Biology, University of Göteborg, Sweden
}

Objective: Neuropeptide Y (NPY) is a potent vasoconstrictor possibly involved in hypertension. We investigated the role of neuropeptide Y2 receptors in NPY contraction of resistance arteries from Wistar Kyoto (WKY) and spontaneously hypertensive rats (SHR).

Methods: In rat mesenteric arteries, isometric tension was recorded in wire myographs, electrical field stimulation (EFS) was performed, and protein evaluated by Western blotting and immunohistochemistry.

Results: In endothelium-intact mesenteric arteries activated with vasopressin, NPY and fragments with selectivity for Y1 receptors, [Leu31,Pro34]NPY, Y2 receptors, NPY13-36, and rat polypeptide (PP) evoked equipotent contractions in segments from WKY, while NPY13-36 was less potent than the other agonists in arteries from SHR rats. In the presence of the Y1 receptor antagonist, BIBP $3226(0.3 \mu \mathrm{M})$, NPY caused relaxation in arteries from WKY, while the other agonists caused equipotent contractions in arteries from both WKY and SHR. In endothelium-denuded arteries from SHR, the Y2 receptor agonist, BIIE246TF displaced concentration-response curves for NPY13-36 to the right, and abolished the maximal NPY13-36 contraction in arteries from WKY. In the presence of prazosin and during vasopressin activation, EFS (16 Hz)-evoked contractions were more pronounced in arteries from SHR compared to WKY. EFS contractions were enhanced by BII246TF, partially inhibited by BIBP 3226, and abolished by the combination of BIBP 3226 and BII246TF in arteries both from WKY and SHR. Neuropeptide Y1 and Y2 receptors were expressed in arteries from WKY and SHR. While Y1 receptor expression was similar in arteries from WKY and SHR, three specific bands for the Y2 receptor were found in arteries from WKY, compared to only two bands in arteries from SHR. Immunoreaction for NPY was enhanced in arteries from SHR, and was further potentiated in the presence of BII246TF, while incubation with this antagonist decreased NPY immunoreactivity in arteries from WKY.

Conclusion: The present results suggest that in addition to neurogenic Y1 receptors, postjunctional Y2 receptors contribute to neurogenic contraction of mesenteric small arteries. Moreover, both enhanced NPY content and altered neuropeptide Y2 receptor activation apparently contribute to the enhanced neurogenic contraction of arteries from SHR. 


\section{$\mathrm{S} 4 \mathrm{O} 28$}

STUDY ON THE IDENTITY AND THE CHARACTERISTICS OF THE RETINAL RELAXING FACTOR (RRF)

\section{K. Boussery, C. Delaey and J. Van de Voorde}

\section{Department of Physiology and Pathophysiology, Ghent University, Ghent, Belgium}

Objective: Vasoactive factors that are released from neighbouring cells are thought to play a major role in the regulation of retinal blood flow. One of these factors is the as yet unidentified Retinal Relaxing Factor (RRF), a vasodilator that is released from retinal tissue. The capital aim of this project was to gain more information on the identity and the characteristics of this intriguing retina-derived factor, in order to improve our understanding of the physiological mechanisms regulating retinal blood flow.

Methods: Three different animal models were used: the bovine model, the rat model and the mouse model. Depending on the animal model used, ring segments of an isolated bovine retinal artery (BRA), a rat carotid artery or a mouse aortic artery were mounted as detector preparations in a wire myograph for isometric tension recording. Retina-induced relaxations were elicited by bringing retinal tissue in close proximity of the ring segments. Agonist-induced relaxations were elicited by adding the agonist to the organ bath of the myograph.

Results: In all three animal models, the retina-induced relaxations were unaffected by the presence of a NOsynthase inhibitor, a soluble guanylyl cyclase inhibitor or a cyclooxygenase inhibitor. Also removal of the endothelium of the detector preparations did not affect the RRF-response. Furthermore, the RRF-induced relaxations were enhanced in hypoxic conditions. In the literature, $\mathrm{H}^{+}, \mathrm{K}^{+}$, lactic acid, prostanoids, adenosine, GABA, glutamic acid, aspartic acid, glycine and taurine have all been suggested to mediate hypoxic vasodilation. These potential mediators were excluded from being involved in the RRF-response. Also the vasorelaxing peptides adrenomedullin (AM), CGRP and the natriuretic peptides (ANP, BNP and CNP) are potential candidates for being the RRF, since they are all thought to be expressed in retinal tissue. We demonstrated that $\mathrm{AM}(1 \mathrm{pM}$ to $0.1 \mu \mathrm{M})$ induces a concentration-dependent relaxation in isolated BRA, and that endothelium-derived NO, CGRP1-receptors and AM-receptors are involved in this relaxation. In the CGRPinduced (10 pM to $30 \mathrm{nM}$ ) relaxations in isolated BRA, endothelium-derived NO, voltage-dependent $\mathrm{K}^{+}$ channels, and possibly also CGRP1-receptors are involved. None of the natriuretic peptides (all tested at $1 \mathrm{pM}-$ $0.1 \mu \mathrm{M})$ induced a relaxation in isolated BRA.

Conclusions: The Retinal Relaxing Factor (RRF) is released from the retina of different species, and could have a role in the hypoxic vasodilation in retinal arteries. The relaxations induced by the RRF showed to be independent from the presence of the vascular endothelium and from the activity of nitric oxide synthase, soluble guanylyl cyclase or cyclooxygenase. Also none of the known mediators of hypoxic vasodilation qualifies for being the RRF. It is furthermore conceivable that adrenomedullin and CGRP are paracrine modulators of retinal arterial tone, but both are excluded from being the RRF because the characteristics of their relaxing effects differ from the characteristics of the RRF-induced relaxations. It is very unlikely that ANP, BNP or CNP could act as a paracrine modulator of retinal arterial tone, and therefore also these natriuretic peptides can be excluded from being the RRF. Further research will be necessary to unravel the identity and the characteristics of the RRF, and to evaluate its physiological and pathophysiological relevance. 
S4O29

APOLIPOPROTEIN E-DEFICIENT MICE SHOW ENHANCED CALCIUM-DEPENDENT RELAXATION TO ACETYLCHOLINE BEFORE DEVELOPMENT OF ATHEROSCLEROTIC LESIONS.

\author{
P. Fransen, T. Van Assche, P.-J. Guns, C. Van Hove, A.G. Herman and H. Bult \\ University of Antwerp - CDE , Department of Pharmacology, Antwerp, Belgium
}

Objective: In apolipoprotein E-deficient ( $\mathrm{apoE}^{-/}$) mice, endothelial dysfunction, as assessed by impaired relaxation to acetylcholine, is independent of hypercholesterolemia alone, but is strictly associated with plaque formation. The present study investigated whether endothelial function in atherosclerosis-prone aorta segments of $\mathrm{apoE}^{-/}$mice is affected when compared with wild type (WT) $\mathrm{C} 57 \mathrm{Bl} / 6 \mathrm{~J}$ mice before the formation of atherosclerotic lesions (age: 4 months).

Methods: Atherosclerosis-prone aortic strips (distal segment of thoracic aorta, width $1 \mathrm{~mm}$, length $\pm 2 \mathrm{~mm}$ ) were mounted in a myograph with the endothelial side down. They were loaded with the calcium-sensitive probe Fura-2 AM to measure internal calcium (340/380 excitation emission ratio in relative units, RU) simultaneously with isometric force. Precontractions were elicited by addition of $1 \mu \mathrm{M}$ phenylephrine (PE). Relaxation was studied by adding a single $\left(2 \times 10^{-6} \mathrm{M}\right)$ or cumulative doses of acetylcholine (ACh, $10^{-9}$ to $3 \times 10^{-6} \mathrm{M}$ ).

Results: Relaxation by $2 \times 10^{-6}$ M ACh was $86 \pm 6 \%$ in WT females ( $\left.\mathrm{n}=10\right), 70 \pm 8 \%$ in WT males ( $\left.\mathrm{n}=13\right), 83$

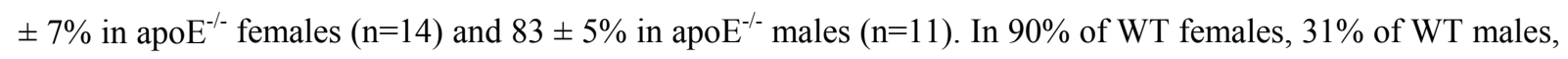

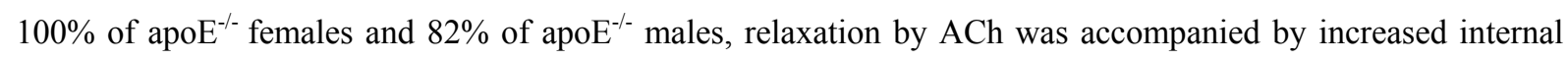
calcium, suggesting that relaxation by ACh in WT males is not strictly related to increase of internal calcium in endothelial cells. ACh-induced calcium increase in WT and apoE ${ }^{-/}$females was respectively $0.15 \pm 0.06$ and $0.14 \pm 0.03 \mathrm{RU}$ and was significantly less in $\mathrm{WT}$ and $\mathrm{apoE}^{-/}$males (respectively $0.03 \pm 0.02$ and $0.06 \pm 0.02 \mathrm{RU}$, $\mathrm{P}<0.05)$. In another group of segments, dose-response curves for ACh revealed maximal relaxations of $67 \pm 17 \%$ in WT females ( $\mathrm{n}=5), 94 \pm 5 \%$ in apoE-/- females $(\mathrm{n}=5), 56 \pm 17 \%$ in WT males $(\mathrm{n}=4)$ and $95 \pm 3 \%$ in apoE-/males $(\mathrm{n}=4)$, suggesting near complete relaxation in $\mathrm{apoE}^{-/}$mice and reduced relaxation in WT mice, especially in males, as observed in the single dose experiments. $\mathrm{EC}_{50}$-values for $\mathrm{ACh}$-induced relaxations were significantly smaller in apoE ${ }^{-/}$than in WT (respectively $21 \pm 7 \mathrm{nM}$ versus $61 \pm 30 \mathrm{nM}$ for females and $51 \pm 22$ versus $82 \pm 14$ $\mathrm{nM}$ for males, $\mathrm{P}<0.05$ ), suggesting higher sensitivity of apoE $\mathrm{E}^{-/}$segments to ACh. Because only one WT male responded to $\mathrm{ACh}$ with increased internal calcium, the mean values of the $\mathrm{ACh}$-induced calcium increase were calculated for the other groups only. Maximum increase of calcium was larger in females $(0.21 \pm 0.08 \mathrm{RU}$ for WT and $0.13 \pm 0.03 \mathrm{RU}$ for apoE $\left.\mathrm{E}^{-/}\right)$than in $\mathrm{apoE}^{-/}$males $(0.07 \pm 0.03 \mathrm{RU})$. There were no differences between the three groups concerning $\mathrm{EC}_{50}$ values of $\mathrm{ACh}$ for calcium increase $(116 \pm 47,124 \pm 16$ and $117 \pm 7 \mathrm{nM}$, respectively). In general, $\mathrm{EC}_{50}$-values of $\mathrm{ACh}$ for calcium increase were larger than for relaxation, indicating that force is more sensitive to $\mathrm{ACh}$ than calcium release.

Conclusions: Before development of atherosclerotic lesions, endothelial function, as assessed by AChinduced relaxation and concomitant calcium increase, is enhanced in apoE $^{-/-}$in comparison with WT mice, especially in males. In apoE $\mathrm{E}^{-/-}$mice, relaxation is more sensitive to $\mathrm{ACh}$ and is always accompanied by an increase of calcium. Thereby, it seems that apoE $^{-/-}$mice are more efficient than WT mice in transducing muscarinic receptor stimulation in an increase of internal calcium and a vasodilator response. Since NO is the only endothelial cell-dependent vasodilator in these preparations, this suggests that the ACh-induced calciumdependent NO-release in apoE $\mathrm{E}^{-/-}$mice is more prominent than in WT mice. 
S4O30

RHO-KINASE AND CALCIUM SIGNALING IN ALPHA-1 ADRENERGIC CONTRACTION OF RESISTANCE ARTERIES OF LYON GENETICALLY HYPERTENSIVE RATS

\author{
M.R. Freitas ${ }^{a}$ and Jean-Claude Stoclet ${ }^{b}$ \\ a Department of Physiology and Pathology, Federal University of Paraiba, Joao Pesoa, Brazil \\ ${ }^{\mathrm{b}}$ Pharmacology and Physico-Chemistry, University Louis Pasteur of Strasbourg and CNRS (UMR \\ 7034), Illkirch, France
}

Objective: It has been suggested that enhanced contraction of resistance arteries implicating Rho-kinase activation is a critical component of hypertension in animal models and human patients, independent from its cause. However there are conflicting reports on the role of Rho-kinase in the control of agonist-induced vascular smooth muscle contraction in arteries of hypertensive animals, depending on the experimental model and protocol. The aim of the present study was to investigate the hypothesis that alterations of Rho-kinase-dependent inhibition of myosin phosphatase, leading to enhanced $\mathrm{Ca}^{2+}$-sensitization of contraction, is involved in the regulation of contraction elicited by stimulation of the $\alpha_{1}$-adrenoceptor, a receptor playing a major role in regulation of blood pressure, in resistance arteries of the Lyon genetically hypertensive rat.

Methods: Small mesenteric arteries from Lyon normotensive (LN) and hypertensive (LH) rats were mounted in an organ bath, stimulated by phenylephrine $(30 \mu \mathrm{M})$ in nominally $\mathrm{Ca}^{2+}$-free medium. After return of the contraction to baseline, the arteries were again brought to contraction by increasing concentrations of $\mathrm{CaCl}_{2}$ in the continuous presence of phenylephrine. The experiments were performed in the absence or the presence of the Rho-kinase inhibitor Y-27632 $(10 \mu \mathrm{M})$ or the protein kinase C inhibitor GF109203X $(3 \mu \mathrm{M})$. Intracellular $\mathrm{Ca}^{2+}$ concentration $\left(\left[\mathrm{Ca}^{2+}\right]_{\mathrm{i}}\right)$ was monitored using fura-2. The two mechanisms proposed to account for Rho-kinaseinduced inhibition of myosin phosphatase, i.e. phosphorylation of the myosin phosphatase inhibitor protein CPI17 at Thr38 and of the myosin targeting subunit of myosin phosphatase MYPT1 at Thr696, were investigated in resting and in stimulated arteries, in the absence and in the presence of calyculin $\mathrm{A}(0.1 \mu \mathrm{M})$, a selective inhibitor of serine/threonine-specific phosphatases. Total and phosphorylated proteins were determined by immunoblotting.

Results: Despite enhanced Rho-kinase and CPI-17 protein levels, the contractile response to phenylephrine obtained before calcium depletion was unchanged in LH. In these conditions, contraction was abolished by Y27632. However, after calcium depletion, contraction elicited by addition of $\mathrm{CaCl}_{2}$ was unmodified by Y-27632 in arteries from LN. In LH, contraction induced in these conditions was increased over the one of obtained in $\mathrm{LN}$, whereas $\mathrm{Ca}^{2+}$ influx was decreased, showing enhanced $\mathrm{Ca}^{2+}$-sensitization of contraction. Both enhanced contraction and impaired $\mathrm{Ca}^{2+}$ influx found in $\mathrm{LH}$ after calcium depletion were eliminated by Y-27632 but not GF109203X.

Both in resting arteries and during sustained contraction elicited by $\mathrm{CaCl}_{2}$, phosphorylation of either $\mathrm{CPI}-17$ or MYPT1 could not be detected in the absence of calyculin A. However phosphorylation of both Thr38 CPI-17 and Thr696 MYTP1 could be seen in the presence of the phosphatase inhibitor. In these conditions, phenylephrine stimulation increased slightly Thr38 CPI-17 but not Thr696 phosphorylation. In addition Thr38 CPI-17 phosphorylation was less in LH than in LN arteries, and Thr696 phoshorylation was unchanged in LH, both in resting and stimulated arteries.

Conclusions:These findings indicate that Rho-kinase is involved in enhanced $\alpha 1$-adrenoceptor-induced $\mathrm{Ca} 2+-$ sensitization of contraction and impaired $\mathrm{Ca} 2+$ influx seen after calcium depletion in arteries from $\mathrm{LH}$ compared with LN.However this $\mathrm{Ca} 2+$-sensitization was not associated with enhanced phosphorylation of either Thr38 CPI-17 or Thr696 MYPT1, suggesting Rho-kinase dysregulation in these conditions. The relationship between Rho-kinase and $\mathrm{Ca} 2+$ handling requires further investigation, but the data suggest a differential role of Rho-kinase in the regulation of contraction in resistance arteries, depending on tissue calcium stores. 
S4O31

EXERCISE AND VASORELAXING EFFECTS OF CARBON MONOXIDE-RELEASING MOLECULES IN HYPERTENSIVE RATS.

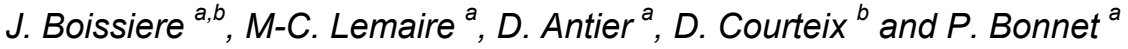 \\ ${ }^{a}$ Laboratoire de Physiopathologie de la Paroi Artérielle, EA 3852 - Université François Rabelais, UFR \\ Médecine, 10 Boulevard Tonnellé B.P. 3223, 37032 Tours Cedex 1, France \\ ${ }^{\mathrm{b}}$ Laboratoire de Physiologie de l'exercice musculaire, Université d'Orléans, Faculté du Sport et de \\ l'Education Physique, Rue de Vendôme B.P. 6237, 45062 Orléans Cedex 2, France
}

Objective: Since carbon monoxide $(\mathrm{CO})$ has been reported to induce a relaxation of smooth muscle cells by activating large-conductance calcium-activated $\mathrm{K}^{+}$channels, we aimed to investigate the effects of endurance training on vasorelaxation induced by the CO-releasing molecule tricarbonyldichlororuthenium $\left(\left[\mathrm{Ru}(\mathrm{CO})_{3} \mathrm{Cl}_{2}\right]_{2}\right)$ on aortic rings of both sedentary and trained hypertensive rats.

Methods: Two groups $(\mathrm{n}=8)$ of hypertensive rats were either trained on a treadmill over a 10 -week period or assigned to a sedentary life and both groups were compared to a normotensive control group ( $\mathrm{n}=8)$. At the end of the protocol, blood pressure was measured and the mechanical activity of isolated endothelium denuded aortic rings was measured in vitro.

Results: Exercise training did not modify significantly the mean arterial pressure in the trained hypertensive animals. However, pulse pressure was significantly decreased in trained hypertensive animals as compared to sedentary ones but it remained higher than in the control normotensive rats. $\left[\mathrm{Ru}(\mathrm{CO})_{3} \mathrm{Cl}_{2}\right]_{2}$ exposure induced significantly more relaxation in aortic rings of trained rats as compared to both control and sedentary hypertensive rats. CO-induced vasorelaxation was reduced and not significantly different between the three groups when aortic rings were exposed to tetraethyl-ammonium chloride (TEA), a non specific $\mathrm{K}^{+}$channel blocker.

Conclusions: Vasorelaxation induced by $\left[\mathrm{Ru}(\mathrm{CO})_{3} \mathrm{Cl}_{2}\right]_{2}$ was more important in aortic rings of trained hypertensive rats in comparison with sedentary hypertensive and control rats. Since TEA reduced the co-induced vasorelaxation in both hypertensive and control animals to a similar degree, the training-induced vasorelaxation might be attributed to an increase in $\mathrm{K}^{+}$channels activity. This could explain the increase in vascular compliance observed subsequently to endurance training in hypertensive rats. 
$\mathrm{S} 4 \mathrm{O} 32$

THE DECREASED PRODUCTION OF COLLAGEN TYPE III IN CULTURED SMOOTH MUSCLE CELLS FROM VARICOSE VEIN PATIENTS IS DUE TO A DEGRADATION BY MMPS: POSSIBLE IMPLICATION OF MMP-3

\author{
P. Sansilvestri-Morel ${ }^{a}$, A. Rupin ${ }^{a}$, N. Lembrez ${ }^{a}$, J.N. Fabiani ${ }^{b}$, P.M. Vanhoutte ${ }^{c}$ and T. J. Verbeuren ${ }^{a}$ \\ ${ }^{a}$ Servier Research Institute, division of Angiology, Suresnes 92150, France \\ ${ }^{b}$ Georges Pompidou European Hospital, Cardiovascular Surgery unit; PARIS 75015, France \\ ${ }^{c}$ Department of Pharmacology, Faculty of Medicine, University of Hong Kong
}

Objective: Varicose veins are a very common manifestation of chronic venous insufficiency. The etiology and pathogenesis of this disease are unknown but genetic predisposition and abnormalities of the connective tissue have been implicated. Indeed, varicose veins are characterized by a decreased reactivity and elasticity. We previously reported alterations of extracellular matrix proteins in varicose veins, and showed a decreased production of collagen type III in cultured smooth muscle cells (SMC) derived from varicose veins. The goal of the present study was to better understand the molecular mechanisms involved in this observed decrease of collagen type III and to define new targets for treatment of this pathology.

Methods: Smooth muscle cells derived from human control and varicose veins were cultured and expression and synthesis of collagen were analyzed by Northern blot and tritiated proline incorporation followed by SDSPAGE. Synthesis and expression of MMPs were quantified by RT-PCR and ELISA technique. Fibronectin was quantified by immunoprecipitation.

Results: Collagen III mRNA levels were comparable in cells from control and varicose veins but the protein level was much lower in varicose vein cells. Steady state levels of collagen III mRNA and its ability to translate into a protein were evaluated. Neither stability nor functionality of the a1(III) coding mRNA were affected in varicose vein cells. Potential intracellular degradations of collagen III were investigated with inhibitors of intracellular proteases but the production of collagen type III was unaffected by these cell treatments. The stability of collagen III was determined by time-course experiments and degradations of the protein were observed after secretion from varicose vein cells. As levels of N-terminal propeptides of collagen III in the culture medium were similar in SMC from control and varicose veins, the degradation of the protein observed must occur after secretion in the extracellular medium. This degradation could be partially prevented and the production of collagen III could be partially restored by Marimastat, a matrix metalloproteinase (MMP) inhibitor. Several MMPs were quantified in culture media and their levels were not modified in varicose vein cells except for MMP-3 for which mRNA expression and protein production were increased. The levels of fibronectin, a potential substrate of MMP-3, were also lower in SMC from varicose veins.

Conclusions: The present findings demonstrate that collagen III and fibronectin are degraded in cultured SMC from varicose veins by a mechanism involving MMPs, most likely MMP-3. This dysregulation is responsible for the decreased accumulation of the collagen III protein and may have functional consequences in varicose veins leading to reduced elasticity. Thus, the primary defect of varicose vein disease may be an increased and abnormal remodeling leading to an exaggerated distensibility of the veins and a decreased elasticity. 


\begin{tabular}{|c|c|c|c|}
\hline $13.00-13.15$ & $\begin{array}{l}\text { Vascular smooth muscle hyperpolarization by cannabinoids in } \\
\text { gastric and mesenteric arteries involves stimulation of VR1 } \\
\text { receptors on perivascular CGRP containing nerves }\end{array}$ & Breyne, Joke & S5 033 \\
\hline $13.15-13.30$ & $\begin{array}{l}\text { Reduced EDHF responses and connexin activity in mesenteric } \\
\text { arteries from the obese Zucker rat }\end{array}$ & Young, Elisa & S5 O34 \\
\hline $13.30-13.45$ & $\begin{array}{l}\text { Contribution of nitric oxide and oxidative stress to impaired } \\
\text { coronary vasodilatation after myocardial infarction }\end{array}$ & Berges, An & S5 O35 \\
\hline $13.45-14.00$ & $\begin{array}{l}\text { Hypoxia-induced endothelial dysfunction in human umbilical } \\
\text { vein endothelial cells }\end{array}$ & Østergaard, Louise & S5 O36 \\
\hline $14.00-14.15$ & $\begin{array}{l}\text { Progestins decrease the expression of endothelial NO } \\
\text { synthase and the formation of NO through activation of the } \\
\text { glucocorticoid receptor }\end{array}$ & Schini-Kerth, Valérie & S5 037 \\
\hline $14.15-14.30$ & $\begin{array}{l}\text { Synergism of } \mathrm{K}+- \text { and hyperosmolarity-induced relaxations } \\
\text { on rat skeletal muscle arterioles }\end{array}$ & De Clerck, Ine & S5 038 \\
\hline $14.30-14.45$ & $\begin{array}{l}\text { Endothelial beta3-adrenoceptors mediate the NO-dependent } \\
\text { angiogenesis and vasorelaxation of coronary microvessels in } \\
\text { response to the third-generation beta-blocker, nebivolol }\end{array}$ & Saliez, Julie & S5 O39 \\
\hline $14.45-15.00$ & $\begin{array}{l}\text { Mechanisms underlying the biphasic neurogenic } \\
\text { vasodilatation in the bovine intraocular long posterior ciliary } \\
\text { artery }\end{array}$ & Overend, Jill & S5 O40 \\
\hline $15.00-15.15$ & $\begin{array}{l}\text { Ca2+-dependent } \mathrm{K}+- \text { channels and endothelium dependent } \\
\text { hyperpolarization in rat isolated cerebral arteries; possible } \\
\text { regulation by NO? }\end{array}$ & McNeish, Alister & S5 041 \\
\hline $15.15-15.30$ & $\begin{array}{l}\text { S-nitroso-N-acetylcysteine prevents left ventricular } \\
\text { hypertrophy but not increased arterial pressure in } \\
\text { hypercholesterolemic LDLr-/- mice }\end{array}$ & $\begin{array}{l}\text { Krieger, Marta } \\
\text { Helena }\end{array}$ & S5042 \\
\hline $15.30-16.00$ & POSTER SESSION 2 & & \\
\hline
\end{tabular}


S5O33

VASCULAR SMOOTH MUSCLE HYPERPOLARIZATION BY CANNABINOIDS IN GASTRIC AND MESENTERIC ARTERIES INVOLVES STIMULATION OF VR1 RECEPTORS ON PERIVASCULAR CGRP CONTAINING NERVES

\section{J. Breyne and B. Vanheel}

Department of Physiology and Physiopathology, Ghent University, De Pintelaan 185, B-9000 Gent, Belgium.

Objective: Endogenous as well as synthetic cannabinoids have been shown to exert potent vasodilator effects in a variety of vascular preparations. Their precise mechanism of action, however, is as yet unclear. Although initially the endocannabinoid anandamide was proposed as an endothelium-derived hyperpolarizing factor (EDHF), more recent studies in rat hepatic and small mesenteric arteries point to the activation of vanilloid receptors (VR1) on perivascular sensory nerves and the subsequent release of vasodilatory neuropeptides (e.g. calcitonine gene-related peptide (CGRP)), which hyperpolarize the vascular smooth muscle cells. In the present study, we explored the effects of the stable endocannabinoid analogue methanandamide in rat small gastric arteries, compared this with the membrane potential responses to exogenous CGRP and to the endotheliumdependent vasodilator acetylcholine, and investigated the involvement of VR1 receptors.

Methods: Membrane potential changes of smooth muscle cells were measured in isolated segments of small gastric arteries using conventional microelectrode techniques. All experiments were performed in the presence of $\mathrm{N}^{\mathrm{G}}$-nitro-L-arginine (L-NA, $\left.10^{-4} \mathrm{M}\right)$ and indomethacin $\left(5 \times 10^{-5} \mathrm{M}\right)$ to rule out the interference of $\mathrm{NO}$ and prostanoids, respectively. Electrical responses produced by application of methanandamide, anandamide, CGRP or acetylcholine in control conditions and in the presence of various inhibitors (capsazepine, glibenclamide) were registered and also compared with results obtained in small mesenteric arteries.

Results: Exposure of the small gastric arteries to methanandamide $(10 \mu \mathrm{M})$ caused a hyperpolarization of the smooth muscle cells $(-8.5 \pm 1.2 \mathrm{mV})$ which was completely abolished by the vanilloid receptor antagonist capsazepine $(3 \mu \mathrm{M})(0 \mathrm{mV}, \mathrm{p}<0.01)$. Conversely, acetylcholine-induced hyperpolarizations were not affected by capsazepine $\left(-7.0 \pm 2.7 \mathrm{mV}\right.$ vs $-7.9 \pm 1.4 \mathrm{mV}$ in control conditions). Exposure to CGRP $\left(3 \times 10^{-9} \mathrm{M}\right)$ evoked fully reproducible hyperpolarizations $(-8.8 \pm 1.8 \mathrm{mV}$ vs $-8.5 \pm 0.7 \mathrm{mV}$ after at least 20 minutes washout) with a similar time course as observed with the cannabinoids. Preincubation with the $\mathrm{K}_{\mathrm{ATP}}$-channel inhibitor glibenclamide $(10 \mu \mathrm{M})$ reversed responses both to methanandamide $(+1.1 \pm 0.4 \mathrm{mV}, \mathrm{P}<0.01)$ and to CGRP $(+2.1$ $\pm 1.2 \mathrm{mV}, \mathrm{P}<0.05$ ), while the response to acetylcholine was unaffected. Similar results were obtained in rat small mesenteric arteries.

Conclusions: These results show that endocannabinoids activate VR1 receptors on perivascular sensory nerves in gastric arteries, thereby stimulating the release of CGRP, which hyperpolarizes the smooth muscle cells. Moreover, in rat small gastric and mesenteric arteries, the vascular smooth muscle hyperpolarization indirectly caused by methanandamide and anandamide, and that mimicked by exogenous CGRP, involve $\mathrm{K}_{\mathrm{ATP}^{-}}$ channels which are not involved in the EDHF-response. 
$\mathrm{S} 5 \mathrm{O} 34$

REDUCED EDHF RESPONSES AND CONNEXIN ACTIVITY IN MESENTERIC ARTERIES FROM THE OBESE ZUCKER RAT

\author{
E.J. Young ${ }^{a}$, M.A. Hill ${ }^{b}$, W.B. Wiehler ${ }^{c}$ and J.J. Reid ${ }^{a}$ \\ ${ }^{\text {a }}$ School of Medical Sciences, RMIT University, Melbourne, Australia. \\ ${ }^{\mathrm{b}}$ School of Medical Sciences, University of New South Wales, Sydney, Australia. \\ ${ }^{\mathrm{c}}$ Faculty of Medicine, University of Calgary, Calgary, Canada.
}

Objective: The objective of this study was to examine the effect of insulin resistance on endothelium-derived hyperpolarising factor (EDHF) and mesenteric endothelial function using 25-week insulin-resistant obese Zucker rats (OZR) and the corresponding lean littermate control rats (LZR). The involvement of gap junctions and their connexin subunits in the EDHF relaxation response was also assessed.

Methods: Third-order mesenteric arteries were mounted on a pressure myograph, and the internal diameter was recorded by video microscopy in the presence of $10 \mu \mathrm{M}$ indomethacin, a prostaglandin synthesis inhibitor. Endothelial function was determined by studying responses to the endothelium-dependent dilator acetylcholine $(\mathrm{ACh}, 1 \mathrm{nM}-10 \mu \mathrm{M})$ and the endothelium-independent dilator cromakalim $(10 \mathrm{nM}-1 \mathrm{mM})$ in the presence of a

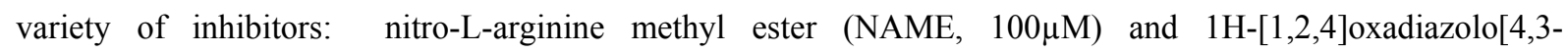
a]quinoxalin-1-one (ODQ, $10 \mu \mathrm{M})$ to block the NO component; charybdotoxin $(0.1 \mu \mathrm{M})$ and apamin $(1 \mu \mathrm{M})$ to block the EDHF response by inhibiting small and intermediate calcium activated potassium channels; and 40Gap27 $(300 \mu \mathrm{M})$ to inhibit gap junctions specifically associated with connexin 40 . The effect of insulin resistance on gap junctions was further assessed by measuring the protein and mRNA expression of vascular connexins. Protein levels were determined by Western blotting followed by semi-quantitative analysis of band intensity, whilst mRNA levels were quantified using real-time PCR, in which beta-actin was used as the housekeeping gene.

Results: Concentration-response curves to ACh for the OZR showed a significant ( $\mathrm{P}<0.01$, ANOVA) 2.5fold rightward parallel shift compared to the LZR. There was no difference in the relaxation to cromakalim between mesenteric arteries from the OZR and LZR. Responses to ACh were not altered in the presence of NAME and ODQ. This NAME/ODQ-resistant response to ACh was attributed to EDHF and abolished by a combination of charybdotoxin and apamin. 40Gap27 significantly attenuated the maximal response to ACh ( $\mathrm{P}<0.0001$, Student's t-test) by $54 \%$ in the LZR, but had no effect in the OZR. Comparison of Western blot band intensity indicated that connexin 40 protein levels in mesenteric vascular homogenates in the OZR $(163 \pm 2.0$ arbitrary units, $n=8)$ were significantly smaller $(P<0.05$, Student's t-test $)$ than in the LZR $(208 \pm 2.0$ arbitrary units, $\mathrm{n}=8)$, with no difference in connexin 43 protein levels. mRNA levels showed a significant $(\mathrm{P}<0.05$, Student's t-test) 4.6-fold decrease in connexin 40 expression in the OZR $(n=6)$ compared with the LZR $(n=7)$, with no change in connexin 43 mRNA expression.

Conclusions: These findings demonstrate a decrease in the EDHF relaxation response to ACh in third-order mesenteric arteries from the 25-week OZR. Additionally, whilst gap junctions associated with connexin 40 appear to be involved in the EDHF response in the LZR, they do not play a role in mesenteric arteries from the OZR. These results are consistent with protein and mRNA analyses which showed a decrease in connexin 40 protein and mRNA expression in the OZR. The data therefore suggest that connexin 40-associated gap junctions are defective in insulin resistance, which may be responsible for endothelial dysfunction in some vascular tissues. 
$\mathrm{S} 5 \mathrm{O} 35$

CONTRIBUTION OF NITRIC OXIDE AND OXIDATIVE STRESS TO IMPAIRED CORONARY VASODILATATION AFTER MYOCARDIAL INFARCTION

\author{
A. Berges ${ }^{a, b}$, L. Van Nassauw ${ }^{b}$, J.-P. Timmermans ${ }^{b}$ and C. Vrints ${ }^{a}$ \\ ${ }^{a}$ Laboratory of Cardiology, University of Antwerp, Belgium \\ ${ }^{b}$ Laboratory of Histology and Cell Biology, University of Antwerp, Belgium
}

Objective: Recent data revealed that postinfarction remodelling is not only characterised by architectural changes but that it also modulates non-infarcted vessels. We previously showed that permanent ischemia leads to endothelial dysfunction in non-infarcted coronary arteries, without affecting vasodilatation capacity of vascular smooth muscle cells.

Methods: The rat coronary ligation model was used to induce an anterior infarction. One day, one week or three weeks after surgery, coronary flow was investigated in a Langendorff perfusion setup. The contribution of the three major endothelium-dependent vasodilatory mediators (nitric oxide (NO), prostanoids and endotheliumderived hyperpolarizing factor (EDHF)) was assessed one week after ischemia. Moreover, the participation of total NO, iNOS-dependent $\mathrm{NO}$ and oxidative stress in vasodilator responses was examined at different time points of remodelling. Additionally, hearts were prepared for immunohistochemical analysis of iNOS, eNOS and NADH oxidase (the major vascular producer of oxygen radicals). Moreover, samples were taken to analyse the amount of serum nitrite, using the Griess reaction, and of tissue superoxide production, using lucigeninenhanced chemiluminescence. The relative quantification of mRNA of iNOS and eNOS versus the housekeeping gene GAPDH was determined using real-time RT-PCR.

Results: In the normal rat circulation, $\mathrm{NO}$ and prostanoids contributed to coronary vasodilatation, while basal involvement of EDHF was restricted. Endothelial dysfunction following myocardial infarction was not mediated by alterations in the prostanoid-mediated response and was only slightly affected by increased involvement of $\mathrm{K}^{+}$ channels. In contrast, NO-mediated vasodilatation was significantly increased one week after MI, but normalised at a later stage. This was further confirmed by a transient increase in serum nitrite levels. In addition, iNOS- and eNOS-immunoreactive cells were significantly increased in number during remodelling with a maximum one week after infarction. Moreover, the amount of iNOS mRNA showed an acute but transient increase, while eNOS mRNA remained augmented throughout remodelling. This apparent duality between increased NO levels and NO-mediated response on the one hand, and decreased coronary vasodilatation on the other hand, might be explained by augmented scavenging and degradation of the generated NO by reactive oxygen species. Indeed, the presence of NADH oxidase progressively increased after MI. Also the superoxide production kept on increasing during postinfarct remodelling. However, continuous perfusion with 1400W (an iNOS inhibitor), Tiron (a cell-permeable oxygen radical scavenger) or apocynin (a NADH oxidase antagonist) had no effect on the coronary flow increases in sham or infarcted hearts.

Conclusion: We conclude that vasodilatory impairment following myocardial infarction did not originate from alterations in the prostanoid-mediated pathway and that only a slightly increased influence of $\mathrm{K}^{+}$channels was observed. However, ischemia significantly increased the impact of the NO-mediated coronary vasoresponse during the subacute remodelling phase, as evidenced by the elevated de novo production of NO by increased synthesis and expression of iNOS and eNOS. In addition, there was an augmented production of superoxide radicals, by activation of NADH oxidase. Consequently, it is suggested that the reduction in vasoreactivity, despite elevated NO levels, is due to augmented scavenging and degradation of the generated NO by superoxide. [Supported by FWO grant G.0422.02] 
S5O36

HYPOXIA-INDUCED ENDOTHELIAL DYSFUNCTION IN HUMAN UMBILICAL VEIN ENDOTHELIAL CELLS

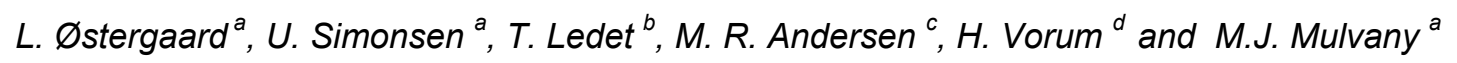

${ }^{a}$ Department of Pharmacology, University of Aarhus, 8000 Århus C, Denmark,

${ }^{\mathrm{b}}$ Research Laboratory for Biochemical Pathology, Aarhus Sygehus, 8000 Århus C, Denmark, ${ }^{c}$ Perinatal Epidemiological Research Unit, Dept. of Obstetrics and Gynaecology, Aarhus Sygehus, 8200 Aarhus, Denmark,

${ }^{d}$ Department of Medical Biochemistry, University of Aarhus, 8000 Århus C, Denmark

Objective: Hypoxia is thought to initiate several signalling cascades in the endothelium, both through gene transcription and through protein stabilization. One protein that is stabilized is the transcription factor hypoxiainducible factor, HIF. A HIF-1 response element is found in the endothelial nitric oxide synthase (eNOS) promoter region in mice and rats and the inducible nitric oxide synthase (iNOS) promoter in humans contains a HIF-2 site indicating a correlation between the two factors. The aim of the present study was to investigate the connection between HIF and NOS and the signalling pathways in hypoxia.

Methods: Primary endothelial cells were isolated from human umbilical veins by perfusion with a $0.1 \%$ collagenase solution. The cells were grown for a maximum of two passages and the hypoxic incubation was carried out in an airtight chamber, flushed with $\mathrm{N}_{2}$ until the $\mathrm{O}_{2}$ concentration was lowered to $5 \%$. The pressure of $\mathrm{O}_{2}$ was continuously monitored using an $\mathrm{O}_{2}$-probe (Unisense, Denmark). The protein contents were evaluated using proteomics with the analysis based on four or five gels in each group. In addition, immunoblotting was employed to investigate specific proteins.

Results: Immunoblotting showed that HIF-1 was stabilized in cells exposed to hypoxia $(\mathrm{n}=3)$. Furthermore, in three separate immunoblotting experiments a time-dependent up-regulation of eNOS and Akt (a kinase linked to the activation of eNOS) was found, starting at 30 minutes of hypoxia and lasting for up to 24 hours. Using proteomics up- and down-regulation of many proteins (up to 60) was seen under hypoxia. During the experiments the oxygen concentration is approximately $5 \%$ in all cases. In the three separate experiments several of the regulated proteins were predicted to be identical based on their localization.

Conclusion: We propose that the up-regulation of eNOS and Akt protein content could function as a protective mechanism against hypoxia-evoked vasoconstriction by contributing to an increase in available NO. Concerning the proteomic analysis we conclude that the cells respond to hypoxia by a change in the protein expression profile. Ongoing mass spectroscopy analyses are needed to identify the nature of these proteins. 
S5O37

PROGESTINS DECREASE THE EXPRESSION OF ENDOTHELIAL NO SYNTHASE AND THE FORMATION OF NO THROUGH ACTIVATION OF THE GLUCOCORTICOID RECEPTOR

\author{
M. Zerr-Fouineau ${ }^{a}$, M. Chataigneau ${ }^{a}$, P. Bonnet ${ }^{b}$ and V.B. Schini-Kerth ${ }^{a}$ \\ a UMR CNRS 7034, Faculté de Pharmacie, Illkirch, France. \\ ${ }^{\mathrm{b}}$ Theramex, Monaco
}

Objective: Hormone replacement therapy with estro-progestin preparations, is associated with an increased risk of cardiovascular diseases in post-menopausal women. Since the early 90's, numerous clinical studies have indicated that estro-progestin treatments increase the risk of venous thrombo-embolic events. More recent clinical studies, (Heart and Estrogen/progestin Replacement Study, Women's Health Initiative and Million Women Study) have indicated that estro-progestin treatments also increase the risk of arterial thrombo-embolic events such as stroke and myocardial infarction. Although, estrogens have been shown to have a beneficial effect on the arterial wall through an increase of endothelial nitric oxide (NO) synthase expression and formation of NO, the vascular effect of progestins remains mostly unclear. Progestins, which form a heterogenous class of compounds, have a high affinity for the progesterone receptor but also for some other nuclear receptors including the glucocorticoid receptor and the mineralocorticoid receptor. Glucocorticoids have been shown to downregulate endothelial NO synthase. Therefore, this study examined whether progestins affect the expression of endothelial NO synthase and the formation of NO, a potent vasoprotective and anti-thrombotic factor, in human endothelial cells and, if so, characterized the role of their partial glucocorticoid activity.

Methods: Human umbilical vein endothelial cells (HUVECs) were obtained by collagenase digestion. Experiments were performed with confluent cultures of HUVECs used at first passage. Endothelial NO synthase expression was assessed by Western blotting. The formation of NO was assessed by electron spin resonance spectroscopy and by the formation of cyclic GMP (an indirect biochemical index of NO formation) determined in the presence of $0.1 \mathrm{mM}$ isobutyl-methyl xanthine (a phosphodiesterase inhibitor) using an ELISA including an acetylation step. The nuclear translocation of the glucocorticoid receptor was assessed by immunofluorescence microscopy.

Results: Exposure of HUVECs to the synthetic progestin medroxyprogesterone acetate (MPA) or progesterone $(\mathrm{P})$ for $24 \mathrm{~h}$ significantly decreased the level of endothelial NO synthase whereas levonorgestrel, nomegestrol acetate (NOMAC) and megestrol acetate did not have such an effect (all tested at $1 \mu \mathrm{M}$ ). A reduced level of NO synthase protein was also observed in response to the glucocorticoid hydrocortisone (HYDRO) and dexamethasone (DEXA, $0.1 \mu \mathrm{M}$ for $24 \mathrm{~h}$ ). The inhibitory effect of MPA and P was concentration-dependent and observed at concentrations $\geq 10 \mathrm{nM}$. Thrombin ( $1 \mathrm{U} / \mathrm{ml}$ ) stimulated the formation of NO and cyclic GMP; these responses were attenuated by pre-treatment of endothelial cells with MPA. RU-486, a glucocorticoid and progesterone receptor antagonist, prevented the inhibitory effect of MPA, P and DEXA on endothelial NO synthase expression. Exposure of endothelial cells to MPA and DEXA but not NOMAC caused nuclear translocation of the glucocorticoid receptor.

Conclusions: The present findings indicate that MPA and P decreased the expression of endothelial NO synthase and the formation of NO in endothelial cells via activation of the glucocorticoid receptor. Such effects are not observed with other progestins like NOMAC, which have a low partial glucocorticoid activity or none at all. 
$\mathrm{S} 5 \mathrm{O} 38$

SYNERGISM OF $\mathrm{K}^{+}-$AND HYPEROSMOLARITY-INDUCED RELAXATIONS ON RAT SKELETAL MUSCLE ARTERIOLES.

\author{
I. De Clerck ${ }^{a}$, J-L. Pannier ${ }^{a}$ and J. Van de Voorde ${ }^{b}$ \\ a Department of Movement and Sports Sciences, Ghent University, Belgium \\ ${ }^{\mathrm{b}}$ Department of Physiology and Physiopathology, Ghent University, Belgium
}

Objective: Exercise hyperemia is thought to be elicited by vasoactive factors released from the contracting skeletal muscle. In the present study, the involvement of $\mathrm{K}^{+}$and of a hyperosmotic environment (HO) (caused by the cumulative release of several factors) was investigated separately and synergetically.

Methods: Gluteal skeletal muscle arteries (mean \pm s.e.m.; diameter: $247 \pm 6 \mu \mathrm{m}, \mathrm{n}=127$ ) from female Wistar rats were isolated and mounted in an organ bath filled with Krebs Ringer solution for isometric tension recording. After precontraction with norepinephrine $\left(10^{-6} \mathrm{M}\right)$, vasodilatation was obtained by adding $\mathrm{K}^{+}[1(\mathrm{~K} 1)$, 2 (K2) or $3 \mathrm{mM}(\mathrm{K} 3)$ ] and sucrose [20 (S20), 40 (S40) or $60 \mathrm{mM}$ (S60)]. Endothelial removal and the addition of ouabain, $\mathrm{BaCl}_{2}$ or NPPB (5-nitro-2-(3-phenylpropylamino) benzoic acid) were used to study the underlying mechanisms. Also, in certain experiments, $\mathrm{S} 60$ was added prior to precontraction to study its effect on the $\mathrm{K}^{+}-$ induced relaxations. A two way repeated measures analysis with follow-up paired univariate tests was used to evaluate statistical significance.

Results: The application of $\mathrm{K}^{+}$caused strong concentration-dependent relaxation of $28.24 \%, 49.54 \%$ and $75.40 \%$ at $\mathrm{K} 1, \mathrm{~K} 2$ and $\mathrm{K} 3$ respectively $(\mathrm{n}=40)$. Removal of the vascular endothelium had no effect on this relaxation $(n=6)$. Inhibition of the $\mathrm{K}_{\mathrm{ir}}$ channels with $\mathrm{Ba}^{2+}(\mathrm{n}=10)$ or of the $\mathrm{Na}^{+} / \mathrm{K}^{+}$pumps with ouabain $(\mathrm{n}=7)$ significantly altered the $\mathrm{K}^{+}$-induced relaxations. Simultaneous application of $\mathrm{Ba}^{2+}$ and ouabain almost totally blocked the $\mathrm{K}^{+}$-induced relaxations (“Control”: K1: $41.61 \pm 11.82 \%$; K2: $62.58 \pm 12.10 \%$; K3: $87.15 \pm 6.89 \%$; "Ouabain $+\mathrm{BaCl}_{2}$ ": K1: $4.06 \pm 0.96 \%, \mathrm{P}<0.05 ; \mathrm{K} 2: 7.45 \pm 1.85 \%, \mathrm{P}<0.01 ; \mathrm{K} 3: 9.22 \pm 2.01 \%, \mathrm{P}<0.001$; $\mathrm{n}=7$ ). Furthermore, the acute application of sucrose on pre-contracted arteries caused moderate concentrationdependent vasodilatations of $17.05 \pm 1.27 \%$ (S20), $31.61 \pm 1.43 \%$ (S40) and $46.15 \pm 1.89 \%$ (S60) (n = 82). After incubation of the preparations with $60 \mathrm{mM}$ sucrose, the $\mathrm{K}^{+}$-induced vasodilatations were significantly increased from f.e. $18.22 \pm 6.38 \%$ in $\mathrm{K} 1$ control conditions up to $62.97 \pm 9.51 \%$ after application of sucrose. However, the contraction force elicited by norepinephrine was identical in control and sucrose conditions. This synergetic effect was not dependent on the presence of vascular endothelium $(\mathrm{n}=6)$. The addition of $\mathrm{BaCl}_{2}$ significantly inhibited the synergetic influence of $\mathrm{HO}(\mathrm{n}=6)$. Remarkably, the addition of the Volume Regulated Anion Channel (VRAC) inhibitor NPPB significantly mimicked the sensitizing effect of $\mathrm{HO}$ and this was also inhibited in the presence of $\mathrm{BaCl}_{2}$.

Conclusions: Small increases in extracellular $\mathrm{K}^{+}$concentration elicit large endothelium-independent, $\mathrm{K}_{\mathrm{ir}}$ channel and $\mathrm{Na}^{+} / \mathrm{K}^{+}$pump dependent relaxations in rat skeletal muscle arteries, suggesting an important role of $\mathrm{K}^{+}$in the exercise hyperemia. Also, raising osmolarity causes moderate vasorelaxations. This suggests that more than one factor released by the active skeletal muscles may play a role in the exercise hyperemia. Furthermore, the presence of a hyperosmotic environment sensitizes the blood vessel for $\mathrm{K}^{+}$, causing the $\mathrm{K}^{+}$-induced vasodilatations to be significantly increased. This synergetic effect may be caused by the activation of smooth muscle VRACs, leading to the activation of $\mathrm{K}_{\mathrm{ir}}$ channels. 
S5O39

ENDOTHELIAL BETA3-ADRENOCEPTORS MEDIATE THE NO-DEPENDENT ANGIOGENESIS AND VASORELAXATION OF CORONARY MICROVESSELS IN RESPONSE TO THE THIRDGENERATION BETA-BLOCKER, NEBIVOLOL

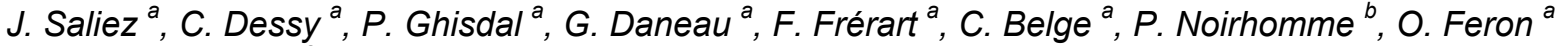 \\ and J.-L. Balligand ${ }^{a}$ \\ a Unit of Pharmacology and Therapeutics \\ ${ }^{\mathrm{b}}$ Department of Cardiac Surgery, Université Catholique de Louvain, Medical School.
}

Objective: The therapeutic effects of non-specific beta-blockers are often limited by vasoconstriction, justifying the interest for molecules endowed with additional vasodilating properties. Nebivolol is a selective antagonist at beta1-adrenoceptors (AR) and releases the vasodilator, nitric oxide (NO) through incompletely characterized mechanisms. We identified endothelial beta3-ARs in human coronary resistance arteries and tested the hypothesis that nebivolol exerts a partial agonist effect on these beta3-AR to mediate NO- and endothelialdependent relaxation and angiogenesis.

Methods: Relaxation of human and rodent cardiac coronary resistance microarteries was analyzed by videomicroscopy. Neoangiogenesis was quantitated using a cultured mouse ring assay. Nitric oxide release and calcium transients were measured by EPR and fura-2 fluorescence, respectively, in cultured bovine aortic endothelial cells (BAEC). Phosphorylation of eNOS was determined using phospho-specific antibodies in BAEC homogenates.

Results: Nebivolol evoked a concentration-dependent relaxation of rodent microvessels (max $86 \pm 6 \%$ of PGF2alpha pre-contracted tone, at $10 \mu \mathrm{mol} / \mathrm{l})$ that was sensitive to NOS inhibition, unaffected by the beta1-2 blocker, nadolol, but prevented by the beta1-3 blocker, bupranolol ( $\mathrm{P}<0.05 ; \mathrm{n}=3-8)$. Importantly, the relaxation to nebivolol was blunted in microvessels from mice genetically deficient in beta3-AR (maximum relaxation at $3 \mu \mathrm{M}$ : $59 \pm 3 \%, \mathrm{n}=5$ in FVB mice versus $10 \pm 2 \%, \mathrm{n}=6$ in beta3-KO mice). In human coronary microvessels, nebivolol $(10 \mu \mathrm{mol} / \mathrm{l})$ also induced a relaxation $(\max 71 \pm 5 \%$ of ET-1 pre-contracted tone) that was dependent on a functional endothelium, attenuated by NOS inhibition but insensitive to nadolol (all $\mathrm{P}<0.05$ ). We found that nebivolol induced neocapillary tube formation in aortic rings from wild-type mice, but not from beta3AR- or eNOS-deficient mice. In BAEC, nebivolol (1-10 $\mu \mathrm{mol} / \mathrm{l})$ increased NO release, measured by EPR, by $200 \%$ (at $10 \mu \mathrm{M} ; \mathrm{n}=3)$ in a L-NAME-inhibitable fashion. In parallel, threonine 495 on eNOS was dephosphorylated ( $\mathrm{n}=3$; $\mathrm{P}<0.05)$ and $\mathrm{Ca}$ fluorescence, increased by $91.8 \pm 23.7 \%(\mathrm{n}=4-11)$. Pre-treatment with nadolol had no effect on the $\mathrm{Ca}$ signal increase with nebivolol, whereas bupranolol significantly blunted the effect $(\mathrm{P}<0.05)$.

Conclusions: Nebivolol dilates rodent and human coronary resistance arteries through an agonist effect on the endothelial beta3AR to release NO. This property may prove particularly beneficial for the treatment of ischemic and failing cardiac diseases. 
S5O40

MECHANISMS UNDERLYING THE BIPHASIC NEUROGENIC VASODILATATION IN THE BOVINE INTRAOCULAR LONG POSTERIOR CILIARY ARTERY

\section{J. Overend, W.S. Wilson and W. Martin}

Institute of Biomedical and Life Sciences, West Medical Building, University of Glasgow, Glasgow, G12 8QQ.

Objective: We have recently established that relaxation in response to nerve stimulation in the bovine intraocular long posterior ciliary artery (LPCA) is biphasic in nature. The first component of relaxation appears to be mediated by nitric oxide (NO) released from nitrergic nerves. As yet, we have not been able to identify the transmitter that mediates the second component because we are unable to block it using conventional neurotransmitter inhibitors and desensitisation protocols. In this study we have attempted to determine the mechanism by which the unknown transmitter produces smooth muscle relaxation.

Methods: Intraocular LPCA segments ( $439 \pm 8 \mu \mathrm{m}$ internal diameter, $\mathrm{n}=47)$ were dissected from bovine eyes obtained at a local abattoir. These were cut into $2 \mathrm{~mm}$ rings, mounted on a wire myograph and set to a transmural pressure equivalent of $\sim 100 \mathrm{mmHg}$. Tone was induced using the thromboxane $\mathrm{A}_{2}$-mimetic U46619 $(0.1-1 \mu \mathrm{M})$. Nerves were stimulated by square wave pulses (10-18 V, $0.3 \mathrm{~ms}$ pulse width, $10 \mathrm{~s}$ train length, 0.5 $32 \mathrm{~Hz})$. Adrenergic vasoconstriction was blocked using guanethidine $(30 \mu \mathrm{M})$. Frequency response curves were obtained in the presence and absence of the neurotoxin tetrodotoxin (TTX, $0.1 \mu \mathrm{M}$ ), the guanylyl cyclase inhibitor ODQ $(3 \mu \mathrm{M})$, the large conductance $\mathrm{K}_{\mathrm{Ca}}$ channel inhibitor iberiotoxin $(0.1 \mu \mathrm{M})$, the large and intermediate $\mathrm{K}_{\mathrm{Ca}}$ channel inhibitor charybdotoxin $(0.1 \mu \mathrm{M})$, the small conductance $\mathrm{K}_{\mathrm{Ca}}$ channel inhibitor apamin $(0.1 \mu \mathrm{M})$ and the $\mathrm{K}_{\text {ATP }}$ channel inhibitor glibenclamide $(10 \mu \mathrm{M})$. Dilator responses are expressed as a percentage of active tone (assessed with papaverine, $500 \mu \mathrm{M}$ ). Data are expressed as mean \pm s.e.m., with differences determined by ANOVA and the Bonferroni post test.

Results: Responses to nerve stimulation were biphasic, comprising a rapid first component followed by a slower second component, peaking at 10 and $50 \mathrm{~s}$, respectively (see Table).

\begin{tabular}{|l|l|l|l|l|}
\hline & $\begin{array}{l}\text { Component } \\
\text { control (\%) }\end{array}$ & $\begin{array}{l}\text { Component } \\
\text { treated (\%) }\end{array}$ & $\begin{array}{l}\text { Component } \\
\text { control (\%) }\end{array}$ & $\begin{array}{l}\text { Component } \\
\text { treated (\%) }\end{array}$ \\
\hline TTX & $25 \pm 3$ & $-1 \pm 1^{*}$ & $19 \pm 3$ & $1 \pm 1^{*}$ \\
\hline ODQ & $26 \pm 5$ & $-9 \pm 3^{*}$ & $31 \pm 6$ & $33 \pm 5$ \\
\hline iberiotoxin & $25 \pm 4$ & $22 \pm 4$ & $18 \pm 4$ & $21 \pm 4$ \\
\hline charybdotoxin & $25 \pm 4$ & $22 \pm 3$ & $24 \pm 3$ & $19 \pm 2$ \\
\hline apamin & $37 \pm 4$ & $44 \pm 3$ & $27 \pm 5$ & $31 \pm 5$ \\
\hline glibenclamide & $32 \pm 4$ & $34 \pm 4$ & $32 \pm 5$ & $40 \pm 6$ \\
\hline
\end{tabular}

Table: First and second components of neurogenic relaxation at $32 \mathrm{~Hz} .{ }^{*} \mathrm{P}<0.001$, denotes a significant difference between control and treated vessels $(n=6-12)$. Negative values indicate reversal of relaxation to contraction.

Conclusions:. Both components of vasodilatation are neurogenic since they were abolished by TTX. The first component only was also sensitive to ODQ. However, neither component was affected by treatment with iberiotoxin, charybdotoxin, apamin or glibenclamide. This would suggest the involvement of the cGMP - NO pathway in mediating only the first component. The mechanism by which the transmitter mediating the second component of relaxation operates does not appear to involve small conductance, intermediate conductance or large conductance calcium-activated potassium channels or ATP-sensitive potassium channels. Therefore, the identity and the mechanism of relaxation of the neurotransmitter responsible for the second component, have still to be identified . 
$\mathrm{S} 5 \mathrm{O} 41$

$\mathrm{CA}^{2+}$-DEPENDENT $\mathrm{K}^{+}$-CHANNELS AND ENDOTHELIUM DEPENDENT HYPERPOLARIZATION IN RAT ISOLATED CEREBRAL ARTERIES; POSSIBLE REGULATION BY NO?

\section{A.J. McNeish, K.A. Dora and C.J. Garland}

Department of Pharmacy and Pharmacology, The University of Bath, UK

Objective: EDHF relaxation and hyperpolarization in the rat mid cerebral artery can be blocked by TRAM-34 alone, indicating that the opening of $\mathrm{IK}_{\mathrm{Ca}}$ channels is critical for the EDHF response in this artery (1). This is unusual, as EDHF mediated responses normally require the blockade of both $\mathrm{SK}_{\mathrm{Ca}}$ and $\mathrm{IK}_{\mathrm{Ca}}$ channels. However, the contribution of $\mathrm{SK}_{\mathrm{Ca}}$ and $\mathrm{IK}_{\mathrm{Ca}}$ to endothelium dependent hyperpolarization can change depending on the background arterial tone (2). Therefore, we investigated if $\mathrm{SK}_{\mathrm{Ca}}$ activation might also be involved in endothelium dependent hyperpolarization under different conditions in the in the rat mid cerebral artery.

Methods: Male Wistar rats (200-300g) were killed by cervical dislocation and exsanguination. The brain was removed and placed immediately in ice-cold Krebs solution. Segments of the mid cerebral artery (length, $\sim 2 \mathrm{~mm}$; diameter, $\sim 150 \mu \mathrm{m}$ ) were mounted in a Mulvany-Halpern myograph containing Krebs solution at $37^{\circ} \mathrm{C}$ and gassed with $95 \% \mathrm{O}_{2}$ and $5 \% \mathrm{CO}_{2}$. Smooth muscle membrane potential was recorded with sharp glass microelectrodes (tip resistances of 80-120 M 2 ) filled with $2 \mathrm{M} \mathrm{KCl}$. Changes in membrane potential and tension induced by the PAR2 agonist SLIGRL $(20 \mu \mathrm{M})$ and their possible blockade by apamin, TRAM-34 or a combination were assessed simultaneously. Experiments were performed under low tone (myogenic tone isometric stretch of $0.5 \mathrm{mN} / \mathrm{mm}$ ) or high tone (induced by either L-NAME, $100 \mu \mathrm{M}$, or by an isometric stretch of $2 \mathrm{mN} / \mathrm{mm}$ ). Data are mean \pm s.e.mean of 3 or more animals. Statistical comparisons were made using one-way ANOVA with Bonferroni's post-test.

Results: Under low tone conditions relaxation and hyperpolarization to SLIGRL $(89.0 \pm 10.7 \%$ and $-18.2 \pm$ $2.7 \mathrm{mV}$, respectively, $\mathrm{n}=11$ ) was unaffected by either TRAM-34 or apamin. Combining TRAM-34 and apamin failed to inhibit SLIGRL-induced relaxation but did inhibit the hyperpolarization ( to $-5.5 \pm 1.4 \mathrm{mV}, \mathrm{n}=8$ ). Increasing stretch to $2 \mathrm{mN} / \mathrm{mm}$ caused an additional vasoconstriction. Under these conditions SLIGRL-induced relaxation and hyperpolarization $(76.9 \pm 1.5 \%, 20.9 \pm 3.6 \mathrm{mV}$, respectively, $\mathrm{n}=6)$ was similar to low tone. While relaxation was unaffected by the combination of TRAM-34 or apamin, hyperpolarization was partially attenuated $(-11.3 \pm 1.8 \mathrm{mV}, \mathrm{n}=8)$. Addition of L-NAME rather than increased stretch, caused vasoconstriction and depolarization $(2.8 \pm 0.4 \mathrm{mN}$ and $12.8 \pm 0.7 \mathrm{mV}$, respectively, $\mathrm{n}=4)$. Under these conditions, SLIGRLinduced relaxation and hyperpolarization $(80.9 \pm 0.7 \%$ and $-19.6 \pm 3.0 \mathrm{mV})$ was almost completely abolished by TRAM-34 alone $(6.0 \pm 1.8 \%$ and $-1.2 \pm 0.3 \mathrm{mV})$.

Conclusions: With high tone and blockade of NOS, $\mathrm{IK}_{\mathrm{Ca}}$ appears to play a critical role in EDHF mediated relaxation and hyperpolarization to SLIGRL. In the presence of NO under either low or high tone conditions, blockade of $\mathrm{IK}_{\mathrm{Ca}}$ alone is not sufficient to modify SLIGRL-induced hyperpolarization. However, a combination of apamin and TRAM-34 did inhibit the hyperpolarization. This suggests that functional $\mathrm{SK}_{\mathrm{Ca}}$ channels are present in rat mid cerebral arteries and can contribute to endothelium dependent hyperpolarization under certain conditions. These data suggest that the contribution of $\mathrm{SK}_{\mathrm{Ca}}$ channels to endothelium dependent hyperpolarization in rat middle cerebral arteries is independent of the level of tone. It is tempting to speculate that $\mathrm{NO}$ may activate $\mathrm{SK}_{\mathrm{Ca}}$ channels in this artery. [Supported by BHF]

1 McNeish et al. (2005) Stroke, in press.

2 Crane et al. (2003) J. Physiol. 553, 183-189. 
$\mathrm{S} 5 \mathrm{O} 42$

S-NITROSO-N-ACETYLCYSTEINE PREVENTS LEFT VENTRICULAR HYPERTROPHY BUT NOT INCREASED ARTERIAL PRESSURE IN HYPERCHOLESTEROLEMIC LDLR ${ }^{-/-}$MICE

\author{
A.C.B.A Wanschel ${ }^{a}$, J.A.D Garcia ${ }^{a}$, L. Santos ${ }^{a}$, A.L. Moura ${ }^{a}$, K.F.R Santos ${ }^{a}$, S.M. Shishido ${ }^{a}$, \\ R.C. Spadari-Bratfisch ${ }^{a}$, M.G. de Oliveira ${ }^{b}$, F.R.M Laurindo ${ }^{c}$ and M.H. Krieger ${ }^{a}$ \\ ${ }^{a}$ Departamento de Fisiologia e Biofísica - Instituto de Biologia, Universidade Estadual de Campinas \\ (UNICAMP),Campinas, Brasil.

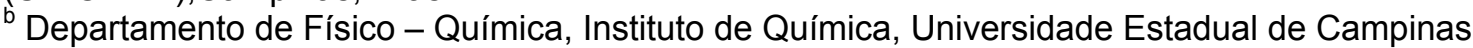 \\ (UNICAMP), Campinas, Brasil. \\ ${ }^{\mathrm{C}}$ Faculdade de Medicina, Instituto do Coração (InCor) - Universidade de São Paulo (USP), São Paulo, \\ Brasil.
}

Objectives: We showed that the nitrosothiol NO donor S-nitroso-N-acetylcysteine (SNAC) prevents early atherogenesis in male hypercholesterolemic $\mathrm{LDLr}^{-/-}$mice. In the present study, we examined whether SNAC $(0.51 \mu \mathrm{mol} / \mathrm{kg} / \mathrm{day}$, ip, 15 days) interferes with the left ventricular hypertrophy exhibited by these mice and whether such effect is due to arterial pressure changes.

Methods and Results: Both normo- and hypercholesterolemic diet fed $\mathrm{LDLr}^{-/}$mice had $11 \%$ increase in mean arterial pressure vs. wild-type (strain C57BL6). However, only hypercholesterolemic LDLr $^{-/}$mice showed significant left ventricular hypertrophy, characterized by: a) 1.25-fold increase in LV index vs. normo diet fed $\mathrm{LDLr}^{-/}$mice or WT $(4.16 \pm 0.1$ vs. $3.34 \pm 0.09 \mathrm{mg} / \mathrm{g}$ body weight, respectively; $\mathrm{P}<0.05)$, b) increased cardiomyocyte diameter ( $25.28 \pm 0.60$ vs. $19.47 \pm 0.67 \mu \mathrm{m}, \mathrm{P}<0.05)$, c) enhanced expression of constitutive and inducible NOS, d) increased cardiac collagen accumulation, and e) supersensitivity to the inotropic and chronotropic effects of isoprenaline. SNAC administration prevented the increase in LV index $(3.57 \pm 0.39 \mathrm{mg} / \mathrm{g}$ body weight), in cardiomyocyte diameter $(20.71 \pm 0.69 \mu \mathrm{m})$, in collagen deposition and NOS (all isoforms) expression, and in the supersensitivity to isoprenaline. Importantly, such effects occurred despite maintainance of increased arterial pressure.

Conclusions: Hypercholesterolemia in $\mathrm{LDLr}^{-/}$mice leads to early left ventricular hypertrophy, associated with overexpression of NOS isoforms, which is prevented by SNAC. Increased arterial pressure, present also in normo diet fed $\mathrm{LDL}^{-/}$mice, is not prevented by SNAC, thus underscoring the role of non-hemodynamic factors in the genesis of hypertrophy. These findings indicate the potential usefulness of S-nitrosothiol compounds for treating ventricular hypertrophy.

[Financial Support: FAPESP, CNPQ and CAPES] 


\section{Potassium channels and ion-sensors in the vasculature}

by

Arthur $\mathrm{H}$ Weston

Leech Professor of Pharmacology

Chairman, Medical Biosciences Board

University of Manchester, Faculty of Life Sciences

Manchester

UK

"Two things excite me about science. One is making a really key observation like the time in 1984 when I watched in amazement as cromakalim hyperpolarized the membrane potential of a vascular myocyte to EK - where it stayed. This was the start of the "potassium channel opener "field. The second is meeting and working with stimulating and clever people. In both categories, I have been very lucky"

\begin{tabular}{|c|c|c|c|}
\hline $09.00-09.45$ & $\begin{array}{l}\text { 2nd Paul M. Vanhoutte Lecture } \\
\text { Potassium channels and ion-sensors in the vasculature }\end{array}$ & Arthur H Weston & $\begin{array}{l}\text { Invited } \\
\text { Lecture }\end{array}$ \\
\hline $09.45-10.00$ & $\begin{array}{l}\text { Cellular mechanisms underlying cutaneous pressure-induced } \\
\text { vasodilation: in vivo involvement of potassium channels }\end{array}$ & Fromy, Bérengère & S6 043 \\
\hline $10.00-10.15$ & $\begin{array}{l}\text { Chronic oral administration of red wine polyphenols prevents } \\
\text { the angiotensin II-induced hypertension and endothelial } \\
\text { dysfunction by inhibiting the vascular expression of NADPH } \\
\text { oxidase }\end{array}$ & Schini-Kerth, Valérie & $\mathrm{S} 6 \mathrm{O} 44$ \\
\hline $10.15-10.30$ & $\begin{array}{l}\text { ACE inhibitors enhance endothelial cyclooxygenase-2 (COX-2) } \\
\text { expression via JNK-dependent ACE-signalling }\end{array}$ & Kohlstedt, Karin & S6 045 \\
\hline $10.30-11.00$ & $\begin{array}{l}\text { POSTER SESSION } 2 \\
\text { - } \\
\text { coffee break }\end{array}$ & & \\
\hline $11.00-11.15$ & $\begin{array}{l}\text { NAD(P)H oxidase-derived superoxide anions do not } \\
\text { contribute to endothelium-derived hyperpolarizing factor/ } \\
\text { H2O2 responses in mice }\end{array}$ & Takaki, Aya & $\mathrm{S} 6 \mathrm{O} 46$ \\
\hline $11.15-11.30$ & $\begin{array}{l}\text { Potassium is a potential EDHF in human coronary } \\
\text { microarteries }\end{array}$ & Dessy, Chantal & S6 047 \\
\hline $11.30-11.45$ & $\begin{array}{l}\text { Cerebral vascular mitochondrial efficiency is increased by } \\
\text { estrogen treatment }\end{array}$ & Duckles, Sue & S6 048 \\
\hline $11.45-12.00$ & $\begin{array}{l}\text { Impaired histamine-induced relaxation in mesenteric artery } \\
\text { of DOCA-salt hypertensive rats involves changes on } \\
\text { mechanisms of NO-independent hyperpolarization }\end{array}$ & Leite, Romulo & S6 049 \\
\hline
\end{tabular}


$\mathrm{S} 6 \mathrm{O} 43$

CELLULAR MECHANISMS UNDERLYING CUTANEOUS PRESSURE-INDUCED VASODILATION: IN VIVO INVOLVEMENT OF POTASSIUM CHANNELS

\author{
B. Fromy, A. Garry, D. Sigaudo-Roussel and J-L. Saumet \\ Laboratory of Physiology, UMR CNRS 6188, Medical School, F-49045 Angers cedex, France
}

Objective: In the skin of humans and rodents, local pressure induces localized cutaneous vasodilation, which may be protective against pressure-induced microvascular dysfunction and lesion formation. Once activated by the local pressure application, the capsaicin-sensitive nerve fibers release neuropeptides that act on the endothelium to synthesize and release NO and prostaglandins, leading to the development of the cutaneous pressure-induced vasodilation (PIV). The present study was undertaken to test in vivo the hypothesis that PIV is mediated or modulated by differential activation of potassium $\left(\mathrm{K}^{+}\right)$channels in anesthetized rats using pharmacological methods.

Methods: We assessed cutaneous microvascular response to local increasing pressure applied at $11.1 \mathrm{~Pa} / \mathrm{s}$ by laser Doppler flowmetry. Endothelium-independent and dependent vasodilation was tested using iontophoretic delivery of sodium nitroprusside (SNP) and acetylcholine (ACh), respectively, and was correlated with the PIV response.

Results: PIV was reduced following systemic administration of tetraethylammonium (TEA, a non-specific $\mathrm{K}^{+}$ channel blocker), iberiotoxin (a specific high conductance $\mathrm{Ca}^{2+}$-activated $\mathrm{K}^{+}\left(\mathrm{BK}_{\mathrm{Ca}}\right.$ ) channels blocker) and glibenclamide (a specific ATP-sensitive $\mathrm{K}^{+}\left(\mathrm{K}_{\mathrm{ATP}}\right)$ channel blocker), whereas PIV was unchanged by apamin (a specific low conductance $\mathrm{Ca}^{2+}$-activated $\mathrm{K}^{+}$channel blocker) and 4-aminopyridine (4-AP, a specific voltagesensitive $\mathrm{K}^{+}$channel blocker). The responses to SNP and ACh were reduced by iberiotoxin, but were unchanged by glibenclamide.

Conclusions: We conclude that the cellular mechanism of PIV in skin involves $\mathrm{BK}_{\mathrm{Ca}}$ and $\mathrm{K}_{\mathrm{ATP}}$ channels. We suggest that the opening of $\mathrm{BK}_{\mathrm{Ca}}$ and $\mathrm{K}_{\mathrm{ATP}}$ channels contribute to the hyperpolarization of vascular smooth muscle cells to produce PIV development mainly via the NO and PG pathways, respectively. 
$\mathrm{S} 6 \mathrm{O} 44$

CHRONIC ORAL ADMINISTRATION OF RED WINE POLYPHENOLS PREVENTS THE ANGIOTENSIN II-INDUCED HYPERTENSION AND ENDOTHELIAL DYSFUNCTION BY INHIBITING THE VASCULAR EXPRESSION OF NADPH OXIDASE

\section{Sarr, M. Chataigneau, S. Martins, C. Schott, J. El Bedoui, M-H. Oak, B. Muller, T. Chataigneau and V.B. Schini-Kerth}

UMR CNRS 7034, Université Louis Pasteur de Strasbourg, Faculté de Pharmacie, Illkirch, France

Objectives: Epidemiological studies have indicated that regular intake of moderate amounts of wine, in particular red wine, is associated with a reduced risk in overall mortality due to a reduction in death from cardiovascular diseases and cancer. The protective effect has been attributable, at least in part, to polyphenols. Red wine polyphenols induce endothelium-dependent relaxations of isolated blood vessels by stimulating the formation of nitric oxide (NO) and endothelium-derived hyperpolarizing factor, two factors with vasoprotective properties. The purpose of the present study was to determine whether red wine polyphenols prevent the angiotensin II (Ang II)-induced development of an endothelial dysfunction in rats, and, if so, to elucidate the underlying mechanism.

Methods: Hypertensive rats were obtained by a 14-day infusion of Ang II using osmotic minipumps. Red wine polyphenols were administered in the drinking water one week before the Ang II infusion and thereafter throughout the Ang II treatment period. Arterial pressure was measured in conscious rats by tail-cuff plethysmography. Ex vivo vascular relaxation of aortic rings was assessed in organ chambers, the vascular formation of superoxide anions by the fluorescent probe hydroethidine, and NADPH oxidase subunit expression by immunohistochemistry.

Results: Chronic infusion of Ang II increased systolic blood pressure from about $125 \mathrm{mmHg}$ to about 180 mmHg. The hypertensive response was associated with impaired relaxations of intact aortic rings to acetylcholine whereas those due to the direct addition of red wine polyphenols to the organ chamber persisted. Aortic rings from Ang II-treated rats had increased vascular superoxide anion production and expression of p22phox and nox-1 proteins. Red wine polyphenols administration in the drinking water prevented the angiotensin II-induced hypertension and endothelial dysfunction to acetylcholine. In addition, the red wine polyphenols treatment also normalized vascular superoxide anion production and NADPH oxidase expression in Ang II-treated rats. Administration of red wine polyphenols alone did affect neither blood pressure nor endothelial relaxation to acetylcholine.

Conclusions: Intake of red wine polyphenols prevents the Ang II-induced hypertension and endothelial dysfunction by inhibiting the vascular expression of NADPH oxidase and formation of superoxide anions. The ability of red wine polyphenols to prevent vascular oxidative stress may contribute to explain their protective effect on the cardiovascular system. 
$\mathrm{S} 6 \mathrm{O} 45$

ACE INHIBITORS ENHANCE ENDOTHELIAL CYCLOOXYGENASE-2 (COX-2) EXPRESSION VIA JNK-DEPENDENT ACE-SIGNALLING

\author{
K. Kohlstedt, R. Busse and I. Fleming
}

Cardiovascular Physiology, Johann Wolfgang Goethe University, Frankfurt am Main, Germany

Objective: ACE inhibitor-induced ACE-signalling in endothelial cells is critically dependent on the CK2mediated phosphorylation of the cytoplasmic tail of ACE on Ser1270. This initial phosphorylation step results in the activation of ACE-associated JNK and the subsequent nuclear translocation of phosphorylated, activated cJun, which affects endothelial gene expression. Since COX-2 has been described as JNK/c-Jun-regulated protein and its expression is reported to be increased in subjects treated with ACE inhibitors, we determined whether ACE inhibitor-induced ACE-signalling induces COX-2 expression in cultured and native endothelial cells.

Methods: COX-2 promoter activity was analysed using a luciferase-reporter gene assay and protein expression was determined by Western blotting. The DNA binding activity of activator protein-1 (AP-1) and the cyclic AMP response element-binding protein (CREB) was measured by electrophoretic mobility shift assays. The production of 6-Keto-PGF1alpha, prostaglandin E2 and thromboxane A2 were determined using commercially available kits.

Results: COX-2 expression was increased in lungs from mice treated with ramipril for 5 days and a similar increase in COX-2 protein was detected in primary cultures of human endothelial cells treated with ramiprilat. Furthermore, ramiprilat increased COX-2 promoter activity in endothelial cells overexpressing human somatic ACE, an effect not observed in either ACE-deficient cells or cells expressing a non-phosphorylatable ACE mutant (S1270A). The ramiprilat-induced and ACE-dependent increase in COX-2 expression and promoter activity was attenuated by the JNK-inhibitor SP600125 and by overexpression of a dominant negative JNK mutant. In ACE-expressing cells, ramiprilat significantly enhanced the DNA binding activity of AP-1 but did not affect that of CREB. AP-1 decoy oligonucleotides attenuated the ACE inhibitor-induced increase in COX-2 promoter activity and protein. However, ramiprilat did not affect AP-1 activity in ACE-deficient or in S1270Aexpressing cells. As a consequence of the ramiprilat-induced increase in COX-2 expression, 6-Keto-PGF1alpha and to a much lesser extent prostaglandin E2, but not thromboxane A2, production was increased and was inhibited by the COX-2 inhibitor celecoxib.

Conclusion: The increase in endothelial COX-2 expression and the subsequent increase in prostacyclin production via ACE inhibitor-induced ACE-signalling may account for some of the beneficial effects of ACE inhibitors on cardiovascular homeostasis. 
$\mathrm{S} 6 \mathrm{O} 46$

NAD(P)H OXIDASE-DERIVED SUPEROXIDE ANIONS DO NOT CONTRIBUTE TO ENDOTHELIUMDERIVED HYPERPOLARIZING FACTOR/ $\mathrm{H}_{2} \mathrm{O}_{2}$ RESPONSES IN MICE

\section{A. Takaki, K. Morikawa, T. Fujiki, M. Hatanaka, Y. Murayama and H. Shimokawa}

Department of Cardiovascular Medicine, Kyushu University Graduate School of Medical Sciences, Fukuoka, Japan.

Objective: Angiotensin II upregulates endothelial $\mathrm{NAD}(\mathrm{P}) \mathrm{H}$ oxidase with resultant superoxide anion production. We have previously identified that hydrogen peroxide $\left(\mathrm{H}_{2} \mathrm{O}_{2}\right)$ is an EDHF in mouse and human mesenteric arteries and porcine coronary microvessels and that endothelial NO synthase (eNOS) is an importance source of it. We also have recently demonstrated that endothelial $\mathrm{Cu}, \mathrm{Zn}$-superoxide dismutase plays a pivotal role to produce EDHF/ $\mathrm{H}_{2} \mathrm{O}_{2}$ as an "EDHF synthase" in mice. Furthermore, we have reported that the activation of endothelial $\mathrm{NAD}(\mathrm{P}) \mathrm{H}$ oxidase by angiotensin II markedly increases production of superoxide anions and suppresses endothelial vasodilator function in rats. In this study, we examined whether superoxide anions derived from up-regulated $\mathrm{NAD}(\mathrm{P}) \mathrm{H}$ oxidase contribute to $\mathrm{EDHF} / \mathrm{H}_{2} \mathrm{O}_{2}$ responses in small mesenteric arteries from angiotensin II-infused mice.

Methods: An osmotic minipump was implanted subcutaneously in adult C57BL/6N mice (male, 10-16 weeks old, weighing 22-28 g). The infusion rate was $2 \mu \mathrm{g} / \mathrm{kg} / \mathrm{min}$ for 1 week. Isometric tensions and membrane potentials of small mesenteric arteries of sham-operated and angiotensin II-infused mice were recorded.

Results: Infusion of angiotensin II for 1 week significantly increased arterial blood pressure. In angiotensin II-infused mice, EDHF-mediated relaxations (in the presence of indomethacin and $\mathrm{N}^{\omega}$-nitro-L-arginine) were markedly reduced and the NO-mediated relaxations were rather enhanced. Endothelium-independent relaxations to sodium nitroprusside were comparable between the two groups, whereas those to NS1619, a direct opener of $\mathrm{K}_{\mathrm{Ca}}$ channels, were slightly attenuated in angiotensin II-infused mice. The acute effect of apocynin $(100 \mu \mathrm{M})$, an $\mathrm{NAD}(\mathrm{P}) \mathrm{H}$ oxidase inhibitor, did not ameliorate endothelium-dependent relaxations in angiotensin II-infused mice. Endothelium-dependent hyperpolarizations were reduced in angiotensin II-infused mice.

Conclusions: These results indicate that superoxide anions derived from $\mathrm{NAD}(\mathrm{P}) \mathrm{H}$ oxidase do not contribute to $\mathrm{EDHF} / \mathrm{H}_{2} \mathrm{O}_{2}$ responses in mice, suggesting a specific link between physiological superoxide production (e.g. eNOS) and EDHF responses. 
$\mathrm{S} 6 \mathrm{O} 47$

POTASSIUM IS A POTENTIAL EDHF IN HUMAN CORONARY MICROARTERIES.

C. Dessy ${ }^{a}$, P. Ghisdal ${ }^{a}$, J. Saliez ${ }^{a}$, P. Noirhomme ${ }^{b}$ and J.L. Balligand ${ }^{a}$

${ }^{a}$ Unit of Pharmacology and Therapeutics

${ }^{\mathrm{b}}$ Department of Cardiac Surgery, Université Catholique de Louvain, Medical School.

Objective: Kinins such as Substance $\mathrm{P}$ or bradykinin evoke an endothelium-dependent relaxation in microvessels, in part through the release of nitric oxide (NO) and endothelium-derived hyperpolarizing factor(s) (EDHF). Since the nature of the latter is still debated, we aimed at characterizing the nature of $\operatorname{EDHF}(\mathrm{s})$ in human coronary resistance arteries (HCRA).

Methods: Vessels (int. diam. $<170 \mathrm{~mm}$ ) dissected from atrial appendages obtained during cardiac surgery, were connected to dual glass micropipettes (no-flow state; constant pressure of $60 \mathrm{mmHg}$ ) for monitoring of external diameter by videomicroscopy or electrode membrane potential measurements.

Results: In endothelium-intact vessels, Substance P (100 nM) evoked a dilation of ET-1 -precontracted HCRA that was 1) resistant to inhibition of NO synthase and cyclooxygenases ; 2) abolished in high (>25mM) $\mathrm{KCl}$ solution ; 3) abolished upon vessels co-incubation with apamin (100nM) and charybdotoxin (100nM) ; 4) associated with a significant hyperpolarization; all consistent with typical EDHF responses as observed in resistance vessels from animal models. In contrast to pig coronary microarteries, however, the EDHF response in HCRA was insensitive to inhibitors of CYP P450 2C9/8 suggesting that human EDHF(s) was not a CYP P450 metabolite. Since $\mathrm{K}^{+}$ions were proposed as a potential EDHF in different animal models, total $\left[\mathrm{K}^{+}\right]$was gradually increased from 4.5 to $6-18 \mathrm{mM}$ in the solution bathing precontracted HCRA. Increasing $\left[\mathrm{K}^{+}\right]$from 4.5 to $10 \mathrm{mM}$ induced a significant relaxation $(30 \% ; \mathrm{n}=6 ; \mathrm{P}<0.05)$, also paralelled with smooth muscle hyperpolarization, while higher $\left[\mathrm{K}^{+}\right]$resulted in vessel contraction. Addition of Kryptofix, a $\mathrm{K}^{+}$-chelator also strongly inhibited the relaxation by Substance $\mathrm{P}$. The mechanism by which potassium could elicit smooth muscle hyperpolarization potentially implicates both the $\mathrm{Na}^{+} / \mathrm{K}^{+}$ATPase and $\mathrm{K}_{\text {ir }}$ channels. Ouabain (100nM) completely prevented the relaxation induced with both low $\left[\mathrm{K}^{+}\right]$and Substance $\mathrm{P}(\mathrm{P}<0.05 ; \mathrm{n}=3)$, but not with cromakalim (a $\mathrm{K}_{\mathrm{ATP}}$ channel activator). We also measured the $\mathrm{K}^{+}$and Substance $\mathrm{P}$ hyperpolarization in the presence of $\mathrm{Ba}^{2+}$, a known inhibitor of $\mathrm{K}_{\text {ir }}$ channels. We observed that $\mathrm{Ba}^{2+}$ partly inhibited the $\mathrm{K}^{+}$-evoked hyperpolarisation; $10 \mathrm{mM}$ $\mathrm{K}^{+}$evoked an hyperpolarization of $-5.5 \pm 1.3 \mathrm{mV}$ in the absence of $\mathrm{Ba}^{2+}(30 \mu \mathrm{M})$ that was reduced to $-3.0 \pm 1.2$ $\mathrm{mV}$ in the presence of $\mathrm{Ba}^{2+}$ (paired $\mathrm{t}$ test: $\mathrm{P}<0.05$ ). $\mathrm{Ba}^{2+}$ also inhibited the Substance-P evoked hyperpolarisation $\left(-26.4 \pm 4.7 \mathrm{mV}\right.$ in the absence of $\mathrm{Ba}^{2+}$ versus $-6.5 \pm 4.0 \mathrm{mV}$ in the presence of $\left.\mathrm{Ba}^{2+}(\mathrm{n}=5)\right)$ (paired $\mathrm{t}$ test, $\mathrm{P}<0.05)$.

Conclusions: We conclude that in human coronary resistance arteries, Substance P evokes an EDHFdependent relaxation probably mediated in part through the release of $\mathrm{K}^{+}$ions by the endothelium, activating $\mathrm{K}_{\mathrm{ir}}$ channels and $\mathrm{Na}^{+} / \mathrm{K}^{+}$ATPase. The inter-species divergence highlights the importance of EDHF characterization in human vessels for its future therapeutic modulation. 
$\mathrm{S} 6 \mathrm{O} 48$

CEREBRAL VASCULAR MITOCHONDRIAL EFFICIENCY IS INCREASED BY ESTROGEN TREATMENT

\section{Stirone ${ }^{a}$, V. Procaccio ${ }^{b}$, D.N. Krause ${ }^{a}$ and Sue P. Duckles ${ }^{a}$}

${ }^{a}$ Department of Pharmacology, School of Medicine, University of California, Irvine, CA 92697, USA

${ }^{\mathrm{b}}$ Center for Molecular and Mitochondrial Medicine and Genetics, University of California, Irvine, CA 92697, USA

Objective: We have previously demonstrated that estrogen, either endogenous or exogenous, increases the production of endothelial vasodilators in the cerebral vasculature. Since mitochondria are thought to play a vital role in vascular dysfunction we have investigated the impact of estrogen treatment on cerebral vascular mitochondrial electron transport and formation and metabolism of reactive oxygen species. We now show that treatment in vivo with 17beta-estradiol also modulates cerebral vascular mitochondrial function and protein expression.

Methods: Mitochondria were isolated from cerebral blood vessels obtained from ovariectomized female rats, with and without estrogen replacement for three weeks. Plasma levels achieved by estrogen replacement mimicked those seen in intact, cycling females.

Results: Estrogen receptor, ER-alpha, but not ER-beta, was detected in mitochondrial fractions, and ERalpha protein was increased following estrogen treatment. Levels of mitochondrial cytochrome c, manganese superoxide dismutase, and subunits I and IV of complex IV also were increased in vessels from estrogen-treated rats. These findings correlated with functional increases in mitochondrial citrate synthase and complex IV activities in vessels from estrogen-treated animals. In contrast, hydrogen peroxide production, measured using succinate in vitro, was decreased in mitochondria from vessels of estrogen-treated animals. Surprisingly, PGC1alpha expression was significantly decreased, and NRF-1 protein levels were unchanged following estrogen exposure, suggesting that estrogen acts independently of these previously defined modulators.

Conclusions: Together, these novel findings suggest that vascular protection by estrogen is mediated, in part, by modulation of mitochondrial function resulting in greater energy producing capacity, more efficient coupling of electron transport, and decreased reactive oxygen species production. 
S6O49

IMPAIRED HISTAMINE-INDUCED RELAXATION IN MESENTERIC ARTERY OF DOCA-SALT HYPERTENSIVE RATS INVOLVES CHANGES ON MECHANISMS OF NO-INDEPENDENT HYPERPOLARIZATION

\section{R. Leite, A. E. Linder and R.C. Webb}

Department of Physiology, Medical College of Georgia, Augusta-GA 30912, USA

Objective: The histamine vasodilator effect is known to be mediated through activation of $\mathrm{H}_{1} / \mathrm{H}_{2}$-receptors in the endothelial or smooth muscle cells, with consequent release of mediators including nitric oxide (NO), prostacyclin $\left(\mathrm{PGI}_{2}\right)$ and endothelium-derived hyperpolarizing factor (EDHF). Chronic hypertension is associated with attenuated endothelium-dependent relaxation and unaltered responses to endothelium-independent agents. Endothelial dysfunction in hypertension is characterized by an imbalance between endothelium-derived contracting and relaxing factors.

We hypothesize that the relaxation induced by histamine is partially impaired in mesenteric arteries from DOCA-salt hypertensive rats due to a change in the hyperpolarizing mechanisms of vasodilatation.

Methods: Superior mesenteric arteries were isolated from 30 days DOCA hypertensive $(\mathrm{n}=5)$ or shamoperated $(\mathrm{n}=5)$ rats (systolic blood pressure $188 \pm 8$ and $148 \pm 7 \mathrm{mmHg}$, respectively), cleaned and prepared for isometric tension recordings. Concentration-effect curves to histamine were performed in mesenteric rings precontracted with phenylephrine in the absence or in the presence of a potassium channel blocker, tetraethylamonium (TEA ,10 mM), a NOS inhibithor, $\mathrm{N}^{\omega}$-nitro-L-arginine methyl ester (L-NAME,100 $\mu \mathrm{M}$ ), and a drug that depletes cholesterol from the membrane and disassemble caveolae, methyl- $\beta$-cyclodextrin (CD, 10 $\mathrm{mM})$.

Results: The relaxation to histamine was significantly impaired in mesenteric rings from DOCA hypertensive when compared to sham-operated animals. Incubation with TEA significantly affected histamine-induced relaxation in mesenteric rings from both DOCA and sham rats. The relaxation to histamine was significantly impaired in vessels from sham-operated animals after treatment with either L-NAME or CD, whereas it was completely abolished in vessels from DOCA rats.

Conclusion: The relaxation induced by histamine is partially mediated by hyperpolarization in mesenteric arteries from either sham-operated or DOCA hypertensive rats. However, in vessels from DOCA rats, this hyperpolarization is apparently mediated by NO produced through eNOS associated with the caveolae, while in vessels from sham-operated rats NO is not the sole mediator of the histamine-induced relaxation. These data suggest that the impaired relaxation to histamine in mesenteric arteries from DOCA hypertensive rats could be due to an alteration on mechanisms of NO-independent hyperpolarization.

[Financial support: NIH (P01 HL074167)] 


\begin{tabular}{|l|l|}
\hline $\begin{array}{l}\text { Wednesday June 1, } 2005 \\
\mathbf{0 9 . 0 0 - 1 2 . 3 0}\end{array}$ & $\begin{array}{l}\text { Chairpersons: } \\
\text { Duckles, Sue (USA) - Schini-Kerth, Valérie ( France) }\end{array}$ \\
\hline \hline & SESSION 1 \\
\hline $10.30-11.00$ & POSTER SESSION 1 \\
\hline
\end{tabular}

\begin{tabular}{|l|l|}
\hline $\begin{array}{l}\text { Wednesday June 1, } 2005 \\
14.00-17.30\end{array}$ & $\begin{array}{l}\text { Chairpersons: } \\
\text { Lévy, Bernard (France) - Van de Voorde, Johan } \\
\text { (Belgium) }\end{array}$ \\
\hline \hline \multicolumn{2}{|c|}{ SESSION 2} \\
\hline $15.30-16.00$ & POSTER SESSION 1 \\
\hline
\end{tabular}

\begin{tabular}{|l|l|l|}
\hline $\begin{array}{l}\text { Thursday June 2, } 2005 \\
\mathbf{0 9 . 0 0 - 1 2 . 0 0}\end{array}$ & $\begin{array}{l}\text { Chairpersons: } \\
\text { Shimokawa, Hiroaki (Japan) - Verbeuren, Tony } \\
\text { (France) }\end{array}$ \\
\hline \hline \multicolumn{1}{|c|}{ SESSION 3 } \\
\hline $10.30-11.00$ & POSTER SESSION 1 & \\
\hline
\end{tabular}


PS1P1

CALCIUM HANDLING AND ISOMETRIC FORCE DEVELOPMENT IN AORTIC SMOOTH MUSCLE CELLS OF APOLIPOPROTEIN E-DEFICIENT MICE

\author{
T. Van Assche, P-J. Guns, C. Van Hove, A.G. Herman, H. Bult and P. Fransen. \\ University of Antwerp - CDE, Department of Pharmacology, Antwerp, Belgium
}

Objective: Apolipoprotein E-deficient mice (apoE ${ }^{-/}$) are considered to be a well established model for studying atherosclerotic processes. Previously, we have shown that in these mice, endothelial dysfunction, defined as a loss of endothelium-dependent relaxation, occurs in the presence of atherosclerotic plaques only. This might suggest that other than endothelial factors play a role in atherogenesis. Therefore, the present study investigated whether smooth muscle cell (SMC) function in the aorta of young apoE ${ }^{-/ 2}$ mice is altered in comparison with WT mice before formation of atherosclerotic plaques.

Methods: Endothelium-denuded aortic rings (width 2mm) from both strains of mice (C57B16 WT: $\mathrm{n}=10$; $\mathrm{C} 57 \mathrm{~B} 16$ apoE $^{-1}: \mathrm{n}=11$, age=4months) were mounted in a wire myograph and loaded with the calcium sensitive dye Fura-2 AM to simultaneously measure free intracellular calcium $\left(\left[\mathrm{Ca}^{2+}\right]_{i}\right)$ and isometric force development. The ratio of emission at 340 to $380 \mathrm{~nm}$ excitation was used as a relative measure of $\left[\mathrm{Ca}^{2+}\right]_{\mathrm{i}}$ (relative units, $\mathrm{RU}$ ).

Results: In comparison with WT, apoE ${ }^{-/-}$mice displayed higher basal, non-stimulated $\left[\mathrm{Ca}^{2+}\right]_{\mathrm{i}}(0.97 \pm 0.02 \mathrm{RU}$ versus $1.02 \pm 0.01 \mathrm{RU})$. Addition of high external $\mathrm{K}^{+}$caused biphasic changes of $\left[\mathrm{Ca}^{2+}\right]_{\mathrm{i}}$ and force. The faster component of force development and concomitant $\left[\mathrm{Ca}^{2+}\right]_{\mathrm{i}}$-increase were significantly faster in female apoE $\mathrm{E}^{-/-}$ than in WT mice, whereas the $\left[\mathrm{Ca}^{2+}\right]_{\mathrm{i}}$-decrease during the slower component of force development was slower in apoE $^{-/ /}$than in WT mice (time constant, $363 \pm 73$ versus $159 \pm 32 \mathrm{~s}$, males and females). Upon stimulation with cumulative doses of phenylephrine $\left(10^{-9}-10^{-5} \mathrm{M}\right)$ the maximal increase of $\left[\mathrm{Ca}^{2+}\right]_{\mathrm{i}}$ was significantly larger in apoE $^{-/-}$than in WT $(0.15 \pm 0.02 \mathrm{RU}$ versus $0.09 \pm 0.02 \mathrm{RU})$. Accordingly, in male apoE $\mathrm{E}^{-/-}$mice, EC50 values for $\left[\mathrm{Ca}^{2+}\right]_{\mathrm{i}}$ and force increase $(50 \pm 7$ and $24 \pm 4 \mathrm{nM})$ were significantly higher than in male WT mice (27 \pm 3 and $9 \pm 2$ $\mathrm{nM})$ with a similar trend in females.

Conclusions: These observations suggest altered force development and $\left[\mathrm{Ca}^{2+}\right]_{\mathrm{i}}$-handling in aortic SMC of $\mathrm{apoE}^{-/-}$mice before formation of atherosclerotic lesions. Hence, modified intracellular calcium handling, which is an important process in the regulation of many physiological phenomena (such as stimulus-secretioncontraction coupling and proliferation) and modified force development of SMC possibly contribute to atherogenesis in $\mathrm{apoE}^{-/}$mice 
PS1P2

IMPAIRED SAPHENOUS ARTERY REACTIVITY IN THE SETTING OF HINDLIMB ISCHEMIA

Michel F., Duriez M., Silvestre J.S., Lévy B.I.

CRC-IL 689, 41 Bd de la Chapelle, 75475 Paris Cedex 10, France

Objective: A minimally invasive technique, using orthogonal polarization spectral (OPS) imaging, was developed as a new model to assess in vivo reactivity of hindlimb artery (1). In this study, we aimed to analyze in vivo vascular reactivity as an index of vascular function in the setting of ischemia.

Methods: Ischemia was induced by right femoral artery ligature in mice for 3 hours ( $\mathrm{t} 0, \mathrm{n}=4), 1$ day ( $\mathrm{t} 1$, $\mathrm{n}=8), 3$ days $(\mathrm{t} 3, \mathrm{n}=6), 7$ days $(\mathrm{t} 7, \mathrm{n}=6)$ and 15 days $(\mathrm{t} 15, \mathrm{n}=8)$. Changes in saphenous artery reactivity were then assessed by analyzing the effects of phenylephrine (Phe, $1 \mu \mathrm{M}$ to $0.1 \mathrm{mM}$ ) and acetylcholine (ACh, 0.3 to 30 $\mu \mathrm{M})$. ACh or Phe concentration-response curves were measured using OPS imaging in ischemic and nonischemic leg and were expressed in $\%$ of luminal diameter.

Results: The in vivo luminal diameter of the mouse saphenous artery was decreased at t0 $(107 \pm 4 \mu \mathrm{m}), \mathrm{t} 1$ $(108 \pm 5 \mu \mathrm{m})$ and $\mathrm{t} 3(106 \pm 3 \mu \mathrm{m})$ versus non-ischemic (NI, $125 \pm 4 \mu \mathrm{m})(\mathrm{P}<0.05)$. In contrast, the luminal diameter was increased at $\mathrm{t} 7(147 \pm 7 \mu \mathrm{m})$ and t15 $(163 \pm 4 \mu \mathrm{m})$ versus NI $(\mathrm{P}<0.05)$. ACh or Phe concentrationresponse curves showed that vasodilatation and vasoconstriction of the hindlimb artery were altered at different time points of ischemia versus NI ( $\mathrm{P}<0.05$, ANOVA repeated measure). Phe reactivity was reduced at $\mathrm{t} 3$ and $\mathrm{t} 7$ and enhanced at $\mathrm{t} 15$ versus $\mathrm{t} 1(\mathrm{P}<0.05$, ANOVA repeated measure). ACh reactivity was dramatically decreased at $\mathrm{t} 0, \mathrm{t} 1, \mathrm{t} 3$ and to a lesser extent at $\mathrm{t} 7$. Nevertheless, ACh perfusion increased vessel diameter in a concentrationdependent manner at $\mathrm{t} 15$ and the experimental maximal response $(30 \mu \mathrm{M})$ was also increased at $\mathrm{t} 7(110 \pm 3 \%)$ and t15 $(123 \pm 10 \%)$ versus t1 $(104 \pm 2 \%)(\mathrm{P}<0.05)$. However, ACh-induced vasodilatation in ischemic vessels did not reach that of non-ischemic vessels $(198 \pm 7 \%)$. Sodium nitroprussiate $(3 \mu \mathrm{M}$ to $0.1 \mathrm{mM}, \mathrm{n}=5)$ did not affect vessel diameter at 3 days of ischemia ( $\mathrm{P}<0.05$ vs NI, ANOVA repeated measure) suggesting that alteration in vessel vasodilatation did not only rely an endothelium dysfunction.

Conclusions: Our study demonstrated for the first time that after acute ischemia, saphenous artery diameter was reduced and was not altered by perfusion of vasodilators suggesting a marked reduction in the vasodilator ability of ischemic vessels. Therapeutic strategies based on administration of vasoactive drugs have been designed to improve tissue perfusion within the ischemic area. However, our results suggest that the use of these therapeutic strategies should be reassessed in the setting of acute ischemia.

${ }^{1}$ Michel \& al. J Cardiovasc. Pharmacol. 2004 


\section{PS1P3}

\section{CILOSTAZOL IMPROVES EDHF-TYPE RELAXATION IN THE MESENTERIC ARTERY OF STREPTOZOTOCIN-INDUCED DIABETIC RATS}

\section{T. Matsumoto, T. Kobayashi and K. Kamata}

Department of Physiology and Morphology, Institute of Medicinal Chemistry, Hoshi University, Shinagawa-ku, Tokyo 142-8501, Japan

Objective: The mechanisms underlying the impaired EDHF-type relaxation in diabetes are still not fully understood. We previously reported that EDHF-type relaxation is impaired in mesenteric arteries from streptozotocin (STZ)-induced diabetic rats. It was recently reported that cAMP facilitates EDHF-type relaxation in conduit arteries by enhancing electrotonic conduction via gap junction. Here, we investigated the involvement of cAMP signalling in the EDHF-type relaxation and whether the chronic treatment with cilostazol, a PDE3 inhibitor, improves EDHF-type relaxation in STZ rats.

Methods: Isometric force was measured in mesenteric arteries obtained from age-matched control, STZdiabetic, and cilostazol (100 mg/kg for 2 weeks)-treated STZ-diabetic rats. The expression of mRNA or protein was estimated by RT-PCR or by immunoblotting. Acetylcholine-induced cAMP production and Protein kinase A (PKA) activity were measured using an enzyme immuno assay and a nonradioactive assay respectively.

Results: The ACh-induced EDHF-type relaxation was significantly smaller in STZ-induced diabetic rats as compared to controls. In both groups of rats it was attenuated by $18 \alpha$-glycyrrhetinic acid, an inhibitor of gap junctions, and enhanced by IBMX, a cAMP-phosphodiesterase (PDE) inhibitor. These enhanced EDHF-type relaxations were very similar in STZ and control rats. The EDHF-type relaxation was also enhanced by cilostamide, a PDE3-selective inhibitor, but not by Ro 20-1724, a PDE4-selective inhibitor. The expression of the mRNAs and proteins for two cAMP PDEs (PDE3A, PDE3B) was increased in STZ-diabetic rats, but not for PDE4D. Chronical treatment with cilostazol (a PDE3 inhibitor, $100 \mathrm{mg} / \mathrm{kg}$ for 2 weeks) of the STZ rats, improved the impaired EDHF-type relaxation significantly. ACh-induced cAMP accumulation rapidly decreased in STZ rats, but was sustained in cilostazol treated animals. The EDHF-type relaxation was significantly decreased by the PKA inhibitor in the cilostazol treated rats but not in the non-treated STZ animals. The cAMP- analogs -induced relaxation and PKA activity was significantly improved in mesenteric arteries from cilostazol-treated STZ rats. The PKA catalytic subunit (Cat $\alpha$ - protein) was significantly decreased in STZ rats, but the regulatory subunit (RII $\beta$ ) was increased. This increased RII $\beta$-protein was significantly decreased by cilostazol treatment.

Conclusions: The impairment of EDHF-type relaxations in STZ-induced diabetic rats is attributed to a reduction in the effect of cAMP via an increased PDE3 activity and a decreased PKA activity. Furthermore, we suggest that cilostazol ameliorates the EDHF-type relaxation in STZ rats via an activated cAMP/PKA signalling. 


\section{PS1P4}

BIPHASIC RESPONSES TO PROSTACYCLIN AND ACETYLCHOLINE IN ISOLATED PERFUSED MOUSE KIDNEYS : INVOLVEMENT OF TP RECEPTORS.

\section{S. Simonet, F. Michel, C. Vayssettes-Courchay, J-S. Silvestre, B.I. Levy and T.J. Verbeuren} Institut de Recherches Servier, 11 rue des Moulineaux, Suresnes, France and Inserm U541, 41 Bd de la Chapelle, Paris, France.

Objective: Renal vascular tone is regulated through the secretion of several vasoactive substances among which $\mathrm{TXA}_{2}$, an arachidonic acid metabolite. The isolated perfused rat kidney has been used in the past to evaluate renovascular responses in conditions of health and disease. The aims of the present study were to set up the isolated perfused mouse kidney model and to examine responses to vasodilators and implication of TPreceptors in this model.

Methods: The mouse kidneys were isolated and perfused at $0.9 \mathrm{ml} / \mathrm{min}$ via the renal artery with oxygenated Tyrode solution at $37{ }^{\circ} \mathrm{C}$, similar to the previously described rat kidney model and changes in renal perfusion pressure were recorded and taken as an index of renovascular resistance changes. The substances were injected as a bolus of $5 \mu \mathrm{l}$ (dose expressed in mole) or infused (concentration expressed in $\mu \mathrm{M}$ ).

Results: During basal conditions, bolus injections of prostacyclin ( $\mathrm{PGI}_{2}, 10$ nmole), acetylcholine (ACh, 0.01-3 nmole), NO (1-100 pmole) and atrial natriuretic peptide (ANP, $10 \mathrm{pmol}$ ) did not alter the basal perfusion pressure ( $41 \pm 2 \mathrm{mmHg}, \mathrm{n}=45$ ). During a sustained constriction caused by methoxamine (115 $\pm 7 \mathrm{mmHg}, \mathrm{n}=10$ ), these substances caused vasodilator responses. However, $\mathrm{PGI}_{2}$ and $\mathrm{ACh}$ caused biphasic responses : constriction followed by a dilatation for $\mathrm{PGI}_{2}$ and the reverse for $\mathrm{ACh}$. The constrictions to $\mathrm{ACh}$ and $\mathrm{PGI}_{2}$ were totally inhibited by the TP-receptor antagonist, S $18886(0.01 \mu \mathrm{M})$. The cyclooxygenase inhibitor, indomethacin (10 $\mu \mathrm{M}$ ), prevented the constrictions to $\mathrm{ACh}$, but not those to $\mathrm{PGI}_{2}$. The dilator responses to ACh and NO were increased by S 18886, but not by indomethacin. Unexpectedly, during a sustained contraction with endothelin-1 (ET-1, $120 \pm 6 \mathrm{mmHg}, \mathrm{n}=9$ ), only vasodilator responses were noted to $\mathrm{ACh}$ and $\mathrm{PGI}_{2}$. The dilator responses to ACh were blocked by the NO synthase inhibitor, L-NNA $(100 \mu \mathrm{M})$ and the selective inhibitor of the soluble guanylyl cyclase, ODQ $(10 \mu \mathrm{M})$.

Conclusion: The present study illustrates that the mouse kidney is a useful model to evaluate vascular responsiveness; this technique can now be proposed to evaluate constrictor and dilator responses in mouse models of health and disease. The data suggest that in the mouse kidney ACh causes vasodilatation through NOrelease and vasoconstriction through production of a COX-dependent factor activating the TP-receptors; further experiments are needed to prove the possible EDCF-nature of this factor. $\mathrm{PGI}_{2}$ most likely caused vasoconstriction through direct activation of TP-receptors. The fact that during ET-1-induced constrictions, all substances only caused dilatation suggests that ET-1 interferes with the renal production or with the effect of factors that activate TP-receptors. 
PS1P5

BALANCE BETWEEN EDHF AND NO RELEASED FROM RENAL ARTERIES OF SHR/NDMCR-CP RATS, A MODEL FOR THE METABOLIC SYNDROME

\section{S. Kagota, Y. Kubota, N. Nejime, K. Nakamura, M. Kunitomo and K. Shinozuka \\ Department of Pharmacology, School of Pharmaceutical Sciences, Mukogawa Women's University, Nishinomiya 663-8179, Japan}

Objective: Metabolic syndrome, which is increasingly being linked with atherogenic vascular diseases, is a cluster of metabolic abnormalities, including hypertension, hyperlipidemia, hyperinsulinemia, glucose intolerance and obesity. These disease states are associated with endothelial dysfunction, which leads to the development of atherosclerosis. EDHF and NO are cooperatively involved in endothelium-dependent relaxations in response to acetylcholine in the renal artery of rats. We have previously proposed that a back-up mechanism operates to preserve the vascular tonus when the release of either NO or EDHF is impaired by hypertension, hypercholesterolemia or diabetes $(1,2)$. Therefore, in the present study we investigated whether the balance between EDHF and NO production in the endothelial cells was altered in the renal arteries of SHR/NDmcr-cp (cp/cp) rats (SHR-cp) in comparison with their lean littermates, SHR/NDmcr-cp (+/+) rats (SHR) as metabolically normal controls.

Methods: Male SHR-cp and SHR at 7 and 18 weeks of age were used. The body weight and the systolic blood pressure (tail-cuff method) were determined. Blood was taken from the abdominal aorta of rats under anesthesia with pentobarbital sodium, and then the plasma glucose, triglycerides and total cholesterol were determined using commercial kits. After the bilateral renal arteries had been isolated, acetylcholine-induced relaxation was determined in arterial rings preconstricted with phenylephrine. Individual concentration-response curves were characterized by determining the area under the curve. The acetylcholine-induced relaxations in the presence of indomethacin and those in the presence of indomethacin plus $\mathrm{N}^{\omega}$-nitro-L-arginine methyl ester were considered as the total of NO plus EDHF-dependent relaxations and EDHF-dependent relaxations, respectively. The NO-dependent relaxations were obtained by subtracting the EDHF-dependent relaxations from the total of NO plus EDHF-dependent relaxations.

Results: Body weights and plasma levels of cholesterol, triglycerides and glucose in the SHR-cp were higher at both 7 and 18 weeks of age than those in the SHR. The systolic blood pressure in the SHR-cp and SHR was the same at 7 weeks of age, while the blood pressure of the SHR-cp at 18 weeks of age was slightly but significantly lower than those of the SHR. In renal arteries, the total of NO plus EDHF-dependent relaxations in response to acetylcholine were not significantly different between the two strains at 7 weeks of age. Both the EDHF-dependent and NO-dependent relaxations were also equivalent. In contrast, at 18 weeks of age, the total relaxations were slightly but significantly attenuated in the SHR-cp compared to the SHR. The NO-dependent relaxations in the SHR-cp were significantly smaller than those in the SHR, while the EDHF-dependent relaxations in the SHR-cp were significantly larger than those in the SHR. On the other hand, the sodium nitroprusside-induced relaxations were not significantly different between both strains at 7 and 18 weeks of age.

Conclusion: These findings indicate that the endothelium-dependent relaxations, which were induced by NO and EDHF in the renal arteries of SHR-cp, were impaired in the chronic state of the metabolic syndrome, and this impairment is due to a lesser release of NO from the endothelium. On the other hand, the endothelial EDHF production seems to increase instead, suggesting compensatory induction to regulate the vascular tonus.

1 J. Cardiovasc Pharmacol 34, 533-539, 1999.

2 Gen Pharmacol 34, 201-209, 2000. 


\title{
PS1P6
}

ENDOTHELIAL DYSFUNCTION IN THE TYPE TWO DIABETIC db/db MOUSE IS ASSOCIATED WITH AN UPREGULATION OF A SARCOLEMMAL MEMBRANE ASSOCIATED PROTEIN, SLMAP

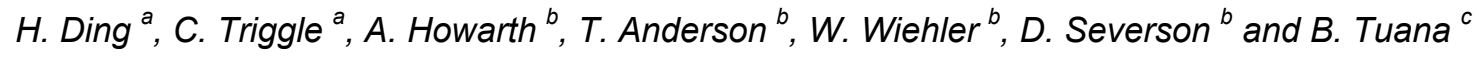 \\ ${ }^{\text {a }}$ RMIT University, Melbourne, Australia. \\ ${ }^{\mathrm{b}}$ University of Calgary, Canada. \\ c University of Ottawa, Canada.
}

Objective: The type 2 diabetic C57BL/KsJ-leprdb/leprdb $(\mathrm{db} / \mathrm{db})$ mouse rapidly develops insulin resistance, hyperglycaemia and elevated triglycerides as well as cardiovascular dysfunction. We have previously reported that male $\mathrm{db} / \mathrm{db}$ mice experience elevated vascular reactivity to vasoconstrictors such as phenylephrine (PE), endothelial dysfunction as reflected by a reduction in endothelium-dependent relaxation to acetylcholine (ACh), and also cardiac contractile dysfunction. The current investigation was designed to study whether a change in the expression of a novel membrane associated protein, sarcolemmal membrane associated protein, SLMAP, is associated with cardiovascular dysfunction in the $\mathrm{db} / \mathrm{db}$ mouse. SLMAPs, of which three isoforms are known, are directed to cellular membranes by a c-terminal anchor, have been shown to be a component of the excitationcontraction coupling apparatus, implicated in the regulation of membrane function in muscle cells and also associated with caveolae as well as centrosomes.

Methods: In the current investigation we treated 8 week old $\mathrm{db} / \mathrm{db}$ and control $\mathrm{db}^{+/ ?}$ mice with $30 \mathrm{mg} / \mathrm{kg} / \mathrm{day}$ of the non-thiazolidinedione PPAR $\gamma$ agonist and insulin sensitizing agent 2-(2-(4-phenoxy-2-propylphenoxy) ethyl)indole-5-acetic acid, $\mathrm{COOH}$. After 8 weeks the treatment groups were "crossed over" to untreated food for a further 5 weeks. A wire myograph was used to assess the contraction and relaxation profiles of small mesenteric arteries (SMA). Protein and gene expression of the 35, 41 and $80 \mathrm{kDa}$ isoforms of SLMAP were investigated with Western blotting and RT-PCR techniques.

Results: The data confirmed the rapid development of vascular dysfunction typified by changes in the contraction and relaxation profiles of small mesenteric arteries (SMA). Contractions of SMA from the $\mathrm{db} / \mathrm{db}$ mouse to PE were significantly enhanced and ACh-induced relaxations were significantly depressed. Treatment with the PPAR $\gamma$ agonist, $\mathrm{COOH}$, corrected blood glucose and completely prevented the changes in endotheliumdependent relaxation; however, neither vascular reactivity nor cardiac contractile deficits were corrected. With discontinuation of therapy with $\mathrm{COOH}$, endothelial dysfunction and hyperglycaemia returned. The dysfunctional SMA were found to specifically up regulate the expression of a $35 \mathrm{kDa}$ isoform of SLMAP. Western blotting and real-time PCR revealed high SLMAP protein and mRNA levels in the $\mathrm{db} / \mathrm{db}$ microvasculature and mRNA levels were markedly down regulated during $\mathrm{COOH}$ treatment but elevated again when drug therapy was discontinued.

Conclusions: These data reveal that the microvasculature in $\mathrm{db} / \mathrm{db}$ mice undergoes significant changes in vascular function with the endothelial component of vascular dysfunction specifically correlating with the over expression of the $35 \mathrm{kDa}$ isoform of SLMAP. No changes in SLMAP expression were noted in cardiac tissue. A single gene that encodes SLMAP maps to human chromosome 3p14.2-21 region - a region that also has been reported to carry genes linked to type 2 diabetic related disorders. Thus changes in SLMAP expression may be an important indicator for microvascular disease associated with type 2 diabetes and reflect specifically to changes in endothelial function 
PS1P7

CIRCULATING ENDOTHELIAL MICROPARTICLES IMPAIR ENDOTHELIAL FUNCTION IN PATIENTS WITH END STAGE RENAL FAILURE

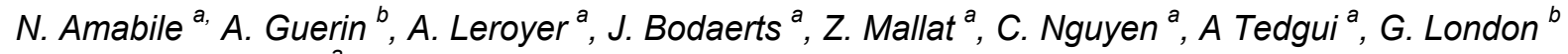 \\ and C.M. Boulanger ${ }^{a}$ \\ ${ }^{a}$ INSERM Cardiovascular Research Center Lariboisière, Paris, France \\ ${ }^{\mathrm{b}}$ Hemodialysis Dept, Manhes Hospital, Fleury-Merogis, France
}

Objective: Microparticles (MPs) are plasma-membrane shed fragments of stimulated or apoptotic cells which circulate in the peripheral blood and are associated with several cardio-vascular diseases. We hypothesized that circulating MPs not only correlate with, but also contribute to endothelial dysfunction in hemodialized patients with end stage renal failure.

Methods: Forty five hemodialyzed patients ( $53 \pm 8$ year) were included in the study. Brachial artery diameter and blood flow velocity were evaluated by echo-doppler in the arm free of arteriovenous shunt before and after application of a thermocontrolled waterbath (flow-induced dilatation) and sublingual application of glycerine trinitrate (TNT). Citrated venous blood samples were withdrawn prior to hemodialysis. Circulating endothelial (EMP), platelet (PMP), erythrocytes (RBCMP) and leucocytes (LMP) microparticles levels were characterized as $100 \mathrm{~nm}$ to 1 micron particles in platelet-free plasma (PFP) using cytofluorometric analysis with anti-CD41 (GpIIb), anti-CD31 (PECAM-1), anti-CD144 (VE-cadherin), anti-CD235a (glycophorin A) and anti-CD45 antibodies. MPs pellets and supernatant were subsequently isolated from platelet-free plasma by several centrifugation steps. NO-mediated relaxations and cyclic GMP production were evaluated in rat aortic rings incubated for 24 hours with either pellets (MP group) or supernatant (control group). In some experiments, EMP were purified from circulating MPs using Pan-Mouse Dynabeads coated with CD41, CD235a and CD45 antibodies to selectively remove MPM, RBCMP and LMP.

Results: Circulating levels of EMP (CD31+/CD41- or CD144+ events), PMP (CD31+/CD41+) and RBCMP $(\mathrm{CD} 235 \mathrm{a}+)$ were respectively $1632 \pm 175,398 \pm 33,13041 \pm 2567,3314 \pm 468$ events $/ \mu 1$ in hemodialyzed patients and were significantly increased when compared to an age-matched healthy group $(n=33)$. CD45+ MP represented less than $0.4 \%$ of the overall MP population in hemodialyzed patients. Flow-induced dilatation in hemodialyzed patients correlated with circulating CD31+/CD41- EMP $(\mathrm{R}=-0.534, \mathrm{P}=0.004)$ or with $\mathrm{CD} 144+$ EMP $(\mathrm{R}=-0.547 ; \mathrm{P}=0.007)$. However, it did not correlate with either PMP or RBCMP. No statistical relation was found between MPs levels and TNT-induced dilation.

Aortic rings were incubated in vitro with circulating levels of MP isolated either from hemodialyzed or control patients. The NO-mediated relaxation induced by acetylcholine was significantly impaired by $46 \pm 6 \%$ in preparations exposed to MP from hemodialyzed ( $\mathrm{P}=0.008)$, but not to those from healthy patients. The degree of dysfunction correlated with EMP $(\mathrm{R}=0.794 ; \mathrm{P}=0.003)$, but not $\mathrm{PMP}$ concentration $(\mathrm{R}=0.136 ; \mathrm{P}=0.39)$. Exposure to MP did not affect the response to the NO donor DEA-NONOate. Finally, acetylcholine-induced cGMP levels were decreased in MPs-exposed rings $(n=8 ; P=0.002)$ and in preparations exposed to purified EMP $(n=6$; $\mathrm{P}=0.003)$.

Conclusions: circulating EMPs are not only markers of pathological arteries and dysfunctional endothelial cells, but also play an key role in the modification of endothelial function and NO pathway. Taken all together, the present study identifies circulating endothelial microparticles as a potential new risk factor in the occurrence of cardiovascular events in patients with end stage renal disease and provides evidence for using EMP as a surrogate marker of endothelial dysfunction in cardiovascular diseases 


\section{PS1P8}

ENDOTHELIUM-DERIVED HYDROGEN PEROXIDE ACCOUNTS FOR THE ENHANCING EFFECT OF AN ANGIOTENSIN-CONVERTING ENZYME INHIBITOR ON ENDOTHELIUM-DERIVED HYPERPOLARIZING FACTOR-MEDIATED RESPONSES IN MICE

\section{T. Fujiki, K. Morikawa, H. Kubota, M. Hatanaka, M.A.H. Talukder, T. Matoba and H. Shimokawa.}

Department of Cardiovascular Medicine, Kyushu University Graduate School of Medical Sciences, Fukuoka, Japan

Objective: Angiotensin converting enzyme (ACE) inhibitors improve endothelium-dependent relaxations mediated by endothelium-derived hyperpolarizing factor (EDHF). We have recently identified that hydrogen peroxide $\left(\mathrm{H}_{2} \mathrm{O}_{2}\right)$ is an EDHF in mice and that endothelial NO synthase (eNOS) is an important source of it. In order to further evaluate our $\mathrm{H}_{2} \mathrm{O}_{2}$ theory, we examined in this study whether endothelium-derived $\mathrm{H}_{2} \mathrm{O}_{2}$ accounts for the enhanced EDHF-mediated responses by long-term treatment with an ACE inhibitor, temocapril, in mice, and if so, what mechanism(s) is involved

Methods: Isometric tensions and membrane potentials of small mesenteric arteries of control and temocapriltreated $(10 \mathrm{mg} / \mathrm{kg} / \mathrm{day}$ in drinking water for 4 weeks) mice were recorded by organ chamber experiments and microelectrode technique, respectively.

Results: In control mice, endothelium-dependent relaxations to acetylcholine ( $\mathrm{ACh}, 10^{-10}$ to $10^{-5} \mathrm{M}$ ) were resistant to indomethacin $\left(10^{-5} \mathrm{M}\right)$ or $\mathrm{N}^{\omega}$-nitro-L-arginine $\left(10^{-4} \mathrm{M}\right)$, but were markedly inhibited by $\mathrm{KCl}$, indicating a primary role of EDHF $(n=8)$. In the temocapril-treated mice, the EDHF-mediated relaxations and hyperpolarizations were significantly enhanced $(\mathrm{P}<0.05, \mathrm{n}=6-8)$. Catalase $(6250 \mathrm{U} / \mathrm{ml})$, a specific scavenger of $\mathrm{H}_{2} \mathrm{O}_{2}$, abolished the beneficial effects of temocapril $(n=6)$. Catalase lost its inhibitory effect when it was inactivated by aminotriazole $(50 \mathrm{mmol} / \mathrm{L})$, indicating a substantial involvement of $\mathrm{H}_{2} \mathrm{O}_{2}$. Endotheliumindependent relaxations to sodium nitroprusside or NS1619, a direct opener of $\mathrm{K}_{\mathrm{Ca}}$ channels, were comparable between the two groups ( $\mathrm{n}=6$ each). Western blot analysis demonstrated a significant upregulation of eNOS in temocapril-treated mice $(\mathrm{P}<0.05, \mathrm{n}=6)$. There was no significant difference in protein expression or enzyme activity of cupper/zinc superoxide dismutase, or enzyme activities of catalase and glutathione peroxidase between the two groups. Importantly, in eNOS-deficient mice, the long-term treatment with temocapril failed to enhance the EDHF-mediated relaxations $(\mathrm{n}=6)$.

Conclusions: These results indicate that endothelium-derived $\mathrm{H}_{2} \mathrm{O}_{2}$ accounts for the beneficial effect of temocapril on EDHF-mediated responses, due in part to eNOS upregulation in mice, thus further supporting our $\mathrm{H}_{2} \mathrm{O}_{2}$ theory. 
PS1P9

EARLY ENDOTHELIAL DYSFUNCTION SEVERELY IMPAIRS SKIN BLOOD FLOW RESPONSE TO LOCAL PRESSURE APPLICATION IN STREPTOZOTOCIN-DIABETIC MICE

\section{Sigaudo-Roussel, C. Demiot, B. Fromy, A. Koïtka, P. Abraham and J-L Saumet}

Laboratory of Physiology, UMR 6188, Medical School, F 49045 Angers cedex, France

Objective: We recently reported a mechanism allowing skin blood flow to increase in response to progressive locally applied pressure in humans and rats, which may be protective against pressure ulcers. The pressure applied is a nonpainful stimulation but we showed that pressure-induced vasodilation (PIV) involved nerve C fibres, since it disappeared after chronic treatment with capsaicin in animals and humans. In addition, we demonstrated a major role for vasodilators such as the calcitonin gene-related peptide, and endothelial vasodilators such as nitric oxide (NO) and prostaglandins in animal studies. In a recent study, we observed an early decrease of skin blood flow in response to locally applied pressure in diabetic patients that could be involved in the development of diabetic ulceration. However, it was unclear whether skin blood flow alteration during diabetes depends directly on vascular and/or neural alterations.

This study was designed to develop a diabetic mouse model exhibiting vascular but not neuropathic changes in order to study the microvascular response 1) to local pressure increase and 2) to endothelium-dependent and independent vasodilators.

Methods: We assessed cutaneous microvascular response to local increasing pressure application measured by laser Doppler flowmetry (LDF), endothelium-dependent and -independent vasodilation by iontophoretic delivery of acetylcholine (ACh) and sodium nitroprusside (SNP), sciatic motor nerve conduction velocity and morphometry.

Results: Nerve function, as assessed by sciatic nerve conduction velocity and morphometry, did not differ between groups. In control mice, LDF increased 34\% from baseline to $0.2 \mathrm{kPa}$ external pressure, showing PIV response. In contrast, diabetic mice had no LDF increase in response to progressive external pressure. Moreover, following iontophoretic delivery of acetycholine, endothelium-dependent vasodilation was largely attenuated in diabetic mice (25\%) compared to control mice (81\%), whereas vasodilation to SNP was not different between groups. PIV and ACh responses were preserved in diabetic mice treated during 1 week with alpha-lipoic acid

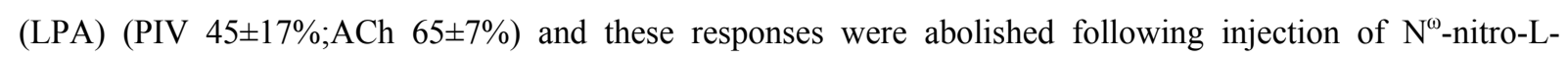
arginine (PIV $3 \pm 2 \%$; ACh $5 \pm 2 \%$ ).

Conclusions: These findings point out the fact that PIV response seems to be highly sensitive to endothelial NO levels and therefore endothelial impairment by itself is sufficient to severely alter the PIV response. Reducing oxidative stress can prevent diabetes-induced PIV alteration by increasing endothelial NO availability. We suggest that PIV could be a sensitive indicator of endothelium alteration occurring during diabetes. Pressureinduced vasodilation suppression could favour diabetic complications such as diabetic foot ulcers. Detecting and preventing early vascular dysfunction could delay the apparition of diabetic neuropathy and limit diabetic complications. 


\section{PS1P10}

\section{AN EXAMINATION OF THE EFFECTS OF CANNABINOID AGONISTS ON ATP RELEASE FROM SYMPATHETIC NERVES}

N.M. Rummery, V. Ralevic and W.R. Dunn.

School of Biomedical Sciences, University of Nottingham Medical School, Nottingham UK.

Objective: In vivo, endocannabinoids are known to cause a range of cardiovascular effects including hypotension and vasodilatation, however the mechanisms of such actions remain largely unknown. In blood vessels, cannabinoids can be released from endothelial, smooth muscle and nerve cells and mediate their effects in part by activating G-protein coupled cannabinoid receptors (1). To date, studies have demonstrated a role for cannabinoids in the modulation of noradrenaline release in various tissues including the rat mesenteric artery (MA) and vas deferens $(2,3)$. However no studies have yet examined whether cannabinoids modulate the release of the sympathetic cotransmitter, adenosine 5'-triphosphate (ATP).

Methods: Male Wistar rats (180-220g) were stunned by a blow to the cranium and decapitated. After removal of the mesentery, segments of primary MA and vein were dissected and pinned to the base of a recording chamber. The proximal end of the MA and vein were cleared of adherent fat and drawn into a suction electrode allowing excitation of perivascular nerves by electrical field stimulation. Preparations were continuously superfused with physiological saline gassed with $95 \% \mathrm{O}_{2}, 5 \% \mathrm{CO}_{2}$, at $37^{\circ} \mathrm{C}$. Membrane potential recordings from smooth muscle cells (SMC) were made using conventional microelectrode techniques (4). The effects of the synthetic cannabinoid, WIN 55,212-2 $(10 \mu \mathrm{M})$ and the endocannabinoids, noladin ether $(1 \mu \mathrm{M})$ and 2-arachidonoylglycerol (2-AG, $1 \mu \mathrm{M})$ on membrane potential and excitatory junction potentials (ejps) evoked by trains of five stimuli at 0.5 and $10 \mathrm{~Hz}(0.5 \mathrm{~ms}$ pulse width, $15 \mathrm{~V})$ were determined. All experiments were performed in the presence of idazoxan $(1 \mu \mathrm{M})$ to inhibit $\alpha_{2}$-adrenoceptor mediated autoinhibition of neurotransmitter release. Data were collected using a PowerLab system and analysed using Prism software.

Results: Under control conditions, the resting membrane potential of SMC was $-58 \pm 0.5 \mathrm{mV}(\mathrm{n}=29)$. The addition of WIN 55,212-2, noladin ether or 2-AG had no significant effect on resting membrane potential (WIN 55,212-2, $-55 \pm 1.8 \mathrm{mV}, \mathrm{n}=6$; noladin ether, $-56 \pm 0.8 \mathrm{mV}, \mathrm{n}=6$; 2-AG, $-56 \pm 2.1 \mathrm{mV}, \mathrm{n}=5 ; \mathrm{P}>0.05$ ). During trains of five stimuli at 0.5 and $10 \mathrm{~Hz}$, the amplitude of ejps increased with each successive stimulus. In the presence of noladin ether, the mean amplitude of ejps evoked by stimuli at $0.5 \mathrm{~Hz}$ but not $10 \mathrm{~Hz}$ was significantly less than in control $(\mathrm{P}<0.05)$. In contrast, 2-AG and WIN 55,212-2 had no effect on the mean amplitude of ejps at either frequency $(\mathrm{P}>0.05)$. Ejps evoked by trains of 5 stimuli at 0.5 and $10 \mathrm{~Hz}$ were significantly reduced in the presence of suramin $(100 \mu \mathrm{M})$ which blocks P2X-purinoceptors, and were abolished in the presence of the calcium channel blocker cadmium $(1 \mathrm{mM})$.

Conclusion: These results demonstrate that of the three cannabinoid agonist molecules examined, only noladin ether had an effect on the release of ATP from sympathetic nerves. At low but not high frequencies of nerve stimulation, noladin ether decreased the magnitude of ejps, reflecting decreased ATP release. Further experiments are required to define whether noladin ether produces this effect by interacting with cannabinoid receptors.

1 Pertwee RG. (1997). Pharmacol Ther, 74:129-180.

2 Ishac EJN et al. (1996). Br J Pharmacol, 118:2023-2028.

3 Ralevic V \& Kendall DA. (2002). Eur J Pharmacol, 444:171-181.

4 Dunn WR et al. (1999). Br J Pharmacol, 128:174-180. 
PS1P11

ROLE OF THE JNK AND HIF1-ALPHA IN THE INHIBITION OF VEGF EXPRESSION BY GREEN TEA CATECHINS IN VASCULAR SMOOTH MUSCLE CELLS

\section{J. El Bedoui, M-H. Oak and V.B.Schini-Kerth}

Pharmacologie et Physico-Chimie des Interactions Moléculaires et Cellulaires, UMR CNRS 7034, Université Louis Pasteur de Strasbourg, Faculté de Pharmacie, Illkirch, France.

Objective: Regular consumption of tea, in particular green tea, has been associated with a reduced risk of coronary heart disease and cancer in several epidemiological studies. Clinical studies have also indicated that intake of green tea reduced the risk of myocardial infarction and increased survival after acute myocardial infarction. Moreover, chronic administration of green tea retarded the development of experimental atherosclerotic lesions. Although the mechanism underlying the beneficial effects of green tea intake remains unclear, it has been attributable at least in part to the high content of flavonoids, especially of the catechin group of the flavanols. Potential protective effects of tea catechins include their ability to prevent LDL oxidation, to inhibit platelet aggregation and pro-thrombotic responses, to decrease smooth muscle cell proliferation and migration, and to stimulate the endothelial formation of nitric oxide and prostacyclin. The formation of new blood vessels is a key event controlling tumour growth and possibly also the development of atherosclerotic lesions. The aim of the present study was to determine whether green tea polyphenols affect vascular endothelial growth factor (VEGF) expression, a major pro-angiogenic and pro-atherosclerotic factor, in vascular smooth muscle cells (VSMCs), and if so, to determine the underlying mechanism.

Methods: All experiments were performed with human aortic VSMCs. VEGF release and the nuclear level of hypoxia-inducible factor-1alpha (HIF1-alpha) protein were assessed by ELISA. Phosphorylation of the MAPK p38, ERK1/2 and JNK were assessed by Western blot analysis.

Results: Exposure of VSMCs to PDGFAB markedly increased the modest basal release of VEGF after a 24hour incubation period. The stimulatory effect of PDGFAB was reduced by pre-treatment of VSMCs with a green tea extract in a concentration-dependent manner. A similar inhibitory effect was also observed with the major green tea polyphenol, (-)-epigallocatechin-3-gallate (EGCG). In contrast, only a small inhibitory effect was obtained with (-)-epicatechin-3-gallate (ECG) and no such effect was obtained with (-)-epigallocatechin (EGC), (-)-epicatechin (EC) and catechin. The PDGFAB-induced release of VEGF was abolished by SP600125 (an inhibitor of JNK), markedly reduced by SB203580 (an inhibitor of p38 MAPK), slightly reduced by PD98059 (an inhibitor of MEK), and not affected by wortmannin (an inhibitor of PI-3-kinase). Green tea extract and EGCG prevented the PDGFAB-induced phosphorylation of JNK whereas that of p38 and ERK1/2 was unaffected. Exposure of VSMCs to PDGFAB for 4 hours markedly increased HIF1-alpha expression and stabilization, a major transcription factor controlling VEGF expression. Green tea extract and EGCG prevented the PDGFAB-induced activation of HIF1- alpha.

Conclusions: Altogether, these findings indicate that green tea polyphenols strongly inhibit PDGFABinduced VEGF expression in VSMCs by preventing JNK phosphorylation and HIF1- alpha activation. This inhibitory effect is mimicked by (-)-epigallocatechin-3-gallate. The potential anti-angiogenic and antiatherosclerotic properties of green tea polyphenols might contribute to their protective effect on the cardiovascular system. 


\section{PS1P12}

\section{EFFECTS OF INDUCING TONE WITH ENDOTHELIN-1 ON NERVE-MEDIATED CONTRACTILE RESPONSES IN THE RAT MESENTERIC VASCULAR BED}

\section{P. Pakdeechote, V. Ralevic and W.R. Dunn}

School of Biomedical Sciences, University of Nottingham Medical School, Queen's Medical Centre, UK, NG7 2UH

Objective: The sympathetic nervous system can release a number of neurotransmitters that cause vasoconstriction, including noradrenaline (NA), ATP and neuropeptide $\mathrm{Y}(1,2)$. While functional neurogenic responses mediated by NA are easily demonstrated in isolated vascular preparations, this is less true for ATP and NPY. Since, in vivo, vessels have some degree of basal tone, the present study investigated whether causing prior vasoconstriction with endothelin-1 (ET-1), influenced the contractile response to nerve stimulation.

Methods: Male Wistar rats (220-250 g) were killed by $\mathrm{CO}_{2}$ asphyxiation. Thereafter the mesenteric vascular bed was removed, separated from the gut and cannulated via the superior mesenteric artery. The mesenteric vascular beds were perfused with pre-gassed $95 \% \mathrm{O}_{2} 5 \% \mathrm{CO}_{2}$ physiological salt solution at a rate of $5 \mathrm{ml} / \mathrm{min}$. In some preparations responses to electrical field stimulation (EFS; $5-50 \mathrm{~Hz}, 90 \mathrm{~V}, 1 \mathrm{~ms}$ for $30 \mathrm{~s}$ at 8 min intervals) were obtained for three reproducible cycles at baseline pressure. In other preparations consecutive frequency response curves were generated after raising tone with ET-1. Some of these latter experiments were carried out in tissues previously treated with capsaicin $(1 \mu \mathrm{M})$ for $20 \mathrm{~min}$ to defunctionalise the sensory nerves. The effects of the sequential addition of the P2X-receptor desensitizing agent, $\alpha, \beta$,-methylene ATP $(1 \mu \mathrm{M})$, and the $\alpha_{1}$ adrenoceptor antagonist, prazosin $(0.1 \mu \mathrm{M})$ were assessed under the three different conditions i.e. basal tension, ET-1-induced raised tone and ET-1-induced raised tone after capsaicin treatment. Mesenteric vascular responses were detected as changes in perfusion pressure $(\mathrm{mmHg})$. Differences between means were compared using Student's t-test.

Results: Under basal tone conditions (baseline pressure, $17 \pm 1.0 \mathrm{mmHg}$ ), $\alpha, \beta$,-methylene ATP did not alter contractile response to nerve stimulation (at $30 \mathrm{~Hz}, 25 \pm 2$ to $22 \pm 1.4 \mathrm{mmHg}, \mathrm{n}=6$ ). Raising tone with ET-1 (pressure $63 \pm 7.9 \mathrm{mmHg}, \mathrm{n}=7)$ increased the size of the contractile responses to nerve stimulation $(\mathrm{P}<0.05)$. Furthermore, under these conditions, contractile responses to EFS $(30 \mathrm{~Hz})$ were significantly reduced by $\alpha, \beta,-$ methylene ATP (control $52 \pm 6.3$; $\alpha, \beta$,-methylene ATP $32 \pm 4.5 \mathrm{mmHg}, \mathrm{n}=7$ ). Preparations exposed to ET-1 after capsaicin exposure (pressure $46 \pm 5.0 \mathrm{mmHg}$ ), had a larger contractile response to EFS when compared to those not exposed to capsaicin $(\mathrm{P}<0.05)$. In these preparations, $\alpha, \beta,-$-methylene ATP also reduced the size of contractile responses to EFS ( $73 \pm 7.5$ to $48 \pm 6.6 \mathrm{mmHg}, \mathrm{n}=6)(\mathrm{P}<0.05)$. The residual contractile response was abolished by prazosin under all conditions.

Conclusions: Inducing tone with ET-1 in the rat perfused mesenteric bed increased the size of the contractile response obtained to EFS, an effect that was further enhanced by chemically desensitizing sensory nerves with capsaicin. Inducing tone with ET-1 also uncovered a contractile response to sympathetic nerve activation that was mediated by ATP and was not evident under basal (no tone) conditions.

1 Wilson, V.G. \& Dunn, W.R. (1996). In: Nervous Control of Blood Vessels, eds. Bennett, T. \& Gardiner, S.M. Harwood Academic Publishers, Netherlands, pp. 1-59.

2 Burnstock, G. (2004). Co- transmission. Curr Opin Pharmacol. 4:47-52. 
PS1P13

CONNEXIN EXPRESSION AND ENDOTHELIUM-DEPENDENT VASODILATOR RESPONSES IN OMENTAL ARTERIES FROM NORMOTENSIVE PREGNANT WOMEN.

\author{
A. M. Mathewson ${ }^{a}$, S. Lim ${ }^{a}$, P. N. Baker ${ }^{b}$, T. M. Mayhew ${ }^{a}$ and W. R. Dunn ${ }^{a}$ \\ ${ }^{a}$ CISBM, School of Biomedical Sciences, University of Nottingham, NG7 2UH. \\ ${ }^{\mathrm{b}}$ Maternal and Fetal Health Research Centre, St Mary's Hospital, University of Manchester, M13 0JH.
}

Objective: During pregnancy, the maternal circulation undergoes a number of changes to ensure that the growing fetus receives an adequate blood supply. Myometrial arteries exhibit an upregulation of EDHF during pregnancy (1), and EDHF-mediated responses have also been reported in omental (2, 3) and subcutaneous (4) arteries isolated from pregnant women. EDHF-mediated responses are sensitive to gap junction inhibition in human myometrial and subcutaneous arteries from pregnant women $(1,4)$. Since gap junctions are formed by the interaction of connexin proteins, here we assess the expression of connexins 37, 40 and 43 in omental arteries isolated from pregnant women and the role of gap junctions in mediating the functional EDHF response.

Methods: Permission for the study was granted by the Ethics Committee at the Queens Medical Centre, Nottingham. All women who participated gave informed consent. Omental biopsies were obtained during surgery from women undergoing elective Caesarean section at term. Small omental arteries were dissected clear of surrounding connective tissue and either prepared for immunofluorescent detection of connexins 37, 40 and 43 or mounted in a pressure myograph for functional studies. Dilator responses to increasing concentrations of bradykinin (BK) were recorded in a pressure myograph $\left(40 \mathrm{mmHg}, 37^{\circ} \mathrm{C}\right)$ before and after treatment with nitroL-arginine methyl ester (L-NAME; $100 \mu \mathrm{M}$ ), high $\mathrm{K}^{+}$(25 mM), 18 alpha-glycyrrhetinic acid (18 alpha-GA; 100 $\mu \mathrm{M})$ or carbenoxolone $(\mathrm{CBX} ; 100 \mu \mathrm{M})$ and compared using a repeated measures two-way ANOVA with a Bonferroni post test. Data are expressed as mean $+/$ - s.e.m from n experiments. A P-value less than 0.05 was considered significant. All experiments were performed in the presence of indomethacin $(1 \mu \mathrm{M})$.

Results: All three connexins were detected by immunofluorescence in human omental arteries from pregnant women. Connexin 37 was the only one to show strong staining in the media. Weak staining for connexin 37 was found in the endothelium. In contrast, intense staining for connexins 40 and 43 was observed only in the endothelium. Pressurised, U46619-constricted arteries relaxed in a concentration dependent manner to BK. Maximal dilator responses to BK were reduced in the presence of L-NAME (Emax: 58.9+/-13.3\% versus control $85.7+/-7.2 \% ; \mathrm{P}=0.05 ; \mathrm{n}=6)$ and significantly inhibited in the presence of elevated $\mathrm{K}+(25 \mathrm{mM})$ in addition to LNAME (Emax: $21.2+/-4.7 \%$ versus control: $89.2+/-5.2 \%, \mathrm{P}<0.001, \mathrm{n}=5$ ). In the presence of L-NAME, the gap junction inhibitors 18 alpha-GA (Emax: +18 alpha GA: $65.3+/-8.5 \%$ versus +L-NAME: $85.9+/-3.5 \%$; $\mathrm{P}=0.05$; $\mathrm{n}=6$ ) or CBX (Emax: 40.8+/-11.1\% versus +L-NAME: $67.4+/-4.9 \%$; $\mathrm{P}<0.05, \mathrm{n}=5$ ) inhibited the maximal dilator response to $\mathrm{BK}$.

Conclusions: Human omental arteries express connexins 37, 40 and 43. Gap junctions, composed of these connexins, may partly be responsible for the EDHF-mediated response to BK.

1 Kenny et al 2002 Br. J. Pharmacol. 136, 8, 1085-8.

2 Pascoal et al 1998 J. Clin. Invest. 101, 2, 464-70.

3 Suzuki et al 2000 J. Physiol. 527, 163-74.

4 Luksha et al 2004 Am. J. Physiol. 286, 6, R1102-9. 


\section{PS1P14}

\section{MODULATION OF CALCIUM HOMEOSTASIS BY NO IN PORCINE ENDOTHELIAL CELLS}

\section{E. Perrier, M-P. Fournet-Bourguignon, S. Molez, N. Villeneuve, J-P. Vilaine.}

Cardiovascular Research Division, Servier Research Institute, Suresnes, France.

Objective: The endothelium plays a key role in different vascular functions by producing various biologically active mediators. Above all, nitric oxide (NO), which is generated during the oxidation of arginine by the endothelial NO synthase (NOS3), is involved in many endothelial functions. Although is well known that the NOS3 activity requires an elevation of the intracellular calcium concentration $\left(\left[\mathrm{Ca}^{2+}\right] \mathrm{i}\right)$ to produce NO, conversely, the effect of $\mathrm{NO}$ on the endothelial $\left[\mathrm{Ca}^{2+}\right] \mathrm{i}$ is not described. The purpose of the present study was to examine the consequences of the modulation of the $\mathrm{NO}$ level on calcium homeostasis in endothelial cells.

Methods: Endothelial cells from porcine aorta (PAEC) in passage one were exposed to different inhibitors and/or activators of the NO pathway. The intracellular calcium concentration was monitored using Fura-2/AM fluorimetry and the NO production was determined by the measurement of intracellular cGMP, the second messenger of NO, using radioimmunoassay.

Results: Bradykinin (BK- $1 \mu \mathrm{M})$, quickly induced an increase in cGMP production (2 fold) and in parallel, a transitory increase in $\left[\mathrm{Ca}^{2+}\right] \mathrm{i}$ ( 2 fold, peak), demonstrating that the NO pathway was functional in PAEC. NitroL-arginine (LNA $10 \mathrm{nM}$ to $1 \mu \mathrm{M}$ ), a NOS3 inhibitor, decreased the basal cGMP production, as expected. In parallel, it also induced a sustained increase in the basal $\left[\mathrm{Ca}^{2+}\right]$ i equivalent to $20 \%$ of the maximal BK-induced $\left[\mathrm{Ca}^{2+}\right]$ i elevation or $35 \%$ of the basal $\left[\mathrm{Ca}^{2+}\right]$ i even though nitro-D-arginine (DNA $10 \mathrm{nM}$ to $1 \mu \mathrm{M}$ ), the inactive form of the NOS3 inhibitor, yielded no effect. This increase was totally prevented by L-arginine $1 \mathrm{mM}$, the NOS3 substrate, suggesting that the effect of LNA on basal $\left[\mathrm{Ca}^{2+}\right]$ i is mediated by the blockade of NO production. On the contrary the NO donor DETA-NONOate ( $1 \mathrm{pM}$ to $1 \mu \mathrm{M})$ induced a $23 \%$ to $36 \%$ decrease in basal $\left[\mathrm{Ca}^{2+}\right] \mathrm{i}$ and, moreover, $10 \mu \mathrm{M}$ of DETA-NONOate was able to reverse the effect of LNA (100 nM) demonstrating that $\mathrm{NO}$ is directly implicated in the regulation of basal $\left[\mathrm{Ca}^{2+}\right] \mathrm{i}$.

Conclusions: The mechanisms involved in the regulation of endothelial cell calcium signalling by NO remain to be defined. Different processes could participate such as calcium entry, reuptake of calcium by $\mathrm{Ca}^{2+}$-ATPase (SERCA), efflux by the ryanodine receptor, mitochondrial buffering or the subplasmalemmal $\mathrm{Ca}^{2+}$ control unit. Since alteration of the NO bioavailability has been described in human cardiovascular diseases, it could be speculated that the associated increase in $\left[\mathrm{Ca}^{2+}\right]$ i could influence other calcium sensitive targets than NOS3. 
PS1P15

PIVOTAL ROLE OF CU,ZN-SOD IN ENDOTHELIUM-DEPENDENT HYPERPOLARIZATION IN MICE AND HUMANS

\author{
K. Morikawa, T. Matoba, H. Kubota, M. Hatanaka, A. Takaki, T. Fujiki and H. Shimokawa \\ Department of Cardiovascular Medicine, Kyushu University Graduate School of Medical Sciences, \\ Fukuoka, Japan.
}

Objective: We have recently identified that endothelium-derived hydrogen peroxide $\left(\mathrm{H}_{2} \mathrm{O}_{2}\right)$ is an EDHF in mice and human mesenteric arteries and porcine coronary microvessels. However, the mechanisms for the endothelial synthesis of $\mathrm{EDHF} / \mathrm{H}_{2} \mathrm{O}_{2}$ remain to be elucidated. In this study, we examined the possible role of $\mathrm{Cu}, \mathrm{Zn}-\mathrm{SOD}$ in the endothelial synthesis of EDHF/ $\mathrm{H}_{2} \mathrm{O}_{2}$.

Methods: Small mesenteric arteries of control and $\mathrm{Cu}, \mathrm{Zn}-\mathrm{SOD}-$ deficient $\left(\mathrm{Cu}, \mathrm{Zn}-\mathrm{SOD}^{-/}\right)$mice, and human mesenteric arteries obtained during gastrectomy operations were used. In those blood vessels, we examined endothelium-dependent relaxations to acetylcholine (ACh) in mice and those to bradykinin (BK) in humans and endothelium-independent relaxations to sodium nitroprusside (SNP, a NO donor), NS1619 (a direct opener of $\mathrm{K}_{\mathrm{Ca}}$ channels), and exogenous $\mathrm{H}_{2} \mathrm{O}_{2}$. We also examined endothelium-dependent hyperpolarizations to $\mathrm{ACh}$ in mice and those to $\mathrm{BK}$ in humans and endothelium-independent hyperpolarizations to levcromakalim. In control and $\mathrm{Cu}, \mathrm{Zn}-\mathrm{SOD}^{-/}$mice, we also examined coronary flow increase to BK using a Langendorff setup and endothelial production of $\mathrm{H}_{2} \mathrm{O}_{2}$ using a confocal microscopy with dichlorodihydrofluorescein diacetate (DCF). We also examined the effect of SOD mimetics on EDHF-mediated responses.

Results: In control mice, endothelium-dependent relaxations to ACh were resistant to indomethacin or $\mathrm{N}^{\omega}$ nitro-L-arginine (L-NNA), but were markedly inhibited by $\mathrm{KCl}$, indicating a primary role of EDHF. In $\mathrm{Cu}, \mathrm{Zn}$ $\mathrm{SOD}^{-/}$mice, control relaxations to $\mathrm{ACh}$ were slightly attenuated and L-NNA markedly inhibited the relaxations to ACh, suggesting an enhanced compensatory role of NO with a marked reduction in EDHF-mediated relaxations. In contrast, endothelium-independent relaxations to nitroprusside, NS-1619 or exogenous $\mathrm{H}_{2} \mathrm{O}_{2}$ were comparable between the two strains. Endothelium-dependent hyperpolarizations were also markedly reduced in $\mathrm{Cu}, \mathrm{Zn}-\mathrm{SOD}^{-/}$mice. In Langendorff perfused hearts, EDHF-mediated increase in coronary flow to $\mathrm{BK}$ was significantly reduced in $\mathrm{Cu}, \mathrm{Zn}-\mathrm{SOD}^{-/}$mice compared with control mice. Catalase significantly inhibited the EDHF-mediated relaxations and hyperpolarizations and the coronary flow increase in control mice but not in $\mathrm{Cu}, \mathrm{Zn}-\mathrm{SOD}^{-/}$mice. Furthermore, the cell-permeable SOD mimetic tempol, significantly improved EDHFmediated relaxations and hyperpolarizations and coronary flow increase in $\mathrm{Cu}, \mathrm{Zn}-\mathrm{SOD}^{-/}$mice and these enhancing effects of tempol on the EDHF-mediated responses were abolished by catalase. Similarly, in human mesenteric arteries, EDHF-mediated relaxations and hyperpolarization were significantly enhanced by pretreatment with tiron, another cell permeable SOD mimetic, and those enhancing effect of tiron on the EDHFmediated responses was again abolished by pretreatment with catalase, suggesting an involvement of $\mathrm{EDHF} / \mathrm{H}_{2} \mathrm{O}_{2}$ in human blood vessels as well. Tiron did not affect endothelium-independent relaxations to SNP, NS1619 or exogenous $\mathrm{H}_{2} \mathrm{O}_{2}$.

Conclusions: These results provide the novel concept that endothelial $\mathrm{Cu}, \mathrm{Zn}-\mathrm{SOD}$ plays a pivotal role as "an EDHF synthase" in both mice and humans. 


\title{
PS1P16
}

RHO KINASE PLAYS AN IMPORTANT ROLE IN THE POSTNATAL CHANGE IN NITRIC OXIDE AND cGMP-MEDIATED RELAXATION OF OVINE CORONARY ARTERIES

\author{
Y. Gao, D. Dou, X. Qin and J.U. Raj
}

${ }^{a}$ Peking University Health Science Center, Beijing, China.

${ }^{\mathrm{b}}$ Geffen School of Medicine at University of California, Los Angeles, USA

Objective: At birth, the marked increase in cardiac output parallels closely the increase in myocardial blood flow. This may be due to a post-natal increase in nitric oxide (NO)-mediated relaxation of coronary arteries. NO can cause vasodilation by elevating intracellular cGMP levels followed by activation of cGMP-dependent protein kinase G (PKG). Studies suggest that Rho Kinase (ROCK) plays an important role in counteracting vasodilation induced by various agents including the NO-cGMP pathway. The present study was performed to determine the role of Rho Kinase in modulating NO-cGMP-mediated relaxation of coronary arteries in the fetus and newborn.

Methods: Isolated coronary arteries of term fetuses (143-149 gestation day) and newborn (7-10 days) lambs were suspended in organ chambers and the isometric tension was recorded. The relaxant response of the vessels was determined during constriction with endothelin-1. The activity of cGMP-dependent protein kinase G (PKG) was assayed by measuring the incorporation of ${ }^{32} \mathrm{P}$ from $\alpha-{ }_{-}^{32} \mathrm{P}$-ATP into a specific PKG substrate BPDEtide. RhoA activation was determined by affinity precipitation of the active GTP-bound RhoA using a glutathione Stransferase (GST)-fusion protein of the Rho-binding domain of the Rho effector rhotekin (GST-RBD). Detection of PKG and RhoA was performed by Western blot using anti-PKG type I and anti-RhoA antibody.

Results: DETA-NONOate (DETA-NO, a stable NO analog) and 8-Br-cGMP (a cell membrane premeant analog of cGMP) induced a greater relaxation in coronary arteries of newborn compared to fetal lambs. The relaxation was largely abolished by ODQ (a specific inhibitor of soluble guanylyl cyclase). 8-Br-cGMP induced relaxation of fetal vessels but not those of the newborn was inhibited by Rp-8-Br-PET-cGMPS, a PKG inhibitor. Y27632, a ROCK inhibitor, caused a greater relaxation of coronary arteries of the fetus than of newborn lambs. In the presence of Y27632, 8-Br-cGMP-induced relaxation was now greater in fetal compared to newborn coronary arteries. Western blotting showed a greater PKG protein level but markedly less PKG activity in the newborn compared to fetal vessels. In comparison to fetal coronary arteries, in newborn vessels, Rho protein level was greater but Rho activation induced by endothelin-1 was significantly lower.

Conclusions: The present study demonstrates a greater NO- and cGMP-mediated relaxation of newborn compared to fetal ovine coronary arteries. This is due to decreased Rho activation and not due to an increase in cGMP-stimulated PKG activity. This decrease in Rho activation after birth might explain the postnatal increase in coronary blood flow. 
PS1P17

EFFECT OF THIAZOLIDINEDIONES ON ADENOSINE TRANSPORT IN VASCULAR SMOOTH MUSCLE CELLS

\author{
G.P.H. Leung, C.M. Tse and R. Y.K. Man
}

a Department of Pharmacology, The University of Hong Kong, Hong Kong SAR

${ }^{\mathrm{b}}$ Department of Medicine, The Johns Hopkins University, Baltimore, Maryland, USA

Objective: Thiazolidinediones are a new class of anti-diabetic agents which increase insulin sensitivity by binding to the peroxisome proliferators-activated receptor $\gamma(\operatorname{PPAR} \gamma)$ and stimulate the expression of insulinresponsive genes involved in glucose and lipid metabolism. These drugs also have vasodilatory and antiproliferative effects on vascular smooth muscle cells (VSMCs). However the mechanisms for these actions are not understood. Adenosine is a vasodilator. Equilibrative nucleoside transporter (ENT)-1, which is an $\mathrm{Na}^{+}-$ independent and nitrobenzylmercaptopurine riboside (NBMPR)-sensitive nucleoside transporter, plays an important role in adenosine functions because it fine-tunes the local concentrations of adenosine in the vicinity of adenosine receptors. In the present study, the effects of three thiazolidinediones, troglitazone, pioglitazone and ciglitazone, on ENT1 in VSMCs were studied.

Methods: The ENT1 activity in VSCMs was determined by the initial rate of [3H]adenosine uptake and $[3 \mathrm{H}] \mathrm{NBMPR}$ binding assay. The mRNA and protein expressions of ENT1 were detected by the reverse transcription-polymerase chain reaction (RT-PCR) and Western blotting, respectively.

Results: Incubating VSMCs for $48 \mathrm{hr}$ with thiazolidinediones had no effect on ENT1 mRNA and protein levels. However, troglitazone inhibited [3H]adenosine uptake and [3H]NBMPR binding of VSMCs with IC50 values of $2.35 \pm 0.35 \mu \mathrm{M}$ and $3.99 \pm 0.57 \mu \mathrm{M}$, respectively. This effect of troglitazone on ENT1 was PPAR $\gamma$ independent and kinetic studies revealed that troglitazone was a competitive inhibitor of ENT1. In contrast, pioglitazone and ciglitazone had minimal effects on $[3 \mathrm{H}]$ adenosine uptake by VSMCs. Troglitazone differs from pioglitazone and ciglitazone as its side-chain contains a vitamin E moiety. This difference in structure of troglitazone did not account for its inhibitory effect on ENT1 because vitamin E did not inhibit $[3 \mathrm{H}]$ adenosine uptake by VSMCs.

Conclusions: Troglitazone inhibits ENT1. It is suggested that troglitazone may alter the vascular effect of adenosine. 


\begin{tabular}{|l|l|l|}
\hline $\begin{array}{l}\text { Friday June 3, } 2005 \\
\text { 09.00-12.00 }\end{array}$ & $\begin{array}{l}\text { Chairpersons: } \\
\text { Mulvany, Michael ( Denmark) - Bult, Hidde (Belgium) }\end{array}$ \\
\hline \hline \multicolumn{2}{|c|}{ SESSION 4 } \\
\hline $10.30-11.00$ & POSTER SESSION 2 \\
\hline
\end{tabular}

\begin{tabular}{|l|l|}
\hline $\begin{array}{l}\text { Friday June 3, } 2005 \\
\text { 13.00-16.00 }\end{array}$ & $\begin{array}{l}\text { Chairpersons: } \\
\text { Vanhoutte, Paul ( Hong Kong) - Herman Arnold } \\
\text { (Belgium) }\end{array}$ \\
\hline \multicolumn{2}{|c|}{ SESSION 5 - YOUNG INVESTIGATORS AWARD COMPETITION } \\
\hline $15.30-16.00$ & POSTER SESSION 2 \\
\hline
\end{tabular}

\begin{tabular}{|l|l|}
\hline $\begin{array}{l}\text { Saturday June 4, } 2005 \\
\text { 09.00-12.00 }\end{array}$ & $\begin{array}{l}\text { Chairpersons: } \\
\text { Busse, Rudi (Germany) - Man, Ricky (Hong Kong) }\end{array}$ \\
\hline \multicolumn{2}{|c|}{ SESSION 6} \\
\hline $10.30-11.00$ & POSTER SESSION 2 \\
\hline
\end{tabular}


PS2P18

GENDER-DEPENDENT BASAL VASODILATOR ACTIVITY OF ENDOTHELIAL CELLS IN APOLIPOPROTEIN E-DEFICIENT MICE

\author{
T. Van Assche, P. Fransen, P-J. Guns, V. Croons, H. Crauwels, C. Van Hove, A.G. Herman and \\ H. Bult
}

University of Antwerp, Department of Pharmacology, CDE, Antwerp, Belgium

Objective: Characterisation of contractile function of the smooth muscle cells (SMC) and basal vasodilator activity of the endothelial cells (EC) in apolipoprotein E-deficient $\left(\mathrm{apoE}^{-/}\right)$mice before development of atherosclerotic lesions.

Methods: Atherosclerosis-prone but plaque-free aorta segments of young $\mathrm{C} 57 \mathrm{Bl} / 6 \mathrm{WT}$ and $\mathrm{apoE}^{-/}$mice (4 months, regular chow) were studied. Segments with endothelium (EC+) and without endothelium (EC-, to study SMC function) were mounted in separate myographs and loaded with the calcium-sensitive probe Fura-2 AM. Internal calcium ( $\left[\mathrm{Ca}^{2+}\right]_{\mathrm{i}}$, expressed as the 340/380 excitation emission ratio in relative units (RU)) was measured simultaneously with isometric force.

Results: A pilot experiment pointed out that before development of atherosclerotic lesions, phenylephrine (PE) elicits increased isometric force in apoE $^{-/}$compared to WT mice. Further study showed that the increased contractility in $\mathrm{apoE}^{-/ 2}$ mice could be totally attributed to females; strain differences were absent in males. Following addition of $1 \mu \mathrm{M}$ PE, isometric force development in apoE $^{-/}$females was $0.59 \pm 0.06 \mathrm{mN} / \mathrm{mm}(\mathrm{n}=7)$ and was significantly increased in comparison with WT females $(0.18 \pm 0.04 \mathrm{mN} / \mathrm{mm}, \mathrm{n}=7)$, apoE ${ }^{-/}$males $(0.20 \pm 0.06 \mathrm{mN} / \mathrm{mm}, \mathrm{n}=5)$ and WT males $(0.20 \pm 0.05 \mathrm{mN} / \mathrm{mm}, \mathrm{n}=6)$. The concomitant PE-induced calcium increase was similar in all mice. Basal $\mathrm{EC}\left[\mathrm{Ca}^{2+}\right]_{\mathrm{i}}$ was, however, significantly lower in apoE $\mathrm{E}^{-/-}$females $(0.40 \pm 0.04 \mathrm{RU}, \mathrm{n}=7)$ than in WT females $(0.73 \pm 0.06 \mathrm{RU}, \mathrm{n}=8)$, WT males $(0.77 \pm 0.07 \mathrm{RU}, \mathrm{n}=8)$ or apoE $\mathrm{E}^{-/}$males $(0.66 \pm 0.09 \mathrm{RU}, \mathrm{n}=7)$. This points to a lower basal activation level of the $\mathrm{EC}$ of apoE $\mathrm{E}^{-/-}$females. Moreover, incubation of $\mathrm{EC}+$ aortic segments with nitric oxide synthase (NOS) inhibitors increased PE force in apoE $\mathrm{E}^{-/}$ males from $0.37 \pm 0.09(\mathrm{n}=4)$ to $0.78 \pm 0.12(\mathrm{n}=4) \mathrm{mN} / \mathrm{mm}(+210 \%)$, whereas the rise in females from $0.61 \pm 0.19$ $(\mathrm{n}=5)$ to $0.80 \pm 0.22(\mathrm{n}=5) \mathrm{mN} / \mathrm{mm}(+131 \%)$ was statistically not significant. This indicates that PE induced larger contractions in female than in male apoE $\mathrm{E}^{-/}$mice, probably because of the lower basal NO release in females. We subsequently investigated the contractile status of the SMC in endothelium-denuded segments. In the absence of EC, high $\mathrm{K}^{+}$-or PE-evoked comparable contractions in female $\mathrm{apoE}^{-/-}$and WT mice, confirming that the increased force in female apoE $\mathrm{E}^{-/}$is endothelium-dependent. ApoE $\mathrm{E}^{-/}$male $\mathrm{PE}$ contractions were significantly decreased compared to male WT mice, suggesting that the contractile capacity of the male apoE $\mathrm{E}^{-/}$ SMC was reduced.

Conclusions: PE evokes similar isometric forces in apoE $^{-/}$and WT males. EC removal and NOS inhibition caused identical increments in contractility in both strains, indicating that basal EC-function is unaltered in $\mathrm{apoE}^{-/-}$males. In contrast, $\mathrm{EC}+$ aorta segments of female $\mathrm{apoE}^{-/}$mice showed increased PE-induced force development in comparison with WT females. Both EC removal and NOS inhibition and calcium measurements suggested that this increased contractility was due to reduced basal NO levels in female apoE ${ }^{-/} \mathrm{EC}$. It remains to be determined whether receptor-stimulated $\mathrm{EC}$ function is altered in $\mathrm{apoE}^{-/-}$mice. However, it is concluded that there are important gender differences in basal vasodilator function and calcium levels in $\mathrm{apoE}^{-/-}$mice. 
PS2P19

INFLUENCE OF DIABETES MELLITUS, HYPERCHOLESTEROLEMIA, AND THEIR COMBINATION ON EDHF-MEDIATED RELAXATIONS IN MICE

\author{
K. Morikawa, H. Kubota, T. Matoba, M. Hatanaka, A. Takaki and H. Shimokawa \\ Department of Cardiovascular Medicine, Kyushu University Graduate School of Medical Sciences, \\ Fukuoka, Japan.
}

Objective: The endothelium synthesizes and releases several vasodilator substances, including prostacyclin, nitric oxide (NO) and endothelium-derived hyperpolarizing factor (EDHF). NO-mediated relaxations are reduced by various risk factors, such as diabetes mellitus (DM) and hypercholesterolemia. However, it remains to be elucidated whether EDHF-mediated relaxations are also reduced by those factors, especially when combined. In this study, we examined whether DM, hypercholesterolemia, and their combination impair EDHFmediated relaxations in mice.

Methods: We used small mesenteric arteries from control (male, 18 weeks of age), DM, apoE-deficient $\left(\mathrm{apoE}^{-/}\right)$, and $\mathrm{DM}$ apoE $\mathrm{E}^{-/}$mice. Mice were made diabetic by intraperitoneal injection of streptozotocin (100 $\mathrm{mg} / \mathrm{kg} /$ day on 3 consecutive days) at the age of 8 weeks. Animals were sacrificed 10 weeks after the injection of streptozotocin and isometric tension and membrane potentials were recorded.

Results: Blood pressure was comparable among the 4 groups. In control mice, endothelium-dependent relaxations in response to acetylcholine ( $\mathrm{ACh}$ ) were resistant to indomethacin or L-NNA, but were markedly inhibited by KCL, indicating a primary role of EDHF. In DM mice, global endothelium-dependent relaxations to ACh were slightly reduced, improved by indomethacin, but further attenuated by indomethacin plus L-NNA.

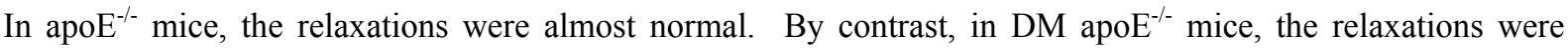
markedly reduced, improved by indomethacin, and significantly attenuated by indomethacin plus L-NNA. Endothelium-independent relaxations to the NO donor sodium nitroprusside (SNP) and NS-1619 (a direct $\mathrm{K}_{\mathrm{Ca}}$ opener) were slightly attenuated in $\mathrm{apoE}^{-/-}$mice and diabetic $\mathrm{apoE}^{-/-}$mice. Endothelium-dependent hyperpolarization to $10^{-5} \mathrm{~mol} / \mathrm{L} \mathrm{ACh}(\mathrm{mV})$ was comparable between control $(-15.5 \pm 0.8)$ and $\mathrm{apoE}^{-/}$mice $(-14.7 \pm 0.8)$, but was significantly attenuated in DM mice $(-9.59 \pm 2.30, \mathrm{P}<0.05)$, and was markedly reduced in $\mathrm{DM}_{\text {apoE }} \mathrm{E}^{-/}$mice $(-5.15 \pm 2.34, \mathrm{P}<0.05)$.

Conclusions: These results indicate that hypercholesterolemia alone minimally affects while diabetes mellitus significantly attenuates EDHF-mediated relaxations, whereas their combination markedly attenuates the responses with a compensatory involvement of NO and a negative contribution of indomethacin-sensitive endothelium-derived contracting factor(s). 
PS2P20

NON-GENOMIC VASCULAR EFFECT OF 17 $\beta$-ESTRADIOL INVOLVES ACTIVATION OF ADENYLYL CYCLASE AND PROTEIN KINASE G IN THE RAT MESENTERIC ARTERY

\section{W. Keung, P.M. Vanhoutte and R.Y.K. Man}

Department of Pharmacology, University of Hong Kong

Objective: The present study aims to elucidate the mechanism of $17 \beta$-estradiol-induced relaxation in the rat mesenteric artery.

Methods: Sprague-Dawley rats (10 weeks old) were employed in the study. Isometric tension was measured in rings of rat superior mesenteric arteries in functional studies. Tissue cAMP and cGMP contents were measured using enzyme-linked immunoassays. Protein kinase $A$ and $G$ activity were determined by measuring the rate of incorporation of 32P-labeled phosphate by cytosolic protein fractions after exposure to agonists.

Results: 17ß-estradiol induced a concentration-dependent relaxation in mesenteric arteries of both male and female rats. This effect was found to be largely endothelium-independent. The classical estrogen antagonist, ICI 182780 did not block this effect. Adminstration of the Gas antagonist, NF449, partially inhibited the relaxation to $17 \beta$-estradiol while the Gao antagonist NF023 did not. The adenylyl cyclase inhibitor, SQ22536 inhibited the relaxation to $17 \beta$-estradiol, as did the protein kinase G antagonist KT5823. However, co-administration of SQ22536 and KT5823 did not further inhibit this relaxation. The protein kinase A antagonist, KT5720, did not affect this response. Tissue cAMP content was found to increase by 2 fold following administration of 17ßestradiol for $30 \mathrm{~min}$ in preparations both with or without endothelium. In contrast, no change in cGMP content was observed. Administration of $17 \beta$-estradiol for 30 min resulted in a modest but significant increase in protein kinase $\mathrm{G}$ activity. However, no change in protein kinase A activity was observed.

Conclusions: $17 \beta$-estradiol elicited a concentration-dependent relaxation in rat mesenteric arteries. This relaxation appears to act, in part, via the activation of adenylyl cyclase in the vascular smooth muscle, leading to an increase in the cAMP level and the activation of protein kinase G. Activation of protein kinase A by cAMP was not observed and did not appear to contribute to the observed relaxation by $17 \beta$-estradiol. 
PS2S21

EDHF-MEDIATED RELAXATION IN RABBIT CAROTID ARTERY IS DEPENDENT ON LUMINAL FLOW

L.E. Rasmussen, P.M. Vanhoutte, B.L. Jensen and O. Skott.

Physiology and Pharmacology, University of Southern Denmark, Winslowparken 21.3, Odense C, 5000 Denmark

Objective: The present experiments were designed to clarify which endothelial factor(s) are involved in acetylcholine-mediated relaxation in isolated carotid arteries of the rabbit exposed to shear stress.

Methods: Isometric force was measured, by means of force transducers, in non-perfused and perfused ( 5 or $50 \mathrm{ml} / \mathrm{min}$; Krebs-Henseleit solution) segments of the same rabbit carotid arteries, studied in parallel. Contractions were obtained with increasing concentrations $(30 \mathrm{nM}-30 \mu \mathrm{M})$ of phenylephrine. Upon maximal contraction, acetylcholine (ACh, $1 \mu \mathrm{M}$ ) was added to evoke an endothelium-dependent relaxation (which was absent after endothelium removal). The relaxations to $\mathrm{ACh}$ were increased in perfused segments [either at 5; or $50 ; \mathrm{ml} / \mathrm{min}]$ compared to non-perfused segments. $\mathrm{N}^{\varpi}$-omega-Nitro-l-Arginine Methyl Ester (L-NAME; $100 \mu \mathrm{M}$ ) almost completely abolished the ACh evoked relaxation in the non-perfused segments, whereas a remnant relaxation was present in the perfused segments. Indomethacin $(10 \mu \mathrm{M})$ did not further reduce the ACh evoked relaxation in L-NAME pretreated perfused segments. Blockade of endothelial $\mathrm{SK}_{\mathrm{Ca}}$ and $\mathrm{IK}_{\mathrm{Ca}}$ by apamin $(0.1$ $\mu \mathrm{M})+$ Tram-34 $(0.1 \mu \mathrm{M})$ inhibited further the ACh evoked relaxation in L-NAME + indomethacin treated perfused segments.

Conclusion: In the carotid artery of the rabbit, acetylcholine-evoked relaxations are increased in segments exposed to flow. This increase can be attributed to a flow-dependent increase in the release of a non-NO, noncyclooxygenase vasodilator, presumably EDHF.

[Supported by the Danish Cardiovascular Research Academy and the Danish Heart Foundation] 
PS2P22

RETINAL TISSUE PRODUCES ACUTE AND BIPHASIC RELAXATIONS IN ISOLATED BOVINE RETINAL ARTERIES

\section{S. Takir, B.S. Uydeş-Doğan and O. Özdemir}

\section{Department of Pharmacology, Faculty of Pharmacy, Istanbul University, Istanbul, Turkey}

Objective: Recently, a retina-derived relaxing factor has been shown to be released from the retinal tissue of different species. Although the nature of this relaxing factor is still unknown, it is suggested to modulate the vascular tone of the retinal artery. In this study, we aimed to evaluate the effect of the retina derived relaxing factor on isolated bovine retinal arteries precontracted with different spasmogenic agents in comparison with choroid tissue.

Methods: Isolated bovine retinal arteries $(232.75 \pm 4.25 \mu \mathrm{m} ; \mathrm{n}=37)$ completely cleaned of retinal tissues were mounted in a multichamber wire myograph and set at a normalized internal circumference under a passive transmural pressure of $100 \mathrm{mmHg}$. The isolated arteries were contracted with noradrenaline $\left(10^{-8}-10^{-4} \mathrm{M}\right)$, prostaglandin $\mathrm{F}_{2 \alpha}\left(10^{-7}-3 \times 10^{-5} \mathrm{M}\right)$, endothelin- $1\left(10^{-10}-10^{-7} \mathrm{M}\right)$ and the thromboxane $\mathrm{A}_{2}$ mimetic U46619 $\left(10^{-9}-10^{-}\right.$ $\left.{ }^{6} \mathrm{M}\right)$ in a cumulative manner and concentration-response curves were generated. A stable and similar contractingtension-inducing-concentrations for each spasmogen were determined. Because of the tendency for a decrease in the precontraction level of noradrenaline, a combination of noradrenaline with potassium chloride $30 \mathrm{mM}$ (NAK) was used for contraction. The relaxant effect of the retina derived factor was investigated by placing a piece of retina in close proximity to the precontracted retinal arteries. The same piece of choroid tissue was also tested in order to eliminate a probable mechanical effect.

Results: Noradrenaline $\left(\mathrm{E}_{\max }=0.74 \pm 0.12 \mathrm{mN} / \mathrm{mm} ; \mathrm{pD} 2=6.34 \pm 0.36 ; \mathrm{n}=11\right)$ prostaglandin $\mathrm{F}_{2 \alpha}\left(\mathrm{E}_{\max }=0.94 \pm\right.$ $0.10 \mathrm{mN} / \mathrm{mm} ; \mathrm{pD} 2=5.53 \pm 0.35 ; \mathrm{n}=8)$, endothelin- $\left(\mathrm{E}_{\max }=0.90 \pm 0.19 \mathrm{mN} / \mathrm{mm} ; \mathrm{pD} 2=8.75 \pm 0.11 ; \mathrm{n}=8\right)$ and the thromboxane A2 mimetic U46619 ( $\left.\mathrm{E}_{\max }=1.26 \pm 0.22 \mathrm{mN} / \mathrm{mm} ; \mathrm{pD} 2=6.99 \pm 0.18 ; \mathrm{n}=8\right)$ caused concentrationdependent contractions in isolated bovine retinal arteries in which endothelin-1 was found as the most potent contractile agent. Putting retinal tissue in close proximity of the precontracted retinal arteries induced complete relaxations in a bifasic manner. The maximal relaxations to retinal tissue in NAK, prostaglandin $\mathrm{F}_{2 \alpha}$, endothelin1 and U46619 precontracted rings were found comparable $\left(\mathrm{E}_{\max }=95.33 \pm 4.58 \%, \mathrm{n}=8 ; 94.45 \pm 1.45 \%, \mathrm{n}=12\right.$; $100.29 \pm 2.76 \%, \mathrm{n}=7$ and $106.79 \pm 7.32 \%, \mathrm{n}=7 ; \mathrm{P}>0.05$; respectively). A similar piece of choroid tissue, however, did not generate such a remarkable relaxant effect and even produced a slight contraction in NAK precontracted bovine retinal arteries $\left(\mathrm{E}_{\max }=22.46 \pm 4.80 \%, \mathrm{n}=7\right)$. We also found that bovine retinal arteries possess a poor endothelial relaxation capacity as compared to a moderate smooth muscle relaxation capacity to acethylcholine (Ach) and the nitrovasodilator sodium nitroprusside (SNP), respectively. ( $E_{\max }$ for Ach $=28.47 \pm$ $7.50 \%$ and $\mathrm{SNP}=48.64 \pm 9.98 \%, \mathrm{n}=6$ ).

Conclusion: Retinal tissue induced complete relaxations in isolated bovine retinal arteries contracted with different spasmogenic agents. The profile of this relaxation was acute and biphasic. Unlike to the retina, choroid tissue did not produce a remarkable relaxation but even a slight contraction particularly in NAK contracted retinal arteries. 
PS2P23

INDUCTION OF CYTOCHROME P450 2C BY CYCLIC STRAIN ENHANCES COX-2 EXPRESSION AND ENDOTHELIAL TUBE FORMATION

\author{
U.R. Michaelis ${ }^{a}$, B. Fisslthaler ${ }^{a}$, J.R. Falck ${ }^{b}$, I. Fleming ${ }^{a}$ and R. Busse ${ }^{a}$
}

${ }^{a}$ Cardiovascular Physiology, J.W. Goethe University, Frankfurt am Main, Germany

${ }^{\mathrm{b}}$ Department of Biochemistry, University of Texas Southwestern Medical Center, Dallas, Texas

Objective: Cytochrome P450 (CYP) epoxygenases of the 2C family metabolize arachidonic acid to epoxyeicosatrienoic acids (EETs), which play an important role in the regulation of vascular tone and homeostasis. EETs contribute to endothelium-derived hyperpolarizing factor-mediated responses, they influence different kinase cascades and induce endothelial cell proliferation. Since the expression of CYP $2 \mathrm{C}$ is regulated by hemodynamic stimuli such as cyclic strain and shear stress, and the overexpression of CYP 2C9 in endothelial cells elicits angiogenesis, we investigated the effects of cyclic strain on endothelial tube formation and the involvement of CYP $2 \mathrm{C}$ in this process.

Methods: Isolated endothelial cells were exposed to cyclic strain (mean elongation 6\%, $1 \mathrm{~Hz}, 24$ hours) using a Flexercell strain unit. In vitro tube formation was assessed in a short-term Matrigel assay or by seeding the cells on a fibrin matrix and culturing them for up to ten days. The angiogenic effect was evaluated by counting branching points and/or measuring total tube length.

Results: Exposure of isolated endothelial cells to cyclic strain increased the expression of CYP 2C mRNA and protein. Endothelial cells pre-exposed to cyclic strain showed a significantly enhanced tube formation when seeded onto Matrigel. The EET antagonist, 14,15-epoxyeicosa-5(Z)-enoic acid, as well as the epoxygenase inhibitors, sulfaphenazole and MS-PPOH, inhibited the strain-induced enhancement of tube formation. Cyclic strain additionally increased the expression of cyclooxygenase-2 (COX-2), an effect that was sensitive to MSPPOH. Furthermore, the CYP 2C-dependent increase in COX-2 expression was abolished by the protein kinase A (PKA) inhibitor KT 5720 demonstrating the involvement of the cyclic AMP/PKA signaling pathway in the CYP 2C-induced COX-2 expression. The CYP $2 \mathrm{C}$ as well as the cyclic strain-induced endothelial cell tube formation were attenuated by the COX-2 inhibitor celecoxib.

Conclusions: Cyclic strain induces CYP 2C expression and the subsequent expression of COX-2 via a PKAdependent pathway. The upregulation of both CYP $2 \mathrm{C}$ and COX-2 contributes to the cyclic strain-induced increase in endothelial cell tube formation. 
PS2P24

KAEMPFEROL ENHANCES ENDOTHELIUM-INDEPENDENT RELAXATION: THE ROLE OF CAMP PATHWAY AND $\mathrm{K}^{+}$CHANNELS

Y.C. XU, S.W.S. Leung, P.M. Vanhoutte and R.Y.K. Man

Department of Pharmacology, Faculty of Medicine, The University of Hong Kong, Hong Kong SAR, China

Objective: There is an increasing interest in the use of Chinese herbal medicine and compounds isolated from these herbs. One of them is the dried flower of Carthamus tincturius. This traditional Chinese herb is used for the management of various cardiovascular disorders, including thrombosis, hypertension and coronary artery disease. It possesses a high content of biological active flavonoid derivatives including kaempferol. The aim of this study was to assess the effect of acute exposure to kaempferol on vasomotor changes in isolated porcine coronary arterial rings and the signalling pathway(s) for its action.

Methods: Isometric tension was recorded in isolated porcine coronary arterial rings incubated in $37^{\circ} \mathrm{C}$ oxygenated modified Krebs-Henseleit solution. Rings were contracted with the thromboxane $\mathrm{A}_{2}$ analogue, U46619 (30 nM) before the addition of increasing concentrations of kaempferol ( $1 \mathrm{nM}-100 \mu \mathrm{M})$. In another study, arterial rings were pretreated with low concentrations of kaempferol $(0.1-10 \mu \mathrm{M})$ for 20 minutes before being contracted with U46619 (30 nM). Responses to sodium nitroprusside (an endothelium-independent vasodilator, $1 \mathrm{nM}-100 \mu \mathrm{M}$ ) were determined in endothelium-denuded and intact rings. In order to investigate the mechanism of action of kaempferol, blockers of the cAMP and cGMP pathways, and various $\mathrm{K}^{+}$channel blockers were used. An enzyme immunoassay kit was used to measure the level of cAMP and cGMP in the porcine coronary arteries after incubation with kaempferol $(10,50$ and $100 \mu \mathrm{M})$.

Results: Kaempferol only caused a significant relaxation at high doses $(>10 \mu \mathrm{M})$ and the relaxation was concentration-dependent. Kaempferol, at a concentration without any relaxing action $(<10 \mu \mathrm{M})$, significantly enhanced the vasorelaxation response to sodium nitroprusside in endothelium-intact and -denuded porcine coronary arteries. Our data also showed that the potentiating effect of kaempferol could be blocked by Rp-8-BrcAMP (a cAMP blocker, $20 \mu \mathrm{M}$ ) but not by Rp-8-Br-cGMP (a cGMP blocker, $10 \mu \mathrm{M}$ ) and ODQ (a guanylyl cyclase inhibitor, $10 \mu \mathrm{M})$. The enhanced relaxation of kaempferol was also partly reversed by various $\mathrm{K}^{+}$ channel blockers (TEA, $10 \mathrm{mM}$, iberotoxin, and apamin + charybdotoxin). Enzyme immunoassay indicated that different concentrations of kaempferol did not increase the cAMP and cGMP levels.

Conclusion: Kaempferol caused direct relaxation and potentiated vascular reactivity to sodium nitroprusside in endothelium-intact and denuded porcine coronary arteries. Our results suggest that kaempferol enhances sodium nitroprusside-induced relaxation via the cAMP pathway but not cGMP pathway. Since kaempferol did not affect the totel cAMP content, it suggests that a specific pool of cAMP might be involved. Furthermore, $\mathrm{K}^{+}$ channels also play a role in this event. The interplay between cAMP and $\mathrm{K}^{+}$channels requires further investigations. 


\title{
PS2P25
}

CYTOCHROME P450 2C-DERIVED EPOXYEICOSATRIENOIC ACIDS (EETS) REGULATE $\mathrm{Ca}^{2+}$ SIGNALLING AND HYPERPOLARIZATION IN ENDOTHELIAL CELLS.

\author{
A. Rueben ${ }^{a}$, R. Popp ${ }^{a}$, B.D. Hammock ${ }^{b}$, R. Busse ${ }^{a}$ and I. Fleming ${ }^{a}$ \\ ${ }^{a}$ Vascular Signalling Group, Cardiovascular Physiology, Johann Wolfgang Goethe University, \\ Frankfurt am Main, Germany \\ ${ }^{\mathrm{b}}$ Department of Entomology and UC Davis Cancer Center, University of California, Davis, USA
}

Objective: Epoxyeicosatrienoic acids (EETs) have been suggested to act as calcium-influx factors, controlling the entry of $\mathrm{Ca}^{2+}$ into non-excitable cells. The aim of the present study was to investigate the role of EETs generated by cytochrome P450 (CYP2C9) on $\mathrm{Ca}^{2+}$ signalling and the activation of $\mathrm{Ca}^{2+}$-dependent $\mathrm{K}^{+}$ channels in human endothelial cells.

Methods: $\mathrm{Ca}^{2+}$ responses to bradykinin were recorded in fura 2-loaded cells. The resting membrane potential and the bradykinin-induced hyperpolarization were examined using the patch clamp technique. Vascular reactivity studies were performed in organ chamber experiments. As CYP2C9 expression rapidly decreases following cell isolation, CYP2C9 expression was either induced using nifedipine ( $1 \mu \mathrm{mol} / \mathrm{L}, 18$ hours $)$ or overexpressed using an adenoviral system.

Results: Stimulation of cultured human umbilical vein endothelial cells, which no longer express CYP2C9 protein, with bradykinin elicited both a $\mathrm{Ca}^{2+}$ transient and membrane hyperpolarization. These responses were not affected by either sulfaphenazole, a selective inhibitor of CYP2C9 or by 1-adamantyl-3-cyclohexylurea (ACU), an inhibitor of the soluble epoxide hydrolase that metabolizes EETs. Incubation of endothelial cells expressing CYP2C9 resulted in a significant increase in the plateau phase of the bradykinin-induced $\mathrm{Ca}^{2+}$ transient. Sulfaphenazole abrogated the effects of enhanced CYP expression on intracellular $\mathrm{Ca}^{2+}$, whereas ACU enhanced the $\mathrm{Ca}^{2+}$ influx during the plateau phase even further. Increased CYP expression was also associated with a small change in the endothelial cell membrane potential as well as in the magnitude and duration of the bradykinin-induced hyperpolarization, effects that were sensitive to sulfaphenazole. However, ACU significantly prolonged the bradykinin-induced hyperpolarization of these cells from $83 \pm 30$ to $205 \pm 80$ seconds, an effect that was prevented by sulfaphenazole. The potentiating effects of ACU on $\mathrm{Ca}^{2+}$ signalling and hyperpolarization were also abrogated by the EET antagonist 14,15-epoxyeicosa-5(Z)-enoic acid (14,15-EEZE), by ruthenium red, an inhibitor of the transient receptor potential (TRP) V4 ion channel and by the protein kinase A inhibitor, adenosine 3',5'-cyclic monophosphothioate. We then assessed the effects of ACU on the EDHF-mediated relaxation of isolated porcine coronary arteries in the presence of diclofenac and $\mathrm{N}^{\omega}$-nitro-L-arginine. Preincubation of arterial rings with ACU resulted in an enhanced EDHF-mediated relaxation to bradykinin. This effect was abolished in the presence of sulfaphenazole.

Conclusions: Taken together, these data indicate that EETs generated intracellularly by CYP2C9 act as $\mathrm{Ca}^{2+}$ influx factors and modulate endothelial cell $\mathrm{Ca}^{2+}$ as well as agonist-induced membrane hyperpolarization via a PKA- and possibly TRPV4-dependent pathway. Moreover, our data highlight the role of the soluble epoxide hydrolase in the control of EET signalling. 
PS2P26

A METHOD FOR RAPID SEPARATION OF ENDOTHELIUM AND SMOOTH MUSCLE RNA FROM RAT AORTA: ITS APPLICATION TO ANALYSIS OF NA,K-ATPASE ISOFORM EXPRESSION IN NATIVE ENDOTHELIAL CELLS.

\author{
P. Krenek ${ }^{b}$, M-C. Hamaide ${ }^{a}$, N. Morel ${ }^{a}$ and M. Wibo ${ }^{a}$ \\ ${ }^{a}$ Laboratoire de pharmacologie expérimentale, Faculté de médecine, Université catholique de \\ Louvain, Avenue Hippocrate 54, 1200 Bruxelles, Belgium \\ ${ }^{\mathrm{b}}$ Katedra farmakológie a toxikológie, Farmaceutická fakulta Univerzity Komenského, Kalinčiakova 8, \\ 83232 Bratislava, Slovak Republic
}

Objective: Distribution of gene expression in the vascular wall can be studied by in situ hybridization, immunocytochemistry, or RT-PCR methods requiring isolation of endothelial and smooth muscle cells. These methods may yield inaccurate and poorly quantitative results, and may be time-consuming and expensive. Our objective was mRNA analysis after rapid separation of RNA from the endothelium and underlying smooth muscle of rat aorta, without prior isolation of endothelial and smooth muscle layers.

Methods: Isolated thoracic aorta was perfused 3 times with $0.2 \mathrm{ml}$ of TriPure ${ }^{\circledR}$, yielding three fractions (E1, E2, E3), presumably enriched in mRNA from endothelial cells; the remaining tissue was designated Ao(E-). RNA from these fractions and intact aorta $[\mathrm{Ao}(\mathrm{E}+)]$ was used for semi-quantitative radioactive RT-PCR using primers for $\mathrm{Na}, \mathrm{K}-\mathrm{ATPase}$ isoforms $\left(\mathrm{NaK} \alpha_{1}, \mathrm{NaK} \alpha_{2}, \mathrm{NaK} \alpha_{3}\right)$. Endothelial markers: endothelial nitric oxide synthase, von Willebrand factor, preproendothelin-1. Smooth muscle markers: L-type calcium channel (Cav1.2), SM22. Ribosomal protein RPL32 was used as loading control. After exponential amplification from cDNA, PCR products were detected and quantified on polyacrylamide gels by means of a Cyclone ${ }^{\circledR}$ phosphorimager.

Results: Compared to intact aorta, endothelial markers were enriched 3-5 fold in E1, E2 and E3 fractions, but were almost absent in Ao(E-). Smooth muscle markers were undetectable in E1, their expression increasing somewhat in E2 and E3; they were similarly expressed in $\mathrm{Ao}(\mathrm{E}-)$ and $\mathrm{Ao}(\mathrm{E}+) . \mathrm{NaK} \alpha_{2}$ closely followed the expression pattern of smooth muscle markers. $\mathrm{NaK} \alpha 1$ and $\mathrm{NaK} \alpha 3$ were uniformly expressed in all fractions. Moreover, NaK $\alpha 3$ expression (relative to RPL32) in whole blood ( a possible contaminant of the fractions) was at least 100 -fold higher than in aorta.

Conclusions: Characteristic distribution patterns for mRNA expressed preferentially in endothelial and smooth muscle cells can be recognized in fractions obtained by Tripure ${ }^{\circledR}$ perfusion of rat aorta. Our results indicate the following pattern of $\mathrm{Na}, \mathrm{K}-\mathrm{ATPase}$ isoform expression in rat aorta: smooth muscle $\mathrm{NaK} \alpha_{1}+++$, $\mathrm{NaK}_{2}+, \mathrm{NaK}_{3}-;$ endothelium $\mathrm{NaKa}_{1}+++, \mathrm{NaK}_{2}-, \mathrm{NaK}_{3}-$. 
PS2P27

ANTIOXIDANT ACTIVITY OF 5-MTHF AND $\mathrm{BH}_{4}$ CAN PRESERVE EDHF-TYPE RESPONSES BY MODULATING ELECTROTONIC SIGNALLING

\section{D.H. Edwards, A.T. Chaytor, L.M. Bakker and T.M. Griffith}

Department of Diagnostic Radiology, Wales Heart Research Institute, Cardiff University

Objective: In many cell types redox mechanisms are thought to modulate gap junctions by regulating the phosphorylation status of the connexin proteins that form these intercellular communication channels. The impaired cell-cell coupling and increased connexin phosphorylation associated with oxidative stress may thus be prevented by a variety of antioxidants. In the present study we have investigated whether the intrinsic antioxidant activity of 5-methyltetrahydrofolate (5-MTHF) and (6R)-tetrahydrobiopterin $\left(\mathrm{BH}_{4}\right)$ can modulate NOindependent relaxations and hyperpolarizations that are mediated by the spread of endothelial hyperpolarization via myoendothelial and smooth muscle gap junctions in the rabbit iliac artery. This was achieved by comparing the effects of 5-MTHF and $\mathrm{BH}_{4}$ and their oxidized forms folic acid and 7,8-dihydrobiopterin $\left(\mathrm{BH}_{2}\right)$ on such EDHF-type responses in the presence of the gap junction inhibitor 2-aminoethoxydiphenyl borate (APB).

Methods: Tissues were obtained from male NZW rabbits $(2-2.5 \mathrm{~kg})$ and incubated in oxygenated $\left(95 \% \mathrm{O}_{2}\right.$, $\left.5 \% \mathrm{CO}_{2}\right)$ buffer containing L-NAME $(300 \mu \mathrm{M})$ and indomethacin $(10 \mu \mathrm{M})$. EDHF-type responses were evoked by the SERCA inhibitor cyclopiazonic acid (CPA). Mechanical relaxation: tone was induced by $1 \mu \mathrm{M}$ phenylephrine in rings of iliac artery and cumulative concentration-relaxation curves to CPA constructed in the presence and absence of APB, 5-MTHF, folic acid, $\mathrm{BH}_{4}, \mathrm{BH}_{2}$ and catalase (which destroys $\mathrm{H}_{2} \mathrm{O}_{2}$ ), as required. Calcium Imaging Ratiometric analysis (F340/380) was used to study the effects of APB on endothelial $\mathrm{Ca}^{2+}$ homeostasis following stimulation with $\mathrm{CPA}(30 \mu \mathrm{M})$ in aortic valve leaflets loaded with $5 \mu \mathrm{M}$ Fura-2 AM. Microelectrode studies: membrane potentials were recorded by whole cell patch clamping of endothelial cells and sharp electrode impalement of subintimal smooth muscle cells in the iliac artery.

Results: EDHF-type relaxations evoked by CPA were depressed by $\sim 75 \%$ in the presence of $10 \mu \mathrm{M} \mathrm{APB}$, whose inhibitory effects were prevented by $100 \mu \mathrm{M} 5-\mathrm{MTHF}$ or $\mathrm{BH}_{4}$ and by $2000 \mathrm{U} / \mathrm{ml}$ catalase, but were insensitive to $100 \mu \mathrm{M}$ folic acid or $\mathrm{BH}_{2}$. In control experiments, relaxations were unaffected by $100 \mu \mathrm{M} 5$-MTHF, $100 \mu \mathrm{M} \mathrm{BH}_{4}$ or $2000 \mathrm{U} / \mathrm{ml}$ catalase. Resting endothelial membrane potential was $-44.8 \pm 2.8 \mathrm{mV}$ and $30 \mu \mathrm{M}$ CPA evoked a peak hyperpolarization of $11.6 \pm 0.7 \mathrm{mV}(\mathrm{n}=9)$. Neither parameter was significantly affected by $10 \mu \mathrm{M}$ APB. The peak increase in F340/380 ratio evoked by $30 \mu \mathrm{M}$ CPA in the aortic valve $(45.4 \pm 2.8 \%, \mathrm{n}=17)$ was also unaffected by $10 \mu \mathrm{M}$ APB. Resting subintimal smooth muscle membrane potential was $-46 \pm 1.2 \mathrm{mV}$ $(n=22)$ and unaffected by $10 \mu \mathrm{M}$ APB $(n=22)$ or the combination of APB with $100 \mu \mathrm{M} 5-\mathrm{MTHF}$, folic acid, $\mathrm{BH}_{4}$ or $\mathrm{BH}_{2}$. Incubation with $10 \mu \mathrm{M} \mathrm{APB}$ reduced the peak subintimal hyperpolarization evoked by $30 \mu \mathrm{M} \mathrm{CPA}$ from $14.5 \pm 1.3 \mathrm{mV}$ to $6.2 \pm 0.8 \mathrm{mV}$, and this action of APB was prevented by $100 \mu \mathrm{M} 5-\mathrm{MTHF}, \mathrm{BH}_{4}$ and by 2000 $\mathrm{U} / \mathrm{ml}$ catalase. In contrast, in preparations incubated with $100 \mu \mathrm{M}$ folic acid or $\mathrm{BH}_{2}$, subintimal hyperpolarizations were statistically similar to those observed in the presence of $10 \mu \mathrm{M} \mathrm{APB}$ alone.

Conclusions: Under control conditions EDHF-type responses evoked by CPA in the rabbit iliac artery are insensitive to 5-MTHF, $\mathrm{BH}_{4}$ and catalase. Redox mechanisms may nevertheless play a key role in regulating electrotonic signalling through the wall of this vessel under conditions where gap junctional communication is already diminished (e.g. in the presence of APB). Preservation of EDHF-type responses by catalase suggests the specific involvement of hydrogen peroxide. 
PS2P28

IMPAIRED RENAL MYOGENIC CONSTRICTION IS ACCOMPANIED BY PARALLEL PROSTAGLANDIN-DEPENDENT ENDOTHELIAL DYSFUNCTION AND INCREASED NITRIC OXIDE-MEDIATED DILATION IN A GENETIC MODEL OF HYPERTENSION-INDUCED RENAL DISEASE.

\author{
P. Ochodnicky ${ }^{a}$, R.H. Henning ${ }^{a}$, H. Buikema ${ }^{a}$, A.P. Provoost ${ }^{b}$, D. de Zeeuw ${ }^{a}$ and R.P.E. van \\ Dokkum $^{a}$ \\ ${ }^{a}$ Department of Clinical Pharmacology, GUIDE, University Medical Center Groningen, the Netherlands \\ ${ }^{\mathrm{b}}$ Erasmus Medical Center, Rotterdam, the Netherlands
}

Objectives: The hypertensive Fawn-Hooded rat (FHH) is characterized by increased genetic susceptibility to hypertension-associated renal damage. The vasomotor defects in small interlobar arteries may result in impaired autoregulation of glomerular filtration and may be responsible for the increased sensitivity of the kidney to hypertensive damage. Therefore we investigated the principal constrictor and dilator mechanisms of these arteries in FHH rats as compared to the control Fawn-Hooded strain with low blood pressure and no renal damage (FHL).

Methods: Systolic blood pressure (SBP, tail-cuff) and urinary protein excretion (UpV, metabolic cages) were measured in young (12 weeks of age) FHH ( $\mathrm{n}=17)$ and FHL $(\mathrm{n}=12)$ rats. Small renal interlobar arteries were isolated from the kidneys prior to the development of renal damage. The arteries were mounted in a microvascular perfused setup and pressure-mediated (myogenic tone), receptor-mediated (phenylephrine) contractility, endothelium-dependent (acetylcholine) and endothelium-independent (sodium nitroprusside) relaxation were investigated. Furthermore, the contribution of prostaglandins (PGs), nitric oxide (NO) and endothelium-dependent hyperpolarizing factor (EDHF) to the endothelial relaxation was assessed.

Results: At the time of in vitro measurements SBP was only mildly elevated in FHH rats as compared to FHL, while UpV were both in the normal range (SBP: $142 \pm 3$ and $133 \pm 3 \mathrm{mmHg}$; UpV: $46.4 \pm 4.2$ and $27.8 \pm$ $0.5 \mathrm{mg} /$ day, in FHH and FHL, respectively). Myogenic tone of renal interlobar arteries was heavily impaired in young FHH rats compared to FHL rats $(16.1 \pm 2.6 \%$ vs. $33.9 \pm 6.9 \%, \mathrm{P}<0.01)$, while receptor-mediated contractility was unchanged. Total relaxation to acetylcholine was impaired in FHH due to a strong increase in the production of contractile PGs (factor 12.7 compared to FHL, P<0.01). Notably, at the same time NOdependent dilation was augmented in FHH (factor 3.8 compared to FHL, $\mathrm{P}<0.01$ ), whereas EDHF-dependent dilation remained unchanged. Endothelium-independent dilation also did not differ between the strains.

Conclusions: The early renal vascular dysfunction in the Fawn-Hooded rat precedes the development of renal damage and is characterized by the specific impairment of myogenic contractility. This is accompanied by the endothelial dysfunction represented by the interesting combination of increased contractile prostaglandins and nitric oxide production. Further investigation of the interplay between these two mechanisms may help to elucidate the changes responsible for the increased susceptibility of the Fawn-Hooded rat to the hypertensioninduced renal damage. 
PS2P29

GONADAL HORMONES MODULATE LPS-INDUCED INFLAMMATORY MARKERS IN RAT CEREBRAL BLOOD VESSELS

\author{
R.J. Gonzales, A. Razmara, L. Sunday, D.N. Krause and Sue P. Duckles \\ Department of Pharmacology, School of Medicine, University of California, Irvine, CA 92697, USA
}

Objective: Following ischemic injury, activation of inflammatory mechanisms plays a significant role in cerebrovascular pathogenesis. In the rodent model, previous studies suggest that endogenous female sex steroids attenuate cerebral ischemia/reperfusion injury following experimental stroke. Because sex hormones modulate the outcome of ischemic injury in brain tissue, we investigated the impact of chronic in vivo estrogen or testosterone administration on cerebrovascular inflammation induced by the potent endotoxin, lipopolysaccharide (LPS). We hypothesized that estrogen will suppress, while testosterone will exacerbate the induction of cyclooxygenase-2 (COX-2) and inducible nitric oxide synthase (iNOS), important mediators of vascular inflammation contributing to the onset of cerebral tissue injury.

Methods: The localization of LPS-induced COX-2 and iNOS protein was confirmed in both the endothelial and vascular smooth muscle layers of cerebral blood vessels using antibody specific staining and confocal microscopy. Initial experiments were performed to establish peak induction of COX-2 and iNOS protein levels in cerebral vessel homogenates from female and male rats using Western blot.

Results: Protein levels of COX-2 and iNOS were greatest at 6 hours post LPS ( $2 \mathrm{mg} / \mathrm{kg}$ i.p.) injection; thus this time point was selected to determine the effect of estrogen or testosterone on LPS-induced inflammation in cerebral blood vessels. Fischer-344 rats were gonadectomized and implanted with hormone filled pellets for 3 weeks. Orchiectomized male rats were treated without (ORX) or with either testosterone propionate $(\mathrm{ORX}+\mathrm{T})$ or $17 \beta$-estradiol $(\mathrm{ORX}+\mathrm{E})$. Ovariectomized female rats were treated without (OVX) or with 17ß-estradiol $(\mathrm{OVX}+\mathrm{E})$. LPS treatment increased protein levels of both COX-2 and iNOS in cerebral blood vessels from all groups compared to saline (6 hr) injected controls. However, the induction of COX-2 and iNOS protein by LPS was significantly attenuated in cerebral vessels from OVX+E and ORX+E compared to OVX and ORX controls, respectively. In contrast, there was a marked increase in LPS-induced COX-2 and iNOS protein levels in cerebral vessels from ORX+T compared to ORX controls.

Conclusion: It is likely that opposing actions of testosterone and estrogen to modulate cerebrovascular inflammation may contribute to the well-known gender differences clinically observed in stroke incidence and outcome. [Supported by NIH grant HL-50775 and AHA Postdoctoral Fellowship (RG)]. 
PS2P30

GUANYLYL CYCLASE ACTIVATORS EVOKE NITRIC OXIDE RELEASE IN THE INTACT RAT SUPERIOR MESENTERIC ARTERY

\section{E. Stankevičius, G. Wegener, M.J. Mulvany and U. Simonsen}

Department of Pharmacology, University of Aarhus, 8000 Aarhus C, Denmark

Objective: The purpose of the present study was to investigate the role of the cyclic GMP-pathway in acetylcholine (ACh)-evoked nitric oxide (NO)-mediated relaxation in rat superior mesenteric artery.

Methods: Segments were mounted in microvascular myographs and by introduction of a NO specific microelectrode in the lumen of the artery, simultaneous measurements of NO concentration and isometric force were performed.

Results: In the presence of indomethacin $(3 \mu \mathrm{M})$ and contracted with noradrenaline $(0.5 \mu \mathrm{M})$, ACh $(10 \mu \mathrm{M})$ increased NO concentration by $11.3 \pm 1.9 \mathrm{nM}$ and relaxed the arteries by $99 \pm 1 \%(\mathrm{n}=6)$. The selective guanylyl cyclase activators, YC-1 $(10 \mu \mathrm{M})$ and BAY $412272(10 \mu \mathrm{M})$, increased NO concentration by respectively $11.3 \pm$ $4.7 \mathrm{nM}(\mathrm{n}=6)$ and $5.9 \pm 1.1 \mathrm{nM}$, and relaxed the arteries by respectively $94 \pm 2 \%(\mathrm{n}=6)$ and $95 \pm 1 \%(\mathrm{n}=6)$. These responses were reversed by oxyhemoglobin $(\mathrm{OxHb})$. In arteries without endothelium, BAY 412272 did not increase NO concentration and relaxation was reduced to $59 \pm 1 \%(\mathrm{n}=6)$. An inhibitor of soluble guanylyl cyclase, ODQ $(3 \mu \mathrm{M})$, reduced ACh-evoked increases $(n=6)$ in NO and relaxations, and abolished S-nitroso-Nacetylpenicillamine (SNAP) relaxation without changing increases in NO concentration. An inhibitor of phosphodiesterase type 5 , sildenafil $(1 \mu \mathrm{M})$ caused endothelium-dependent relaxations sensitive to OxHb, without increasing the $\mathrm{NO}$ concentration $(\mathrm{n}=6)$, and shifted concentration-relaxation curves for acetylcholine and SNAP to the left. The protein kinase G (PKG) activator, 8-br-cGMP $(400 \mu \mathrm{M})$, did not increase NO concentration, but caused relaxation which was inhibited by the PKG inhibitor, 8 br-PET-cGMPS $(30 \mu \mathrm{M})$. $8 \mathrm{br}$ PET-cGMPS and an inhibitor of PKA, Rp-8Br-cAMPS $(50 \mu \mathrm{M})$, did not change ACh-induced increases in NO concentration. The inhibitor of heat shock protein (HSP90) geldanamycin, shifted the acetylcholine concentration-relaxation curves to the right.

Conclusions: The present study provides evidence for a guanylyl cyclase-dependent mechanism, probably independent of protein kinase $\mathrm{G}$ activation, to enhance ACh-evoked release of NO. We propose a model, where conformational changes in guanylyl cyclase induced by NO or guanylyl cyclase activators through the scaffold protein HSP90, increases endothelial NO synthase activity and enhances NO formation. The effect on relaxation by sildenafil and ODQ confirms a role for a smooth muscle cyclic GMP-pathway in acetylcholine-evoked relaxation. 
PS2P31

EPOXYEICOSATRIENOIC ACID SYNTHESIS CONTRIBUTES TO ENDOTHELIUM-DEPENDENT HYPERPOLARIZATION IN THIRD-ORDER MESENTERIC RESISTANCE ARTERIES OF ENOSDEFICIENT MICE

\section{R.H.P. Hilgers and R.C. Webb}

Department of Physiology, Medical College of Georgia, Augusta GA 30912, USA

Objective: The endothelium plays a crucial role in regulating vasomotor tone by synthesizing several relaxing factors, including nitric oxide (NO), prostacyclin, and the unidentified endothelium-derived hyperpolarizing factor (EDHF). In this study we determine whether cytochrome P450 (CYP) epoxygenases are possible sources for EDHF in small mesenteric arteries of eNOS KO mice.

Methods: Third-order mesenteric resistance arteries (MrA) were isolated and mounted in the wire-myograph. MrA pre-contracted with the thromboxane analog (U46619, $0.1 \mathrm{mM}$ ) dilated in response to cumulative concentrations of acetylcholine.

Results: In MrA of wild-type mice, vasodilatation was mainly mediated by NO and EDHF. In eNOS-KO mice, vasodilatation was L-NAME $(100 \mathrm{mM})$ - and indomethacin $(10 \mathrm{mM})$-insensitive. In both strains, the non$\mathrm{NO}$ and non-prostacyclin residual vasodilation was almost completely blocked by a mixture of apamin $(0.5 \mathrm{mM})$ and charybdotoxin $(0.1 \mathrm{mM})$. The selective cytochrome $\mathrm{P} 450$ epoxygenase inhibitor 6-(2-propargyloxyphenyl) hexanoic acid (PPOH, $50 \mathrm{mM}$ ) inhibited EDHF-mediated relaxation in MrA of eNOS KO mice only. However, the selective cytochrome P450 mono-oxygenase inhibitor 17-octadecynoic acid (17-ODYA, $10 \mathrm{mM}$ ) did not affect $\mathrm{ACh}$-induced dilation.

Conclusions: These results indicate that vasodilator EETs act as EDHFs and can compensate for the loss of endothelial-derived NO during eNOS deficiency. 
PS2P32

ENDOTHELIUM CALCIUM SIGNAL AND EDHF-DEPENDENT RELAXATION IN DIFFERENT MODELS OF HYPERTENSION

\section{N. Morel, P. Ghisdal and G. Vandenberg}

Laboratoire de Pharmacologie - Université catholique de Louvain - Bruxelles, Belgium.

Objective: Impairment of EDHF-dependent relaxation has been reported in several models of hypertension. Since EDHF-mediated responses require prior increase in cytosolic calcium concentration in the endothelium, the objective of the present study was to determine whether the decrease in EDHF-dependent relaxation associated with hypertension could be related to an alteration in the calcium response in endothelial cells.

Methods: EDHF-dependent responses were evoked by acetylcholine in the presence of L-NNA and indomethacin, in the superior mesenteric arteries from normotensive Wistar Kyoto rats (WKY, n=12), NaClloaded stroke-prone hypertensive rats (SHR-SP, $1 \% \mathrm{NaCl}$ in drinking water, $\mathrm{n}=6$ ), and L-NAME-treated WKY rats (L-NAME-WKY, 4 weeks treatment with $0.5 \mathrm{mg} \mathrm{L}^{-N A M E} \cdot \mathrm{ml}^{-1}$ in drinking water, $\mathrm{n}=6$ ). Endothelial cell calcium signal was measured in indo-1 loaded mesenteric arteries mounted in the cuvette of a fluorimeter. The increase in calcium signal evoked by acetylcholine was expressed as a percentage of the basal ratio of fluorescence at $340 \mathrm{~nm}$ and $380 \mathrm{~nm}$. Membrane potential of smooth muscle cells was recorded with intracellular microelectrodes in arteries mounted in myographs. Systolic blood pressure was measured by the tail cuff method.

Results: WKY-L-NAME and SHR-SP rats had similar significantly higher blood pressure $(242 \pm 12 \mathrm{~mm} \mathrm{Hg}$ and $246 \pm 4 \mathrm{~mm} \mathrm{Hg}$, respectively) as compared to WKY $(151 \pm 5 \mathrm{~mm} \mathrm{Hg}, \mathrm{P}<0.05)$. The acetylcholine concentration-effect curves for the EDHF-dependent hyperpolarization and relaxation were depressed in mesenteric arteries from hypertensive rats compared to WKY. Maximum hyperpolarization evoked by acetylcholine $(3 \mu \mathrm{M})$ was decreased from $15 \pm 0.7 \mathrm{mV}$ in WKY ( $\mathrm{n}=9$ ), to $7 \pm 2 \mathrm{mV}$ and $9 \pm 0.7 \mathrm{mV}$, in WKY-LNAME $(n=6, P<0.05)$ and SHR-SP $(n=3, P<0.05)$, respectively. Maximum relaxation to acetylcholine in noradrenaline-contracted arteries was depressed from $75 \pm 4 \%$ in WKY ( $n=12)$, to $21 \pm 11 \%$ and $15 \pm 4 \%$ of the contraction, in WKY-L-NAME $(\mathrm{n}=6)$ and SHR-SP $(\mathrm{n}=6)$, respectively. The calcium signal evoked by acetylcholine in endothelial cells from L-NAME-hypertensive rats was not different from the calcium signal observed in normotensive rats: $1 \mu \mathrm{M}$ acetylcholine increased the fluorescence ratio by $16 \pm 5$ and $17 \pm 3 \%$, in WKY-L-NAME $(\mathrm{n}=6)$ and WKY $(\mathrm{n}=11)$, respectively. The endothelium calcium signal was significantly depressed in NaCl-loaded SHR-SP $(4 \pm 1 \%, \mathrm{n}=5, \mathrm{P}<0.05$ versus WKY $)$.

Conclusion: These results indicate that, while a similar alteration in EDHF-dependent hyperpolarization and relaxation was observed in the mesenteric artery in two different models of hypertension, endothelial calcium function was impaired in SHR-SP rats only, suggesting that an alteration in endothelial cell calcium signalling cannot be the only cause of the EDHF dysfunction observed in hypertension. 
PS2P33

SOME CLINICAL AND HEMODYNAMIC ASPECTS OF THE USE OF LASER THERAPY IN STABLE ANGINA

\section{I.G Alizade and N.T Aliyeva-Karayeva}

Cardiology Department, Hospital of Ministry of internal Affairs, Baku, Azerbaijan

Objective: It is known that the use of traditional vasodilator drugs does not always lead to success. Therefore the aim of our study was to evaluate the use of laser therapy in patients with stable angina (SA).

Methods: Autotransfusion of laser-irradiated blood (ALIB) was carried out in 68 patients with SA (8-10 procedures at a 1-2- day interval). A control group consisted of 22 SA patients who received traditional therapy .

Results: Central hemodynamic measurements and ECG control were carried out before and after therapy. In the ALIB group ECG revealed a significant decrease in the ST segment elevation. Handgrip stress test (HST) was associated with a decrease of the ST elevation $(\mathrm{P}<0.05)$ which indicated an improvement of the coronary circulation and an increase of the coronary reserve. Furthermore a decrease in cardiac output (CO) and left ventricular filling pressure (LVFP) $(\mathrm{P}<0.001)$ was observed. Comparison of the ALIB group with the control group demonstrated that CO, LVFP and a number of ischemic reactions decreased more in the treated patients than in the controls.

Conclusions: Analysis of the central hemodymanic parameters and the ECG data revealed a considerable increase of the coronary and contractile reserve and a decrease in the ischemic area and in the number of ischemic reactions in SA patients receiving ALIB. 